Universidade de São Paulo

Escola Superior de Agricultura "Luiz de Queiroz"

Resposta hiperespectral de folha na diferenciação de adubação nitrogenada e predição do teor de clorofila na cultura de capim 'Mombaça'

Miller Andrés Ruiz Sánchez

Dissertação apresentada para obtenção do título de Mestre em Ciências. Área de concentração: Engenharia de Sistemas Agrícolas

Piracicaba

2019 


\section{Miller Andrés Ruiz Sánchez \\ Engenheiro Agrônomo}

Resposta hiperespectral de folha na diferenciação de adubação nitrogenada e predição do teor de clorofila na cultura de capim 'Mombaça'

versão revisada de acordo com a resolução CoPGr 6018 de 2011

Orientador:

Prof. Dr. PETERSON RICARDO FIORIO

Dissertação apresentada para obtenção do título de Mestre em Ciências. Área de concentração: Engenharia de Sistemas Agrícolas

\section{Piracicaba}


Dados Internacionais de Catalogação na Publicação DIVISÃO DE BIBLIOTECA - DIBD/ESALQ/USP

\section{Ruiz Sánchez, Miller Andrés}

Resposta hiperespectral de folha na diferenciação de adubação nitrogenada e predição do teor de clorofila na cultura de capim 'Mombaça'/ Miller Andrés Ruiz Sánchez - - versão revisada de acordo com a resolução CoPGr 6018 de 2011. - - Piracicaba, 2019.

$59 \mathrm{p}$.

Dissertação (Mestrado) - - USP / Escola Superior de Agricultura "Luiz de Queiroz".

1. Megathyrsus maximus 2. Reflectância espectral 3. Clorofila 4. Análise linear discriminante 5. Machine learning I. Título 
Dedico

A minha família, por ser o motor e a força nos momentos mais difíceis, participar em cada um dos meus logros, sem importar a distância, e sempre acreditar nos meus sonhos e projetos. 


\section{AGRADECIMENTOS}

A Deus, primeiramente por ter me levado pelos melhores caminhos para ter grandes apresndizagens e conseguir todos os meus objetivos.

À Escola Superior de Agricultura "Luiz de Queiroz" - ESALQ, ao Programa de Pós-Graduação em Engenharia de Sistemas Agrícolas e ao Departamento de Engenharia de Biossistemas, pela oportunidade de realizar o curso de mestrado e continuar meu crescimento professional e acadêmico.

À Coordenação de Aperfeiçoamento de Pessoal de Nível Superior - CAPES, pela bolsa de estudos concedida para o desenvolvimento do curso de mestrado.

À Fundação de Amparo à Pesquisa do Estado de São Paulo (FAPESP), por fomentar o projeto de pesquisa $n^{\circ} 2013 / 22435-9$

Ao meu orientador, professor Dr. Peterson Ricardo Fiorio, pela confiança oferecida desde o início do mestrado, pelos ensinamentos, pela orientação e paciência durante mais de dois anos de trabalho.

Ao Grupo de Pesquisa e Extensão em Topografia e Geoprocessamento - TopoGeo, pela infraestrutura ofertada e, principalmente, pelo apoio no trabalho de campo.

Ao pessoal do Laboratório de Sensoriamento Remoto e Geoprocessamento Aplicado a Solos e Planejamento do Uso da Tera, do Departamento da Ciência do Solo da ESALQ, pela colaboração e infraestrutura ofertada durante o desenvolvimento do trabalho de campo desta pesquisa.

Ao pessoal do Laboratório de Fisiologia e Bioquímica Pos Colheita, do Departamento de Ciências Biológicas da ESALQ, pela infraestrutura e colaboração ofertada durante o desenvolvimento da fase de laboratório deste trabalho.

Aos membros da banca de defesa, Érica Silva Nakai, Pedro Paulo da Silva Barros e Fernando Campos Mendonça, pelos comentarios, correções e aportes nesta dissertação.

Ao grupo de estrangeiros da ESALQ, que se tornaram parte da minha família durante minha estadia no Brasil, e que fazem parte de momentos inesquecíveis que enriqueceram essa parte da minha vida.

À Republica Matadouro, seus moradores, ex-moradores e agregados, por ser um exemplo do caráter acolhedor do povo brasileiro, por ter me dado a oportunidade de conviver com eles no melhor ambiente de amizade, alegria e confiança, nos bons momentos, mas principalmente nas situações mais difíceis.

A todos os colegas que foram de grande ajuda na avaliação do experimento em campo, preparo de amostras e escrita do documento: Matheus Luís Docema, Camilo Ernesto Bohórquez Sánchez, Fabian Kemps Verhage, Laecio Sampaio, Caio Barbosa, Ariane Silveira Paiva, Hugo Seixas, e Artur Díaz. 


\section{EPÍGRAFE}

"Aunque lo exíguo de nuestras personalidades nos impide ser voceros de su causa,

creemos, y después de este viaje más firmemente que antes, que la división de América en nacionalidades inciertas e ilusorias es completamente ficticia.

Constituimos una sola raza mestiza que desde México hasta el estrecho de Magallanes presenta notables similitudes etnográficas."

\section{Ernesto Guevara}




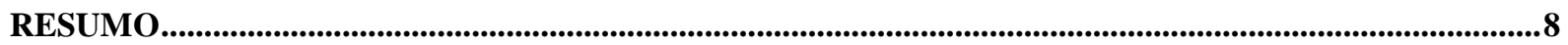

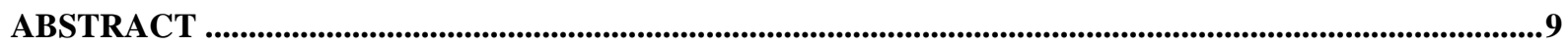

1. INTRODUÇÃ

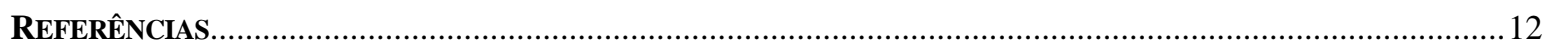

2. USO DA RESPOSTA HIPERESPECTRAL NA DIFERENCIAÇÃO DO TEOR DE CLOROFILA EM DIFERENTES TRATAMENTOS DE ADUBAÇÃO NITROGENADA EM CAPIM 'MOMBAÇA'..........18

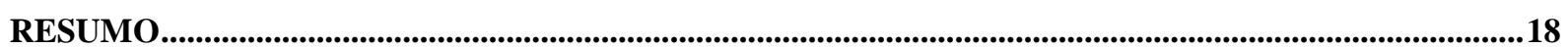

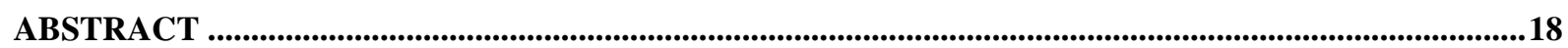

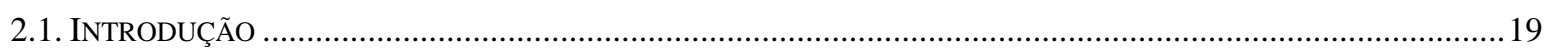

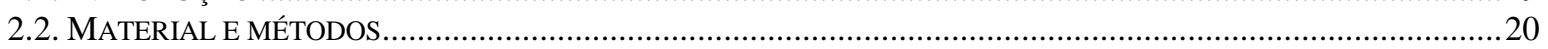

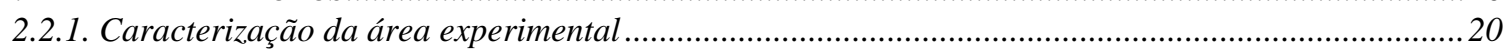

2.2.2. Características da cultura................................................................. ;Error! Marcador no definido.

2.2.3. Medição da reflectância espectral e do teor de clorofila ...................................................................22

2.2.4. Determinação do teor de clorofila na folha em laboratório ............................................................22

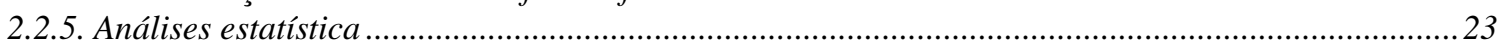

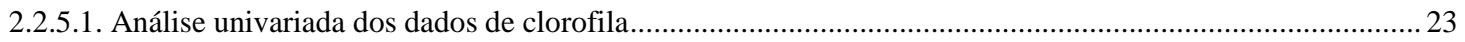

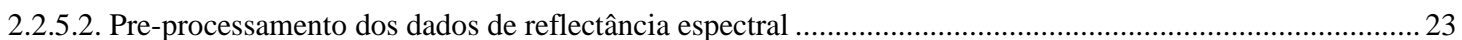

2.2.5.3. Análise discriminante das assinaturas espectrais …………………………………………………....2 23

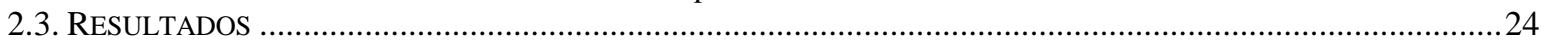

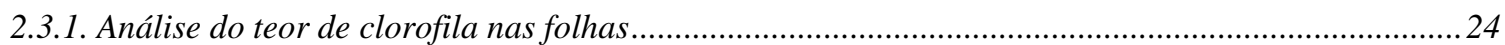

2.3.2. Análise descritiva da assinatura espectral dos tratamentos ............................................................26

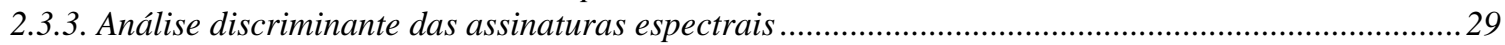

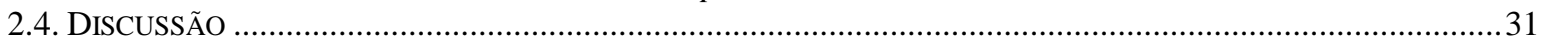

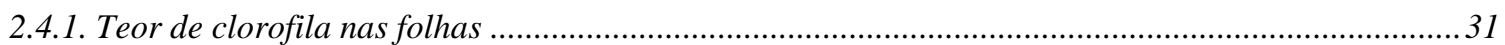

2.4.2. Análise descritiva da assinatura espectral dos tratamentos ............................................................... 31

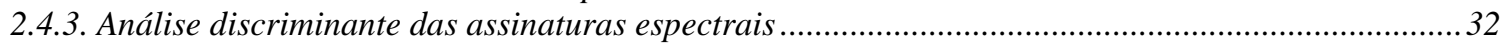

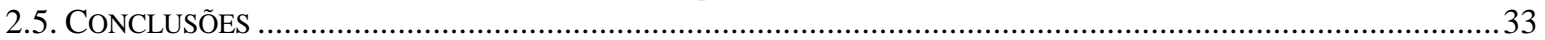

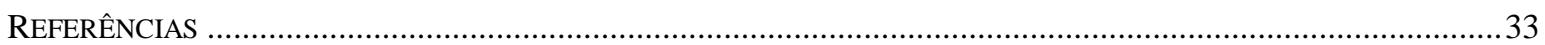

3. COMPARAÇÃO DE TÉCNICAS DE ESTATÍSTICA MULTIVARIADA E MACHINE LEARNING NA ESTIMATIVA DE CLOROFILA A PARTIR DA RESPOSTA ESPECTRAL DE FOLHAS DE CAPIM 'MOMBAÇA' ........................................................................................................................................39

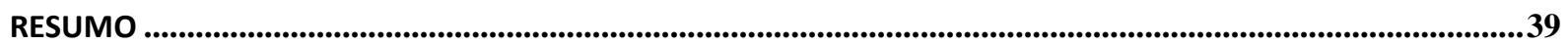

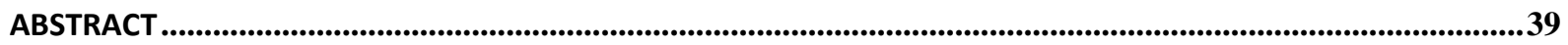

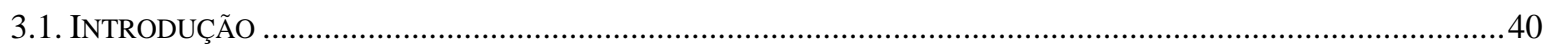

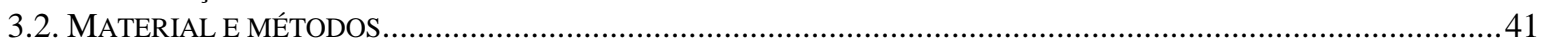

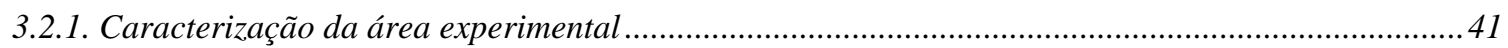

3.2.2. Características da cultura................................................................ ;Error! Marcador no definido.

3.2.3. Medição da reflectância espectral e do teor de clorofila ....................................................................4

3.2.4. Determinação do teor de clorofila na folha em laboratório ................................................................43

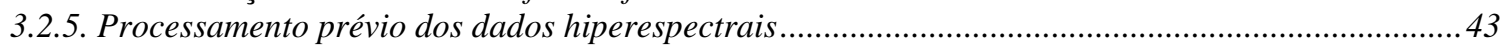

3.2.6. Análises da reflectância spectral para estimar o teor de clorofila …………………….....................4 44

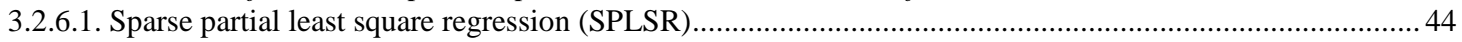

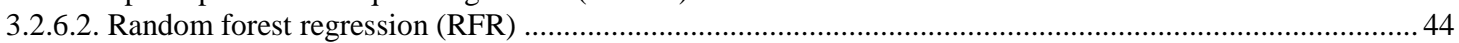

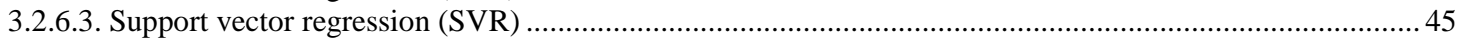

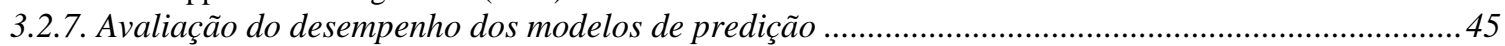

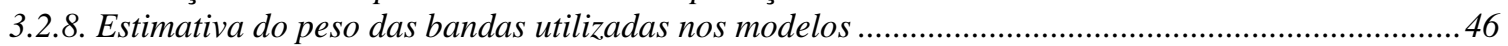

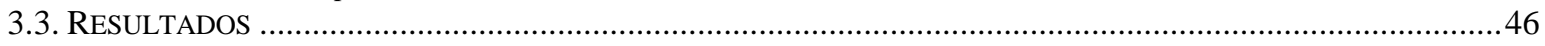

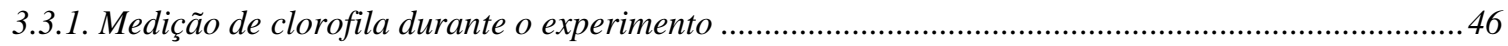

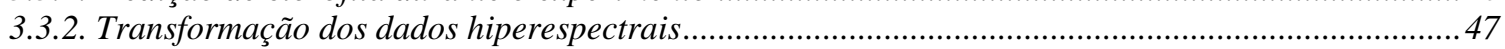




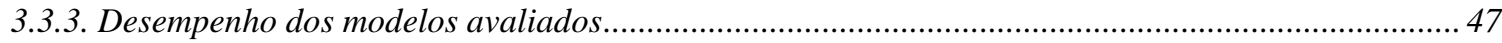

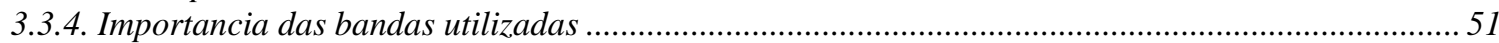

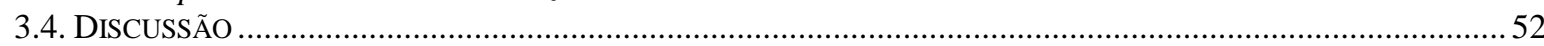

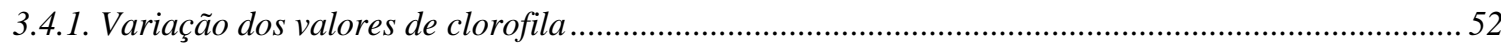

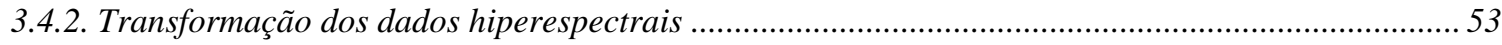

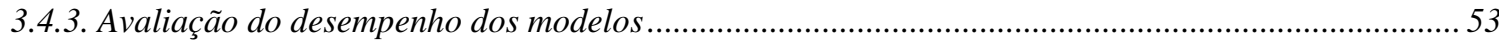

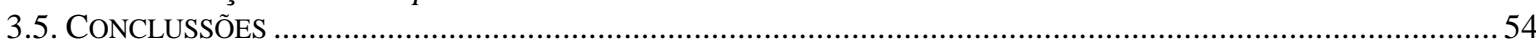

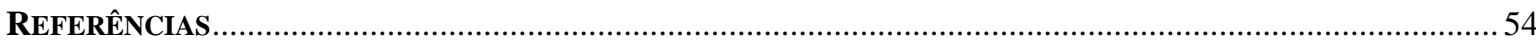


RESUMO

\title{
Resposta hiperespectral de folha na diferenciação de adubação nitrogenada e predição do teor de clorofila na cultura de capim 'Mombaça'
}

\begin{abstract}
A atividade bovina do Brasil é uma das maiores do mundo, devido principalmente, ao uso predominante de pastagens tropicais na dieta do gado, porém, o alto custo dos insumos, com destaque para a adubação nitrogenada, dificulta a obtenção de altas produções de forragens. Por esta razão, a utilização de novas tecnologias que permitam melhorar o manejo e aumentar o rendimento de culturas como o capim 'Mombaça', por meio do uso racional dos fatores de produção, é de alta relevância. O objetivo deste estudo foi avaliar o uso de dados hiperespectrais para a discriminação de diferentes tratamentos de adubação nitrogenada, e comparar diferentes métodos para obter valores de concentração de clorofila a partir de assinaturas espectrais de capim 'Mombaça'. Foram estabelecidos quatro tratamentos de com doses diferentes de adubação nitrogenada. Foi medida a reflectância espectral de folhas coletadas em cada tratamento por meio de um sensor hiperespectral em laboratório além de medições de clorofila das folhas. Foi encontrado que as assinaturas espectrais de cada tratamento tiveram comportamentos diferentes, principalmente nas regiões do verde e do red-edge, sendo que tais diferenças dependeram da quantidade de adubo nitrogenado aplicado e do teor de clorofila foliar. A separação dos tratamentos foi possível mediante o uso de análise linear discriminante, baseando-se nos dados de reflectância espectral obtidos em cada tratamento. A obtenção de valores de concentração de clorofila da folha por meio de reflectância espectral foi possível por meio de técnicas de machine learning, destacando-se o support vector machine, como a melhor alternativa. As regiões do red-edge e do verde foram as mais influentes para realizar o cálculo dos valores de concentração de clorofila na folha.
\end{abstract}

Palavras-chave: Megathyrsus maximus; Reflectância espectral; Clorofila; Análise linear discriminante; Machine learning 
ABSTRACT

Hyperspectal response of leaf on the differentiation of nitrogen fertilization and prediction of chlorophyll content in 'Mombaça' grass

\begin{abstract}
Brazil's cattle production is one of the largest in the world, due mainly, to the predominant use of tropical pastures in the cattle diet. However, the high cost of inputs, especially nitrogen fertilizer, makes it difficult to obtain high forage production, for this reason, the use of new technologies to improve the management and to boost the yield of crops such as Mombaça grass, through the rational use of resources, is of high relevance. The aim of this study was to evaluate the use of hyperspectral data to discriminate different treatments of nitrogen fertilization, and to compare different methods to obtain chlorophyll values of chlorophyll concentration based on spectral signatures of 'Mombaça' grass. Four treatments were established with different doses of nitrogen fertilization. The spectral reflectance of leaves collected in each treatment was measured with a hyperspectral sensor, and leaf chlorophyll measurements were performed, both, on laboratory conditions. It was found that the spectral signatures of each treatments had different behaviors, mainly in the green and red-edge regions, and such differences depended on the amount of nitrogen fertilizer applied and the chlorophyll content of the leaf. The separation of the treatments was possible through the use of linear discriminant analysis, based on the spectral reflectance data obtained in each treatment. Retrieve chlorophyll concentration values from the leaf spectral reflectance was possible by the use of machine learning techniques, highlighting the support vector machine as the best alternative. The red-edge and green regions were the most influential in calculating the values of leaf chlorophyll concentration.
\end{abstract}

Keywords: Megathyrsus maximus; Spectral reflectance; Chlorophyll; Linear discriminant analyisis; Machine learning 


\section{INTRODUÇÃO}

O Brasil é um dos países de destaque na produção bovina a nível mundial, sendo que uma das principais causas deste sucesso é o baixo custo da alimentação animal, devido ao predomínio das pastagens na dieta do gado, sendo esta a forma mais barata de oferecer nutrientes para o desenvolvimento dos animais de corte (DA SILVA et al., 2013; DIAS FILHO, 2014). Desta forma, há uma constante preocupação pela melhoria contínua desta importante cultura, utilizando-se materiais genéticos adequados, além da aplicação dos melhores manejos agronômicos que permitem o máximo desenvolvimento da cultura (BARCELLOS et al., 2008).

Neste sentido, as forragens do gênero Megathyrsus se destacam dentro do mercado brasileiro, por ser as pastagens, mais produtivas e de melhor qualidade (Araujo et al., 2013). Dentro deste grupo, destaca-se a cultivar Megathyrsus maximus cv. Mombaça (sinônimo Panicum maximum cv. Mombaça), pela alta produção de matéria seca e pela boa qualidade para seu uso como forrageira (Zago et al., 2010). Esta cultivar tem a capacidade de produzir até 33 t/ha/ano de matéria seca foliar, 130\% mais do que o capim-colonião (Panicum maximum cv. Colonião), outra importante forrageira utilizada na pecuária, permitindo assim uma maior lotação de animais por unidade de área (Costa et al., 2009; Fernandes et al., 2015).

Esta cultivar pertence ao grupo de forragens consideradas exigentes de solos com alta fertilidade, fazendo com que a adubação seja de grande relevância para a obtenção dos melhores rendimentos (Escarela et al., 2017). Considerando isto, ressalta-se que no caso das pastagens, o nitrogênio $(\mathrm{N})$ está diretamente relacionado com o rendimento e a qualidade da cultura, sendo responsável pela emergência e desenvolvimento de perfilhos, folhas e caules (Heinrichs et al., 2016). Portanto, o N é um nutriente chave para promover a produção de biomassa neste tipo de pastagens tropicais, pelo fato destas serem muito responsivas às adubações nitrogenadas, aumentando consideravelmente a produção de matéria seca (Sarmento et al., 2005). Por outro lado, enquanto a deficiência de nitrogênio na cultura pode levar a diminuições de rendimento, quantidades excessivas podem gerar poluições do solo e de águas subterrâneas (Bao et al., 2013). Além disso, é importante considerar que a produtividade das pastagens tem uma alta variação dentro da lavoura, devido principalmente à variabilidade do estado nutricional gerada pela heterogeneidade das propriedades físicas e químicas do solo (M. Da Silva et al., 2013). Assim, um dos aspectos mais importantes na consecução de melhores rendimentos, é o desenvolvimento de ferramentas para determinar o estado nutricional das plantas de forma prática e rápida (Bao et al., 2013).

Nas pastagens, a informação do teor de nutrientes na planta é obtida por meio de uma série de metodologias laboratoriais, no entanto, estes procedimentos são dispendiosos e demorados (A. J. Neto et al., 2016). Neste sentido, utilizando a relação existente em várias culturas, onde plantas com escassez de nitrogênio têm uma concentração menor de clorofila, tem sido desenvolvidas teorias de estimação de nitrogênio a partir do teor de clorofila na folha e o efeito que a concentração desse pigmento tem na radiação refletida e no estado fisiológico das plantas (Kooistra \& Clevers, 2016). Assim sendo, a produtividade, ao nível do dossel, depende da radiação fotossinteticamente ativa, absorbida por todos os pigmentos da clorofila, os quais estão distribuídos em três dimensões dentro da arquitetura da planta (Croft et al., 2014). Igualmente, medidas do conteúdo de clorofila fornecem informações do estado fisiológico das culturas pois este pigmento está relacionado com a atividade fotossintética das plantas (Haboudane et al., 2008). Por outro lado, foi encontrada uma alta relação entre o conteúdo total de clorofila, a radiação fotossinteticamente ativa e a produtividade primária bruta em culturas tipo C3 e C4 com características anatômicas diferentes, o qual ressalta a utilidade da clorofila como um parâmetro na modelagem do estado fisiológico de plantas e a produtividade das culturas (Houborg et al., 2015; Peng \& Gitelson, 2012). 
Levando em conta a importância da estimação da clorofila, têm sido desenvolvidos equipamentos portáveis para estimar a proporção do pigmento presente nos vegetais (M. Da Silva et al., 2013). Tendo em conta que medições diretas da clorofila, sobre grandes áreas são caras pois precisam de um grande esforço e mão de obra, o sensoriamento remoto é uma ferramenta importante para complementar informações de campo e conseguir uma agricultura sustentável e eficiente. (Haboudane et al., 2008). Desta forma, estimativas do teor de clorofila de uma maneira rápida e não destrutiva, são importantes no âmbito do sensoriamento remoto (Liu et al., 2014).

Vários trabalhos têm sido desenvolvidos com a finalidade de obter valores do teor de clorofila em culturas a partir do uso de ferramentas do sensoriamento remoto. Assim, vários índices de vegetação têm sido propostos para estimar os teores de clorofila ou nitrogênio no dossel das plantas, baseando-se principalmente na refletância na região do verde e do red-edge (Kooistra \& Clevers, 2016; Schlemmer et al., 2013). Há divergências na escolha de um comprimento de onda específico que seja indicador da fisiologia da planta, desta forma, foi proposto o uso de técnicas de estatística multivariada para usar a maior parte do espetro eletromagnético na modelagem de parametros biofísicos da vegetação (Hansen \& Schjoerring, 2003; Wu et al., 2008).

Além disso, existem diferenças nos estudos realizados para diferentes culturas, encontrando-se, por exemplo, fortes correlações entre índices de vegetação e teor de clorofila para trigo e cevada, no entanto, no caso de planta perenes, como lichia, esta relação é fraca (Jay et al., 2017). Por esta razão, e com os constantes avanços no campo do sensoriamento remoto, existe a necessidade de desenvolver técnicas mais robustas, precisas e rápidas para a obtenção de informações da vegetação a partir desta ferramenta (Verrelst et al., 2015). Diante disso, o presente trabalho estuda o comportamento espectral do capim 'Mombaça' com diferentes doses de nitrogênio, para explorar diferentes metodologias que permitam determinar o teor de clorofila a partir do uso de sensores hiperespectrais.

\section{Referências}

Abdel-Rahman, E. M., Ahmed, F. B., \& Ismail, R. (2013). Random forest regression and spectral band selection for estimating sugarcane leaf nitrogen concentration using EO-1 Hyperion hyperspectral data. International Journal of Remote Sensing, 34(2), 712-728. doi:10.1080/01431161.2012.713142

Abdel-Rahman, E. M., Mutanga, O., Odindi, J., Adam, E., Odindo, A., \& Ismail, R. (2014). A comparison of partial least squares (PLS) and sparse PLS regressions for predicting yield of Swiss chard grown under different irrigation water sources using hyperspectral data. Computers and Electronics in Agriculture, 106, 11-19. doi:10.1016/j.compag.2014.05.001

Abdel-Rahman, E. M., Mutanga, O., Odindi, J., Adam, E., Odindo, A., \& Ismail, R. (2017). Estimating Swiss chard foliar macro- and micronutrient concentrations under different irrigation water sources using ground-based hyperspectral data and four partial least squares (PLS)-based (PLS1, PLS2, SPLS1 and SPLS2) regression algorithms. Computers and Electronics in Agriculture, 132, 21-33. doi:10.1016/j.compag.2016.11.008

Alexandrino, E., Gomide, J. A., \& De Miranda Gomide, C. A. (2005). Crescimento e desenvolvimento do dossel de Panicum maximum cv. Mombaça. Revista Brasileira de Zootecnia, 34(6 SUPPL.), 2164-2173. doi:10.1590/S151635982005000700002

Amaral, L. R., \& Molin, J. P. (2014). The effectiveness of three vegetation indices obtained from a canopy sensor in identifying sugarcane response to nitrogen. Agronomy Journal, 106(1), 273-280. doi:10.2134/agronj2012.0504

Amaral, L. R., Molin, J. P., \& Schepers, J. S. (2015). Algorithm for variable-rate nitrogen application in sugarcane based on active crop canopy sensor. Agronomy Journal, 107(4), 1513-1523. doi:10.2134/agronj14.0494

Araujo, L. C., Santos, P. M., Rodriguez, D., Pezzopane, J. R. M., Oliveira, P. P. A., \& Cruz, P. G. (2013). Simulating guinea grass production: Empirical and mechanistic approaches. Agronomy Journal, 105(1), 61-69. doi:10.2134/agronj2012.0245

Arshad, M., Ullah, S., Khurshid, K., \& Ali, A. (2017). Estimation of leaf water contents from mid- A nd thermal infrared spectra by coupling genetic algorithm and partial least squares regression. Journal of Applied Remote Sensing, 12(2), 10. doi:10.1117/12.2277822 
Azadbakht, M., Ashourloo, D., Aghighi, H., \& Radiom, S. (2019). Wheat leaf rust detection at canopy scale under di ff erent LAI levels using machine learning techniques. Computers and Electronics in Agriculture, 156(September 2018), 119-128. doi:10.1016/j.compag.2018.11.016

Bandos, T. V., Bruzzone, L., \& Camps-Valls, G. (2009). Classification of hyperspectral images with regularized linear discriminant analysis. IEEE Transactions on Geoscience and Remote Sensing, 47(3), 862-873. doi:10.1109/TGRS.2008.2005729

Bao, Y., Xu, K., Min, J., \& Xu, J. (2013). Estimating wheat shoot nitrogen content at vegetative stage from in situ hyperspectral measurements. Crop Science, 53(5), 2063-2071. doi:10.2135/cropsci2013.01.0012

Barnes, J. D., Balaguer, L., Manrique, E., Elvira, S., \& Davison, A. W. (1992). A reappraisal of the use of DMSO for the extraction and determination of chlorophylls $\mathrm{a}$ and $\mathrm{b}$ in lichens and higher plants. Environmental and Experimental Botany, 32(2), 85-100. doi:10.1016/0098-8472(92)90034-Y

Basso, K. C., Cecato, U., Barbero, L. M., Lempp, B., Gomes, J. A. N., \& Lugão, S. M. B. (2014). INFLUENCE OF NITROGEN LEVELS ON LEAF ANATOMY AND NUTRITIVE VALUE OF MILLENIUM GRASS. Bioscience Journal, 30(3), 792-801.

Belgiu, M., \& Drăgu, L. (2016). Random forest in remote sensing: A review of applications and future directions. ISPRS Journal of Photogrammetry and Remote Sensing, 114, 24-31. doi:10.1016/j.isprsjprs.2016.01.011

Cavallo, D. Pietro, Cefola, M., Pace, B., Logrieco, A. F., \& Attolico, G. (2017). Contactless and non-destructive chlorophyll content prediction by random forest regression: A case study on fresh-cut rocket leaves. Computers and Electronics in Agriculture, 140, 303-310. doi:10.1016/j.compag.2017.06.012

Chemura, A., Mutanga, O., \& Dube, T. (2017). Remote sensing leaf water stress in coffee (Coffea arabica) using secondary effects of water absorption and random forests. Physics and Chemistry of the Earth, 100, 317-324. doi:10.1016/j.pce.2017.02.011

Chen, B., Li, S., Wang, K., Zhou, G., \& Bai, J. (2012). Evaluating the severity level of cotton Verticillium using spectral signature analysis. International Journal of Remote Sensing, 33(9), 2706-2724. doi:10.1080/01431161.2011.619586

Chlingaryan, A., Sukkarieh, S., \& Whelan, B. (2018). Machine learning approaches for crop yield prediction and nitrogen status estimation in precision agriculture : A review. Computers and Electronics in Agriculture, 151(November 2017), 61-69. doi:10.1016/j.compag.2018.05.012

Chun, H., \& Keleş, S. (2010). Sparse partial least squares regression for simultaneous dimension reduction and variable selection. Journal of the Royal Statistical Society. Series B: Statistical Methodology, 72(1), 3-25. doi:10.1111/j.14679868.2009.00723.x

Clevers, J. G. P. W., \& Gitelson, A. A. (2013). Remote estimation of crop and grass chlorophyll and nitrogen content using red-edge bands on Sentinel-2 and -3. International Journal of Applied Earth Observation and Geoinformation, 23(1), 334-343. doi:10.1016/j.jag.2012.10.008

Clevers, J. G. P. W., \& Kooistra, L. (2012). Using Hyperspectral Remote Sensing Data for Retrieving Canopy Chlorophyll and Nitrogen Content. Journal of Selected Topics in Applied Earth Observation and Remote Sensing, 5(2), 574-583. doi:10.1109/JSTARS.2011.2176468

Colombani, C., Croiseau, P., Fritz, S., Guillaume, F., Legarra, a, Ducrocq, V., \& Robert-Granie, C. (2012). A comparison of partial least squares (PLS) and sparse PLS regressions in genomic selection in French dairy cattle. J Dairy Sci, 95(4), 2120-2131. doi:10.3168/jds.2011-4647

Costa, F., Corrêa, E., Melo, G., Cardoso, E., Pereira, M., \& Miranda, C. (2009). Avaliação dos impactos econômicos de quatro forrageiras lançadas pela Embrapa. (E. C. Lima, Ed.) Embrapa Gado de ... (Primeira.). Campo Grande, MS: Embrapa. Retrieved from https://www.infoteca.cnptia.embrapa.br/infoteca/bitstream/doc/853367/1/DOC174.pdf

Croft, H., Chen, J. M., \& Zhang, Y. (2014). The applicability of empirical vegetation indices for determining leaf chlorophyll content over different leaf and canopy structures. Ecological Complexity, 17(1), 119-130. doi:10.1016/j.ecocom.2013.11.005

Cui, S., \& Zhou, K. (2017). A comparison of the predictive potential of various vegetation indices for leaf chlorophyll content. Earth Science Informatics, 10(2), 169-181. doi:10.1007/s12145-016-0281-3

Cui, Z., \& Kerekes, J. (2018). Potential of Red Edge Spectral Bands in Future Landsat Satellites on Agroecosystem Canopy Green Leaf Area Index Retrieval. Remote Sensing, 10(1), 1-14. doi:10.3390/rs10091458 
Curran, P. J., Dungan, J. L., \& Peterson, D. L. (2001). Estimating the foliar biochemical concentration of leaves with reflectance spectrometry: Testing the Kokaly and Clark methodologies. Remote Sensing of Environment, 76(3), 349359. doi:10.1016/S0034-4257(01)00182-1

Da Silva, M., Pinto, F., Queiroz, D., Vieira, L., \& Resende, R. (2013). USING AN AERIAL SYSTEM OF REMOTE SENSING TO DETECT DIFFERENT NUTRITIONAL STATUS IN Brachiaria decumbens. Engenharia Agricola Jaboticabal, 34(5), 1049-1062.

Delegido, J., Verrelst, J., Meza, C. M., Rivera, J. P., Alonso, L., \& Moreno, J. (2013). A red-edge spectral index for remote sensing estimation of green LAI over agroecosystems. European Journal of Agronomy, 46, 42-52. doi:10.1016/j.eja.2012.12.001

Diacono, M., Rubino, P., \& Montemurro, F. (2013). Precision nitrogen management of wheat. A review. Agronomy for Sustainable Development, 33(1), 219-241. doi:10.1007/s13593-012-0111-z

Diezma, B., Lléo, L., Roger, J. M., Herrero-Lengreo, A., Lunadei, L., \& Ruiz-Altisent, M. (2013). Examination of the quality of spinach leaves using hyperspectral imaging. Postharvest Biology and Technology, 85, 8-17.

Doktor, D., Lausch, A., Spengler, D., \& Thurner, M. (2014). Extraction of plant physiological status from hyperspectral signatures using machine learning methods. Remote Sensing, 6(12), 12247-12274. doi:10.3390/rs61212247

Emanuel, M., Costa, D. A., Duarte, S. N., Neto, D. D., Cabral, E., \& Silva, D. A. (2009). TEOR DE NITROGÊENIO, ÍNDICES DE ÁREA FOLIAR E DE COLHEITA, NO MILHO, EM FUNÇÃO DA ADUBAÇÃO NITROGENADA, EM SOLO DE VÁRZEA. Revista Brasileira de Milho e Sorgo, 8(1), 13-26.

Erudel, T., Fabre, S., Houet, T., Mazier, F., \& Briottet, X. (2017). Criteria Comparison for Classifying Peatland Vegetation Types Using In Situ Hyperspectral Measurements. Remote Sensing, 9(7), 748. doi:10.3390/rs9070748

Escarela, C. M., Pietroski, M., De Mello Prado, R., Campos, C. N. S., \& Caione, G. (2017). Effect of nitrogen fertilization on productivity and quality of Mombasa forage (Megathyrsus maximum cv. Mombasa). Acta Agronomica, 66(1), 42-48. doi:10.15446/acag.v66n1.53420

Féret, J. B., Gitelson, A. A., Noble, S. D., \& Jacquemoud, S. (2017). PROSPECT-D: Towards modeling leaf optical properties through a complete lifecycle. Remote Sensing of Environment, 193, 204-215. doi:10.1016/j.rse.2017.03.004

Fernandes, J. C., Buzetti, S., Dupas, E., Teixeira, C. M., \& Andreotti, M. (2015). Sources and rates of nitrogen fertilizer used in Mombasa guineagrass in the Brazilian Cerrado region. African Journal of Agricultural Research, 10(19), 20762082. doi:10.5897/AJAR2014.9276

Filella, I., Serrano, L., Serra, J., \& Peñuelas, J. (1995). Evaluating Wheat Nitrogen Status with Canopy Reflectance Indexes and Discriminant-Analysis. Crop Science, $35(5), \quad$ 1400-1405. doi:10.2135/cropsci1995.0011183X003500050023x

Gbenou, B., Adjolohoun, S., Bignon, D., Houndjo, M., Ahoton, L., Saidou, A., ... Sinsin, B. A. (2018). Practical aspects of grass forage seed production and quality with particular reference to planting row spacing and nitrogen fertilization in tropical regions : A review. International Journal of Biological and Chemical Sciences, 12(February), 508518.

Gitelson, A. A., Arkebauer, T. J., \& Suyker, A. E. (2018). Convergence of daily light use e ffi ciency in irrigated and rainfed C3 and C4 crops. Remote Sensing of Environment, 217(August), 30-37. doi:10.1016/j.rse.2018.08.007

Gitelson, A. A., Gritz, Y., \& Merzlyak, M. N. (2003). Relationships between leaf chlorophyll content and spectral reflectance and algorithms for non-destructive chlorophyll assessment in higher plant leaves reflectance and algorithms for non-destructive chlorophyll assessment. Journal of Plant Physiology, 160(November), 271-282. doi:10.1078/0176-1617-00887

Gitelson, A. A., Merzlyak, M. N., \& Lichtenthaler, H. K. (1996). Detection of Red Edge Position and Chlorophyll Content by Reflectance Measurements Near $700 \mathrm{~nm}$. Journal of Plant Physiology, 148(3-4), 501-508. doi:10.1016/S0176-1617(96)80285-9

Gitelson, A. A., Peng, Y., Arkebauer, T. J., \& Suyker, A. E. (2015). Productivity, absorbed photosynthetically active radiation, and light use efficiency in crops: Implications for remote sensing of crop primary production. Journal of Plant Physiology, 177, 100-109. doi:10.1016/j.jplph.2014.12.015

Greef, J. M. (1994). Productivity of Maize ( Zea mays L .) in Relation to Morphological and Physiological Characteristics under Varying Amounts of Nitrogen Supply. J. Agronomy and crop Science, 172, 317-326. 
Guo, B.-B., Qi, S.-L., Heng, Y.-R., Duan, J.-Z., Zhang, H.-Y., Wu, Y.-P., ... Zhu, Y.-J. (2017). Remotely assessing leaf $\mathrm{N}$ uptake in winter wheat based on canopy hyperspectral red-edge absorption. European Journal of Agronomy, 82, 113-124. doi:10.1016/j.eja.2016.10.009

Guo, P. T., Shi, Z., Li, M. F., Luo, W., \& Cha, Z. Z. (2018). A robust method to estimate foliar phosphorus of rubber trees with hyperspectral reflectance. Industrial Crops and Products, 126(September), 1-12. doi:10.1016/j.indcrop.2018.09.055

Haboudane, D., Tremblay, N., Miller, J. R., \& Vigneault, P. (2008). Remote Estimation of Crop Chlorophyll Content Using Spectral Indices Derived From Hyperspectral Data. IEEE Transactions on Geoscience and Remote Sensing, 46(2), 423-437. doi:10.1109/TGRS.2007.904836

Hansen, P. M., \& Schjoerring, J. K. (2003). Reflectance measurement of canopy biomass and nitrogen status in wheat crops using normalized difference vegetation indices and partial least squares regression. Remote Sensing of Environment, 86(4), 542-553. doi:10.1016/S0034-4257(03)00131-7

Hatfield, J. L., Gitelson, A. A., Schepers, J. S., \& Walthall, C. L. (2008). Application of spectral remote sensing for agronomic decisions. Agronomy Journal, 100(3 SUPPL.), 117-131. doi:10.2134/agronj2006.0370c

Heinrichs, R., Monreal, C. M., Santos, E. T., Soares Filho, C. V., Rebonatti, M. D., Teixeira, N. M., \& Moreira, A. (2016). Phosphorus Sources and Rates Associated with Nitrogen Fertilization in Mombasa Grass Yield. Communications in Soil Science and Plant Analysis, 47(5), 657-669. doi:10.1080/00103624.2016.1141923

Horler, D. N. H., Dockray, M., \& Barber, J. (1983). The red edge of plant leaf reflectance. International Journal of Remote Sensing, 4(2), 37-41.

Houborg, R., McCabe, M. F., Cescatti, A., \& Gitelson, A. A. (2015). Leaf chlorophyll constraint on model simulated gross primary productivity in agricultural systems. International Journal of Applied Earth Observation and Geoinformation, 43, 160-176. doi:10.1016/j.jag.2015.03.016

Inoue, Y., Guérif, M., Baret, F., Skidmore, A., Gitelson, A., Schlerf, M., .. Olioso, A. (2016). Simple and robust methods for remote sensing of canopy chlorophyll content: a comparative analysis of hyperspectral data for different types of vegetation. Plant, Cell \& Environment, 2609-2623. doi:10.1111/pce.12815

Jay, S., Maupas, F., Bendoula, R., \& Gorretta, N. (2017). Retrieving LAI, chlorophyll and nitrogen contents in sugar beet crops from multi-angular optical remote sensing: Comparison of vegetation indices and PROSAIL inversion for field phenotyping. Field Crops Research, 210(March), 33-46. doi:10.1016/j.fcr.2017.05.005

Kira, O., Linker, R., \& Gitelson, A. (2015). Non-destructive estimation of foliar chlorophyll and carotenoid contents: Focus on informative spectral bands. International Journal of Applied Earth Observation and Geoinformation, 38, 251260. doi:10.1016/j.jag.2015.01.003

Kooistra, L., \& Clevers, J. G. P. W. (2016). Estimating potato leaf chlorophyll content using ratio vegetation indices. Remote Sensing Letters, 7(6), 611-620. doi:10.1080/2150704X.2016.1171925

Krishna, G., Sahoo, R. N., Singh, P., Bajpai, V., Patra, H., Kumar, S., .. Sahoo, P. M. (2019). Comparison of various modelling approaches for water deficit stress monitoring in rice crop through hyperspectral remote sensing. Agricultural Water Management, 213(October 2017), 231-244. doi:10.1016/j.agwat.2018.08.029

Li, C., Zhu, X., Wei, Y., Cao, S., Guo, X., Yu, X., \& Chang, C. (2018). Estimating apple tree canopy chlorophyll content based on Sentinel-2A remote sensing imaging. Scientific Reports, 8(1), 1-10. doi:10.1038/s41598-018-21963-0

Li, D., Cheng, T., Zhou, K., Zheng, H., Yao, X., Tian, Y., ... Cao, W. (2017). WREP: A wavelet-based technique for extracting the red edge position from reflectance spectra for estimating leaf and canopy chlorophyll contents of cereal crops. ISPRS Journal of Photogrammetry and Remote Sensing, 129, 103-117. doi:10.1016/j.isprsjprs.2017.04.024

Li, X., Chen, X., Zhou, Y., Nong, M., Liu, X., \& Ai, J. (2015). Spectral characteristics analysis and chlorophyll content of sugarcane leaves under different fertilizer treatments. Transactions of the Chinese Society if Agricultural Engineering, 31(2), 1-6.

LI, Z. wang, XIN, X. ping, TANG, H., YANG, F., CHEN, B. rui, \& ZHANG, B. hui. (2017). Estimating grassland LAI using the Random Forests approach and Landsat imagery in the meadow steppe of Hulunber, China. Journal of Integrative Agriculture, 16(2), 286-297. doi:10.1016/S2095-3119(15)61303-X

Liang, L., Qin, Z., Zhao, S., Di, L., Zhang, C., Deng, M., ... Liu, Z. (2016). Estimating crop chlorophyll content with hyperspectral vegetation indices and the hybrid inversion method. International Journal of Remote Sensing, 37(13), 
2923-2949. doi:10.1080/01431161.2016.1186850

Liao, Q., Wang, J., Yang, G., Zhang, D., Li, H., Fu, Y., \& Li, Z. (2013). Comparison of spectral indices and wavelet transform for estimating chlorophyll content of maize from hyperspectral reflectance. Journal of Applied Remote Sensing, 7(1), 073575. doi:10.1117/1.JRS.7.073575

Liu, B., Yue, Y.-M., Li, R., Shen, W.-J., \& Wang, K.-L. (2014). Plant Leaf Chlorophyll Content Retrieval Based on a Field Imaging Spectroscopy System. Sensors, 14(10), 19910-19925. doi:10.3390/s141019910

Macedo, C. H. O., Alexandrino, E., Jakelaitis, A., Vaz, R. G. M. V., Reis, R. H. P. dos, \& Vendrusculo, J. (2010). Características agronômicas, morfogênicas e estruturais do capim Panicum maximum cv. Mombaça sob desfolhação intermitente. Revista Brasileira de Saúde e Produção Animal, 11(4), 941-952.

Mirzaie, M., Darvishzadeh, R., Shakiba, A., Matkan, A. A., Atzberger, C., \& Skidmore, A. (2014). Comparative analysis of different uni- and multi-variate methods for estimation of vegetation water content using hyper-spectral measurements. International Journal of Applied Earth Observation and Geoinformation, 26(1), 1-11. doi:10.1016/j.jag.2013.04.004

Morellos, A., Pantazi, X., Moshou, D., Alexandridis, T., Whetton, R., Tziotzios, G., ... Mouazen, A. M. (2016). Machine learning based prediction of soil total nitrogen, organic carbon and moisture content by using VIS-NIR spectroscopy. Biosystems Engineering, 152, 104-116. doi:10.1016/j.biosystemseng.2016.04.018

Mountrakis, G., Im, J., \& Ogole, C. (2011). Support vector machines in remote sensing: A review. ISPRS Journal of Photogrammetry and Remote Sensing, 66(3), 247-259. doi:10.1016/j.isprsjprs.2010.11.001

Müller, M. S., Fancelli, A. L., Dourado-Neto, D., García, A. G., \& Ovejero, R. F. L. (2002). Produtividade do Panicum maximum cv . Mombaça, sob pastejo rotacionado. Scientia Agricola, 59(3), 427-433. doi:10.1590/S010390162002000300003

Neto, A. J., Lopes, D. C., Pinto, F. A. C., \& Zolnier, S. (2017). Vis/NIR spectroscopy and chemometrics for nondestructive estimation of water and chlorophyll status in sunflower leaves. Biosystems Engineering, 155, 124-133. doi:10.1016/j.biosystemseng.2016.12.008

Neto, A. J., Lopes, D. de C., Silva, T. G. F. da, Ferreira, S. O., \& Grossi, J. A. S. (2016). Estimation of leaf water content in sunflower under drought conditions by means of spectral reflectance. Engineering in Agriculture, Environment and Food, 1-5. doi:10.1016/j.eaef.2016.11.006

Neto, A., Lopes, D., \& Borges Júnior, J. (2017). Assessment of Photosynthetic Pigment and Water Contents in Intact Sunflower Plants from Spectral Indices. Agriculture, 7(2), 8. doi:10.3390/agriculture7020008

Newman, Y. C., Sinclair, T. R., Blount, A. S., Lugo, M. L., \& Valencia, E. (2007). Forage production of tropical grasses under extended daylength at subtropical and tropical latitudes. Enviromental and Experimental Botany, 61(1), 18-24. doi:10.1016/j.envexpbot.2007.02.005

Paciullo, D. S. C., Gomide, C. A. M., Castro, C. R. T., Maurício, R. M., Fernandes, P. B., \& Morenz, M. J. F. (2016). Morphogenesis, biomass and nutritive value of Panicum maximum under different shade levels and fertilizer nitrogen rates. Grass and Forage Science, (August), 1-11. doi:10.1111/gfs.12264

Peng, Y., \& Gitelson, A. A. (2012). Remote estimation of gross primary productivity in soybean and maize based on total crop chlorophyll content. Remote Sensing of Environment, 117, 440-448. doi:10.1016/j.rse.2011.10.021

Pontes, L. da S., Baldissera, T. C., Giostri, A. F., Stafin, G., dos Santos, B. R. C., \& Carvalho, P. C. d. F. (2017). Effects of nitrogen fertilization and cutting intensity on the agronomic performance of warm-season grasses. Grass and Forage Science, 72(4), 663-675. doi:10.1111/gfs.12267

Putnam, R. A., Mohaidat, Q. I., Daabous, A., \& Rehse, S. J. (2013). A comparison of multivariate analysis techniques and variable selection strategies in a laser-induced breakdown spectroscopy bacterial classification. Spectrochimica Acta - Part B Atomic Spectroscopy, 87, 161-167. doi:10.1016/j.sab.2013.05.014

Rasmussen, I. S., Dresbøll, D. B., \& Thorup-Kristensen, K. (2015). Winter wheat cultivars and nitrogen (N) fertilization-Effects on root growth, $\mathrm{N}$ uptake efficiency and $\mathrm{N}$ use efficiency. European Journal of Agronomy, 68, 38-49. doi:10.1016/j.eja.2015.04.003

Rosolem, C. A., Ritz, K., Cantarella, H., Galdos, M. V., Hawkesford, M. J., Whalley, W. R., \& Mooney, S. J. (2017). Enhanced Plant Rooting and Crop System Management for Improved N Use Efficiency. Advances in Agronomy (1st ed., Vol. 146). Elsevier Inc. doi:10.1016/bs.agron.2017.07.002 
Sarmento, P., Rodrigues, L., Lugão, S., Da Cruz, M., Campos, F., \& Ferreira, M. (2005). Respostas agronômicas e morfológicas de Panicum maximum Jacq. Cv IPR - 86 Milênio, sob pastejo, à adubação nitrogenada. Boletim de Induistria Animal, 62(4), 333-346.

Schlemmer, M., Gitelson, A., Schepersa, J., Fergusona, R., Peng, Y., Shanahana, J., \& Rundquist, D. (2013). Remote estimation of nitrogen and chlorophyll contents in maize at leaf and canopy levels. International Journal of Applied Earth Observation and Geoinformation, 25(1), 47-54. doi:10.1016/j.jag.2013.04.003

Silva, R., Gomes, V., Mendes-Faia, A., \& Melo-Pinto, P. (2018). Using support vector regression and hyperspectral imaging for the prediction of oenological parameters on different vintages and varieties ofwine grape berries. Remote Sensing, 10(2), 1-23. doi:10.3390/rs10020312

Sonobe, R., Sano, T., \& Horie, H. (2018). Using spectral reflectance to estimate leaf chlorophyll content of tea with shading treatments. Biosystems Engineering, 175, 168-182. doi:10.1016/j.biosystemseng.2018.09.018

Stewart, S., Ivy, M. A., \& Anslyn, E. V. (2013). The use of principal component analysis and discriminant analysis in differential sensing routines. Chemical Society Reviews, 43(1), 70-84. doi:10.1039/c3cs60183h

Tan, K., Wang, S., Song, Y., Liu, Y., \& Gong, Z. (2018). Estimating nitrogen status of rice canopy using hyperspectral reflectance combined with BPSO-SVR in cold region. Chemometrics and Intelligent Laboratory Systems, 172(November 2017), 68-79. doi:10.1016/j.chemolab.2017.11.014

Thakur, A. K., Rath, S., \& Mandal, K. G. (2013). Differential responses of system of rice intensification ( SRI ) and conventional flooded-rice management methods to applications of nitrogen fertilizer. Plant Soil, 370, 59-71. doi:10.1007/s11104-013-1612-5

Verrelst, J., Camps-Valls, G., Muñoz-Marí, J., Rivera, J. P., Veroustraete, F., Clevers, J. G. P. W., \& Moreno, J. (2015). Optical remote sensing and the retrieval of terrestrial vegetation bio-geophysical properties - A review. ISPRS Journal of Photogrammetry and Remote Sensing, 108, 273-290. doi:10.1016/j.isprsjprs.2015.05.005

Vibhute, A., Kale, K., Mehrotra, S., Dhumal, R., \& Nagne, A. (2018). Determination of soil physicochemical attributes in farming sites through visible, near-infrared diffuse reflectance spectroscopy and PLSR modeling. Ecological Processes, 7(26), 12.

Wang, L., Zhou, X., Zhu, X., Dong, Z., \& Guo, W. (2016). Estimation of biomass in wheat using random forest regression algorithm and remote sensing data. Crop Journal, 4(3), 212-219. doi:10.1016/j.cj.2016.01.008

Were, K., Bui, D. T., Dick, Ø. B., \& Singh, B. R. (2015). A comparative assessment of support vector regression, artificial neural networks, and random forests for predicting and mapping soil organic carbon stocks across an Afromontane landscape. Ecological Indicators, 52, 394-403. doi:10.1016/j.ecolind.2014.12.028

Wu, C., Niu, Z., Tang, Q., \& Huang, W. (2008). Estimating chlorophyll content from hyperspectral vegetation indices: Modeling and validation. Agricultural and Forest Meteorology, 148(8-9), 1230-1241. doi:10.1016/j.agrformet.2008.03.005

Xie, Y., Sha, Z., \& Yu, M. (2008). Remote sensing imagery in vegetation mapping: a review. Journal of Plant Ecology, 1(1), 9-23. doi:10.1093/jpe/rtm005

Zago, L. A., Lempp, B., Borges do Valle, C., Jank, L., Rocha, L., Postiglioni, S., ... Soares, C. (2010). Principais espécies forrageiras utilizadas em pastagens para gado de corte. In Bovinoultura de corte (pp. 375-417). Retrieved from file:///C:/Users/usuario/Downloads/digitalizar0006.pdf 


\section{USO DA RESPOSTA HIPERESPECTRAL NA DIFERENCIAÇÃO DO TEOR DE CLOROFILA EM DIFERENTES TRATAMENTOS DE ADUBAÇÃO NITROGENADA EM CAPIM 'MOMBAÇA'}

\section{RESUMO}

Melhorar o rendimento das culturas depende de vários fatores, sendo a adubação, um dos mais importantes. As espécies de forragens tropicais, como Megathyrsus maximus, são plantas altamente demandantes de adubação nitrogenada, razão pela qual é importante procurar novas tecnologias que ajudem a aumentar o rendimento destas culturas de maneira sustentável. O teor de clorofila tem sido utilizado como um fator relacionado com diferentes aspectos fisiológicos da cultura, fornecendo também informações do manejo empregado na mesma. Contudo, sua medição pode ser cara e pouco prática. Neste sentido, o sensoriamento remoto tem o potencial de avaliar diferentes características da vegetação por meio da reflectância espectral. Diante do exposto, o objetivo deste estudo foi avaliar o uso da resposta espectral de capim 'Mombaça' na discriminação de teores de clorofila. Para isso, foi medida a reflectância espectral, a nível foliar, de quatro tratamentos com doses diferentes de adubação nitrogenada. Foram feitas medições de concentração de clorofila em laboratório das folhas amostradas, durante cinco meses. Foi aplicado análise linear discriminante nos dados de reflectância espectral das folhas coletadas, encontrando-se que foi possível separar as amostras pela quantidade de adubo aplicado em cada um dos meses avaliados. Além disso, foi encontrado que que a resposta espectral das folhas apresentou diferenças de comportamento dependendo do teor de clorofila dos tecidos. Essas mudanças na reflectância espectral foram mais relevantes no comprimento de onda correspondente ao red-edge.

Palavras-chave: Megathyrsus maximus; Reflectância espectral; Clorofila; Análise linear discriminante

\section{ABSTRACT}

Improving crop yield depends on several factors, with fertilization being one of the most important. Tropical forage species, such as Megathyrsus maximus, are highly demanding plants for nitrogen fertilization, for this reason, it is important to look for new technologies that boost the yield of this type of crops in a sustainable way. The chlorophyll content has been used as a factor related to different physiological aspects of the crop, and can give information on the management used in it. However, its measurement can be expensive and little practical. Hence, remote sensing has the potential to evaluate different vegetation characteristics through spectral reflectance. Thus, the objective of this study was to evaluate the use of the spectral response of 'Mombaça' grass in the discrimination of chlorophyll content. For this, the spectral reflectance, at leaf level, of four treatments with different doses of nitrogen fertilization was obtained, and measurements of chlorophyll concentration were made in laboratory conditions, during five months. A linear discriminant analysis was applied to the spectral reflectance data of the collected leaves. It was found that it was possible to separate the samples by the amount of fertilizer applied in each of the months. In addition, it was found that the spectral response of the leaves showed differences in behavior depending on the chlorophyll content of the tissues. These changes in spectral reflectance were more relevant at the wavelength corresponding to the red-edge.

Keywords: Megathyrsus maximus; Spectral reflectance; Chlorophyll; Linear discriminant analysis 


\subsection{Introdução}

Melhorar o rendimento das culturas de uma maneira sustentável é um dos objetivos da agricultura de precisão, no entanto, o crescimento e o rendimento potencial dependem de vários fatores, tais como o clima, solo, topografia, disponibilidade de água e o manejo da fertilização (Chlingaryan et al., 2018). Neste sentido, a otimização no uso de fertilizantes, principalmente aqueles com fontes nitrogenadas, é uma das maiores preocupações da agricultura moderna (Escarela et al., 2017; Fernandes et al., 2015; Foster et al., 2016).

O nitrogênio é um nutriente essencial para a produção das culturas, porém, na maioria dos casos é aplicado de maneira excessiva, sem levar em consideração as exigências nutricionais da planta ou o risco ambiental que isso pode gerar (Hatfield et al., 2008). As pastagens tropicais, como Megathyrsus sp. são exemplo de plantas consideradas altamente demandantes de nitrogênio para que possam atingir a máxima produtividade. Desta forma, pesquisas que almejam conseguir melhores rendimentos para tais culturas e que diminuam a utilização de fontes nitrogenadas são de grande importância para a garantia de uma agricultura sustentável (Escarela et al., 2017; Pontes et al., 2017).

É importante destacar que o nitrogênio tem valiosa participação na atividade fotossintética das plantas. Diferentes estudos demonstram a relação entre produtividade primária bruta e teor de clorofila, estabelecendo que o monitoramento do nitrogênio e da clorofila provê informação importante do estado fotossintético de várias culturas (Schlemmer et al., 2013). Boa parte das pesquisas relacionadas com o estudo do nitrogênio nas folhas por meio de técnicas de sensoriamento remoto estão baseadas nos valores de reflectância espectral nas faixas do visível e do infravermelho próximo, sendo influenciadas principalmente pelo teor de clorofila e pela estrutura celular das plantas (Starks et al., 2006). Esta relação é causada pela interação que os pigmentos foliares possuem com a radiação solar, o qual gera mudanças no metabolismo das plantas, atuando como um mecanismo de resposta às condições ambientais em função dos limitantes e os recursos disponíveis (Féret et al., 2017). Desta forma, alterações no teor de nitrogênio na folha promovem mudanças na absorção da luz, devido à clorofila fazendo com que seja alterada a capacidade fotossintética das plantas (Schlemmer et al., 2013).

Nos últimos anos a determinação do teor de clorofila nas plantas é empregada como um fator determinante na avaliação do rendimento das culturas obtendo-se informações como as respostas da cultura às aplicações de nitrogênio, assim como os diferentes tipos de manejos a serem empregados na fase do crescimento e desenvolvimento vegetal (Kooistra \& Clevers, 2016). Por isso, analisar o teor de clorofila é uma metodologia relevante para estudar o crescimento de diferentes culturas, além de obter informações referentes ao ataque de pragas e doenças, e também da percepção das etapas de maturidade fisiológica da cultura (C. Li et al., 2018).

Medições espectrais em diferentes culturas proveem uma oportunidade para o estudo não destrutivo, instantâneo e rápido do teor de clorofila nas folhas in situ, o qual leva a melhorar o desempenho de aplicações de fertilizantes em locais específicos (X. Li et al., 2015). Por essa razão, várias pesquisas têm sido desenvolvidas a fim de estabelecer metodologias que permitam empregar o uso eficiente de adubos nitrogenados por meio de técnicas de sensoriamento remoto (Li et al., 2018).

Recentemente desenvolveu-se metodologias estatísticas e de computação para aproveitar os dados da reflectância espectral de diversas culturas, a fim de obter informações valiosas de seus estados fisiológicos e nutricionais (Chlingaryan et al., 2018). Dessa maneira, a combinação de espectroscopia e análise de dados multivariados é aplicável para diferentes produtos da indústria alimentícia e agrícola, com o objetivo de identificar sua composição com acurácia (Neto et al., 2017; Neto et al., 2016). Uma das técnicas de análise multivariada aplicadas à otimização da fertilização em diferentes culturas é a análise discriminante, a qual permite agrupar diferentes medições espectrais baseando-se em 
fatores específicos gerados pela combinação das variáveis medidas (Carvalho et al., 2013; Filella et al., 1995). Neste sentido, o objetivo deste estudo foi avaliar o uso da resposta espectral de capim 'Mombaça' na discriminação dos teores de clorofila.

\subsection{Material e métodos}

\subsubsection{Caracterização da área experimental}

O estudo foi realizado na área experimental da Escola Superior de Agricultura "Luiz de Queiroz"

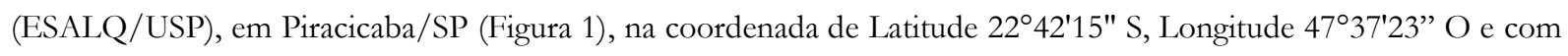
altitude $530 \mathrm{~m}$ ). O solo da área experimental foi classificado como Nitossolo Vermelho Eutroférrico latossólico segundo o Sistema Brasileiro de Classificação de Solos (EMBRAPA, 2006). O clima da região é subtropical úmido (Cwa), segundo a classificação de Köppen-Geiger, com verão quente e úmido e inverno seco, com temperatura média inferior a $18^{\circ} \mathrm{C}$ no mês mais frio e superior a $22^{\circ} \mathrm{C}$ no mês mais quente (ALVARES et al., 2013). As condições meteorológicas consideradas para o desenvolvimento do experimento foram registradas de julho de 2017 a janeiro de 2018. (Tabela 1).

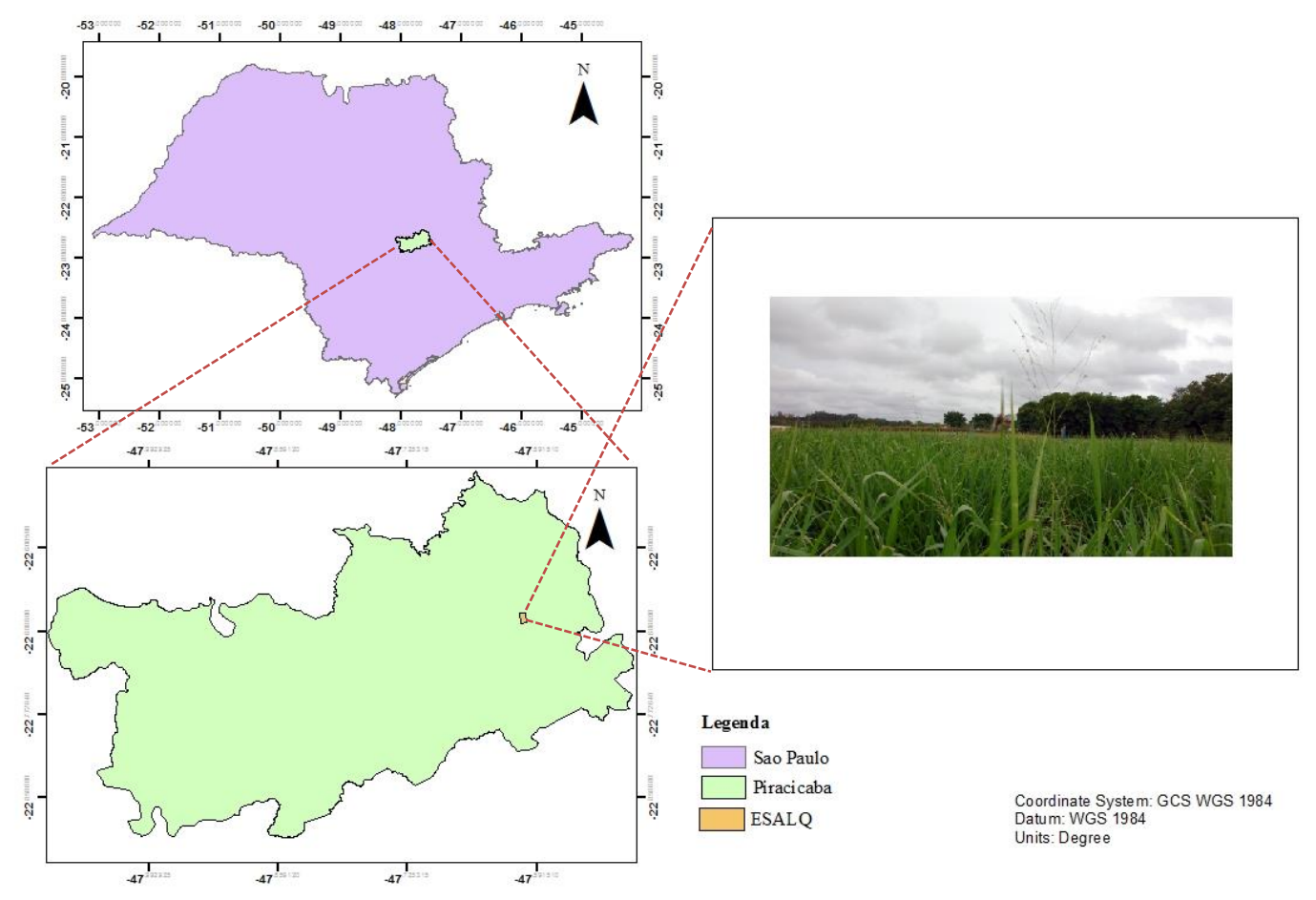

Figura 1 - Localização do experimento com destaque a cidade de Piracicaba e a área experimental. 
Tabela 1. Condições meteorológicas médias durante o desenvolvimento do experimento

\begin{tabular}{cccccc} 
Mês & $\begin{array}{c}\text { Precipitação } \\
(\mathbf{m m})\end{array}$ & $\begin{array}{c}\text { Temperatura } \\
\text { média }\left({ }^{\circ} \mathbf{C}\right)\end{array}$ & $\begin{array}{c}\text { Temperatura } \\
\text { máxima média } \\
\left({ }^{\circ} \mathbf{C}\right)\end{array}$ & $\begin{array}{c}\text { Temperatura } \\
\text { mínima } \\
\text { média }\left({ }^{\circ} \mathbf{C}\right)\end{array}$ & $\begin{array}{c}\text { Radiação } \\
\text { Global } \\
(\mathbf{M J} / \mathbf{m} \mathbf{2 . d})\end{array}$ \\
\hline Julho & 0 & 17 & 25.2 & 9.5 & 13.69 \\
Agosto & 51.3 & 19.2 & 26.6 & 12.6 & 14.64 \\
Setembro & 46.7 & 23.2 & 32.1 & 14.4 & 21.82 \\
Outubro & 81.5 & 23.3 & 30.4 & 17.5 & 18.72 \\
Novembro & 236 & 22.7 & 29.6 & 17.2 & 22.43 \\
Dezembro & 152.2 & 24.3 & 31 & 19.7 & 21.39 \\
Janeiro & 224.9 & 23.7 & 30.3 & 19.5 & 20.3 \\
\hline
\end{tabular}

A cultura utilizada para esse experimento foi Megathyrsus maximus cv. Mombaça, semeada em fevereiro de 2016, sendo realizados cortes sucessivos e irrigação suplementar até conseguir as condições de fertilidade ideais para o estabelecimento do experimento. Uma vez atingidos os níveis desejados de nutrientes no solo, começou o processo de adubação com doses de nitrogênio e boro, as quais foram distribuídas em quatro blocos ao acaso, cada um de 88 $\mathrm{m}^{2}$, com quatro repetições cada, e usando irrigação suplementar até atingir a capacidade de campo (Figura 2).

Utilizou-se para o delineamento experimental, quatro doses de adubação nitrogenada, sendo estes nomeados como N1 (104,2 $\left.\mathrm{kg} \mathrm{ha}^{-1}\right)$, N2 (208,4 kg ha-1), N3 (312,5 kg ha-1) e N4 (416,7 kg ha-1). Foi utilizada ureia como fonte nitrogenada, dividindo-se a aplicação em 5 doses iguais para cada um dos tratamentos, as quais foram incorporadas igualmente entre os meses de agosto a dezembro de 2017. O ácido bórico foi utilizado como fonte de boro, aplicado em uma única dose $\left(0,92 \mathrm{~kg} \mathrm{ha}^{-1}\right)$ no começo do experimento.

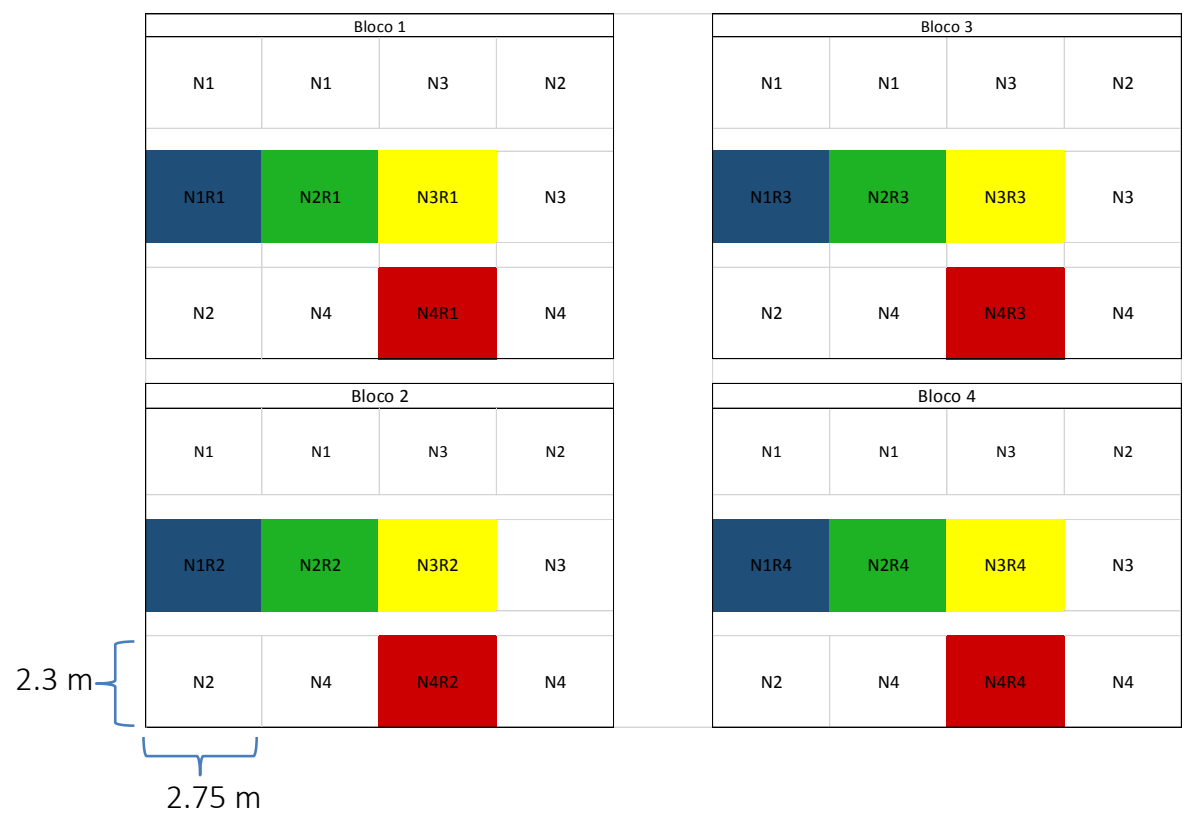

Figura 2 - Croqui da área experimental com a distribuição dos tratamentos e os blocos casualizados. 


\subsubsection{Medição da reflectância espectral e do teor de clorofila}

As medições de reflectância espectral e de clorofila foram realizadas em 6 ocasiões, de setembro de 2017 até janeiro de 2018, a cada 28 dias, antes do corte periódico da cultura. Foram colhidas 8 folhas +1 de 'Mombaça', por repetição, somando 128 folhas para cada amostragem, a exceção da primeira amostragem, a qual foi realizada antes da implementação dos tratamentos, quando foram amostradas somente 32 folhas.

A reflectância espectral foi medida usando um espectroradiômetro ASD FieldSpec FR Spectroradiometer ${ }^{\circledR}$ (Analytical Spectral Devices, Boulder, CO, EUA) com uma faixa de comprimento de onda de 350 até $2500 \mathrm{~nm}$, utilizando uma resolução espectral de 1,4 nm no comprimento de onda dos 350 até os $1050 \mathrm{~nm}$ e de $2 \mathrm{~nm}$ no comprimento de onda dos 1050 até os $2500 \mathrm{~nm}$. Para facilitar a tomada de dados de refletância das folhas amostradas foi acoplado ao espectroradiômetro o equipamento Leaf Clip ${ }^{\circledR}$ (ASD - Analytical Spectral Devices Inc., Boulder, CO, EUA), o qual conta com uma fonte de iluminação estável, um campo de visada fixo e um ângulo constante de 90 graus. A calibração do espectrorradiômetro foi feita a cada 10 minutos, usando como branco de referencia a superfície lambertiana inserida no Leaf Clip ${ }^{\circledR}$.

\subsubsection{Determinação do teor de clorofila na folha em laboratório}

Após a realização da leitura espectral, as folhas recolhidas em campo foram congeladas em nitrogênio líquido, e armazenadas a $0^{\circ} \mathrm{C}$ para evitar a degradação da clorofila. Utilizou-se o protocolo para extração de pigmentos foliares baseado no uso de dimetilsulfóxido (DMSO) (BARNES et al., 1992). Para cada folha coletada foram utilizados 0,025 g de tecido vegetal, os quais foram submergidos em tubos de ensaio, cada um deles com $2 \mathrm{ml}$ de DMSO. Estes tubos foram armazenados durante 48 horas em um espaço escuro à temperatura ambiente. Após 48 horas, foram adicionados $3 \mathrm{ml}$ de DMSO em cada tubo de ensaio e com a solução resultante foi realizada a leitura em um espectrofotômetro usando $2 \mathrm{ml}$ do sobrenadante para cada tubo de ensaio. Os teores de cada pigmento foram calculados utilizando os valores de refletância nos comprimentos de onda dos 645 e $663 \mathrm{~nm}$ e aplicando as seguintes equações

$$
\begin{aligned}
& \text { Clorofila A }(\mathrm{mg} / \mathrm{g})=[(12,7 * \mathrm{~A} 663)-(2,69 * \mathrm{~A} 645)] *(\mathrm{~V} / 1000 * \mathrm{~W}) \\
& \text { Clorofila B }(\mathrm{mg} / \mathrm{g})=[(22,9 * \mathrm{~A} 645)-(4,68 * \mathrm{~A} 663)]^{*}(\mathrm{~V} / 1000 * \mathrm{~W}) \\
& \text { Clorofila Total }=(20,08 * \mathrm{~A} 645+8,02 * \mathrm{~A} 663) *(\mathrm{~V} / 1000 * \mathrm{~W})
\end{aligned}
$$

Sendo A645, o valor da leitura no comprimento de onda dos 645 nm; A663 o valor da leitura no comprimento de onda dos $663 \mathrm{~nm}$; V o volume total da solução de DMSO, e W o peso fresco da amostra (Barnes et al., 1992). 


\subsubsection{Análises estatísticas}

\subsubsection{Análise univariada dos dados de clorofila}

Para o conjunto de dados de concentração de clorofila extraída das folhas coletadas mensalmente, foi realizado o teste de Shapiro Wilks, sendo descartada a distribuição normal dos dados. Por esta razão, foram realizados cálculos de estatística descritiva, utilizando testes de medianas. Aplicou-se o teste de Kruskal-Wallis ( $>0.05)$ para constatar diferenças na respota dos tratamentos avaliados, e o teste de Wilcox ( $\mathrm{P}>0.05)$, para identificar diferenças significativas entre os tratamentos. Nestas análises utilizou-se o pacote MASS do software R da versão 3.1.3 (R Development Core Team, 2016).

\subsubsection{Pre-processamento dos dados de reflectância espectral}

Os dados foram exportados do formato ASD para txt usando o software ViewSpec Pro ${ }^{\circledR}$ para que antes de realizar a análise estatística dos dados, fosse feita a limpeza destes mediante a eliminação de regiões de ruído, entre os 350 - 399 nm e 2470 e $2500 \mathrm{~nm}$, as quais têm sido reportadas em outros estudos (ZHAO et al., 2007; ABDEL-RAHMAN et al., 2014).

\subsubsection{Análise discriminante das assinaturas espectrais}

Para determinar a combinação de bandas que melhor diferenciasse as concentrações das doses foi realizada uma análise discriminante linear para cada um dos meses avaliados. Esta é uma técnica estatística multivariada que permite agrupar diferentes medições se baseando em fatores específicos da combinação das variáveis medidas (FILELLA et al., 1995). Assim, a análise discriminante, basicamente, encontra a melhor maneira para organizar os dados maximizando a separação em classes (Stewart et al., 2013). Esta técnica usa fatores independentes para calcular uma variável dependente para classificar ou discriminar entre dois ou mais grupos, e assim é construido um conjunto de funções discriminantes que maximizam a variância entre os dados (Putnam et al., 2013).

Dentre essas análises, destaca-se a análise discriminante linear como uma das metodologias de classificação supervisionada mais usada no campo do sensoriamento remoto, sendo aplicada, entre outras, para a classificação de espécies de árvores da floresta tropical mediante o uso de dados hiperespectrais em diferentes escalas (Bandos et al., 2009). Esta metodologia de análise de informação reduz a alta dimensionalidade das variáveis envolvidas mediante o uso de uma matriz de transformação linear $\mathbf{G}$, que reduz um vetor original $\mathbf{X}$ de $m$ dimensões a um vector de $/$ dimensões. Tudo isso para cumprir com o objetivo da discriminante de maximizar o critério de separabilidade entre a distribuição das classes (BANDOS; BRUZZONE; CAMPS-VALLS, 2009; SHARMA; PALIWAL, 2014). 
2.3. Resultados

\subsubsection{Análise do teor de clorofila nas folhas}

Os resultados das medições de clorofila foram analisados para cada um dos meses avaliados por meio de estatística descritiva. Observou-se que as concentrações de clorofila apresentaram variações para cada um dos tratamentos nos diferentes momentos de amostragem. Sendo que as maiores concentrações de clorofila foram obtidas pelo tratamento N4, para os meses de dezembro e janeiro (Tabela 2). 
Tabela 2. Concentração de clorofila nas folhas dos tratamentos avaliados após cada corte realizado ao longo do experimento.

\begin{tabular}{|c|c|c|c|c|c|c|}
\hline \multirow[b]{2}{*}{ Mês } & \multicolumn{6}{|c|}{ Teor de Clorofila (mg/g) } \\
\hline & Tratamento & Mediana & Média & $\begin{array}{l}\text { Desvio } \\
\text { Padrão }\end{array}$ & Máximo & Mínimo \\
\hline \multirow{4}{*}{ Setembro } & N1 & $1.731^{\mathrm{a}}$ & 1.758 & 0.328 & 2.650 & 1.224 \\
\hline & $\mathrm{N} 2$ & $1.844^{\mathrm{a}}$ & 1.901 & 0.292 & 2.458 & 1.368 \\
\hline & N3 & $1.753^{\mathrm{a}}$ & 1.722 & 0.332 & 2.345 & 0.907 \\
\hline & N4 & $1.814^{\mathrm{a}}$ & 1.797 & 0.451 & 2.612 & 0.979 \\
\hline \multirow{4}{*}{ Outubro } & N1 & $1.965^{\mathrm{b}}$ & 1.954 & 0.311 & 2.620 & 1.331 \\
\hline & $\mathrm{N} 2$ & $2.115^{\mathrm{ab}}$ & 2.153 & 0.326 & 2.843 & 1.531 \\
\hline & N3 & $2.277^{\mathrm{a}}$ & 2.319 & 0.312 & 3.062 & 1.786 \\
\hline & N4 & $2.209^{\mathrm{a}}$ & 2.218 & 0.306 & 2.936 & 1.543 \\
\hline \multirow{4}{*}{ Novembro } & N1 & $1.307^{\mathrm{c}}$ & 1.343 & 0.254 & 1.909 & 0.930 \\
\hline & $\mathrm{N} 2$ & $1.520^{\mathrm{b}}$ & 1.516 & 0.247 & 1.956 & 0.984 \\
\hline & N3 & $1.778^{\mathrm{a}}$ & 1.786 & 0.271 & 2.320 & 1.170 \\
\hline & N4 & $1.740^{\mathrm{a}}$ & 1.788 & 0.330 & 2.500 & 1.193 \\
\hline \multirow{4}{*}{ Dezembro } & N1 & $1.465^{c}$ & 1.625 & 0.416 & 2.849 & 1.034 \\
\hline & N2 & $1.761^{b c}$ & 1.743 & 0.330 & 2.505 & 1.093 \\
\hline & N3 & $1.946^{\mathrm{ab}}$ & 1.963 & 0.372 & 2.894 & 1.202 \\
\hline & N4 & $2.156^{\mathrm{a}}$ & 2.189 & 0.433 & 3.611 & 1.564 \\
\hline \multirow{4}{*}{ Janeiro } & N1 & $1.382^{c}$ & 1.410 & 0.260 & 1.851 & 1.004 \\
\hline & N2 & $1.634^{\mathrm{b}}$ & 1.648 & 0.313 & 2.347 & 1.132 \\
\hline & N3 & $1.579 \mathrm{bc}$ & 1.580 & 0.255 & 2.046 & 1.013 \\
\hline & N4 & $1.964^{\mathrm{a}}$ & 1.978 & 0.389 & 3.099 & 1.259 \\
\hline
\end{tabular}

Os valores de mediana seguidos pela mesma letra não diferem entre eles, segundo teste de KruskalWallis ao $5 \%$ de significância

Por meio da análise não paramétrica dos dados foi constatado que existem diferenças significativas no teor de clorofila para a maioria dos meses do experimento, com exceção de setembro, o qual foi o único mês em que o teor de clorofila dos tratamentos avaliados não foi estatisticamente diferente. (Figura 3a)

Pode se observar que para o mês de outubro o tratamento da menor dose de nitrogênio resultou em as menores concentrações de clorofila, diferindo estatisticamente dos demais tratamentos (Figura 3b). Entretanto, para o mês de novembro, os tratamentos N3 e N4 apresentaram os maiores teores de clorofila e, ao mesmo tempo, não apresentam diferenças significativas entre eles (Figura 3c). Para o mês de dezembro, embora existissem diferenças significativas para os diferentes tratamentos, manteve-se a tendência para as doses N3 e N4 pois tiveram comportamentos estatisticamente similares e apresentaram os maiores teores de clorofila (Figura 3d). Por outra parte, os tratamentos N1 e N2 também não apresentaram diferenças significativas entre eles. No entanto, para esse mesmo mês, os tratamentos $\mathrm{N} 2$ e N3 foram estatisticamente iguais, segundo a análise das medianas.

Finalmente, para o mês de janeiro, pode-se observar que N1 e N3 tiveram os menores valores de mediana e, além disso, o tratamento N3 não teve diferenças significativas com os tratamentos N1 e N2 (Figura 3e). No entanto, o tratamento de maior dose de adubação, apresentou os maiores valores de clorofila e obteve diferenças altamente significativas com o restante dos tratamentos. 


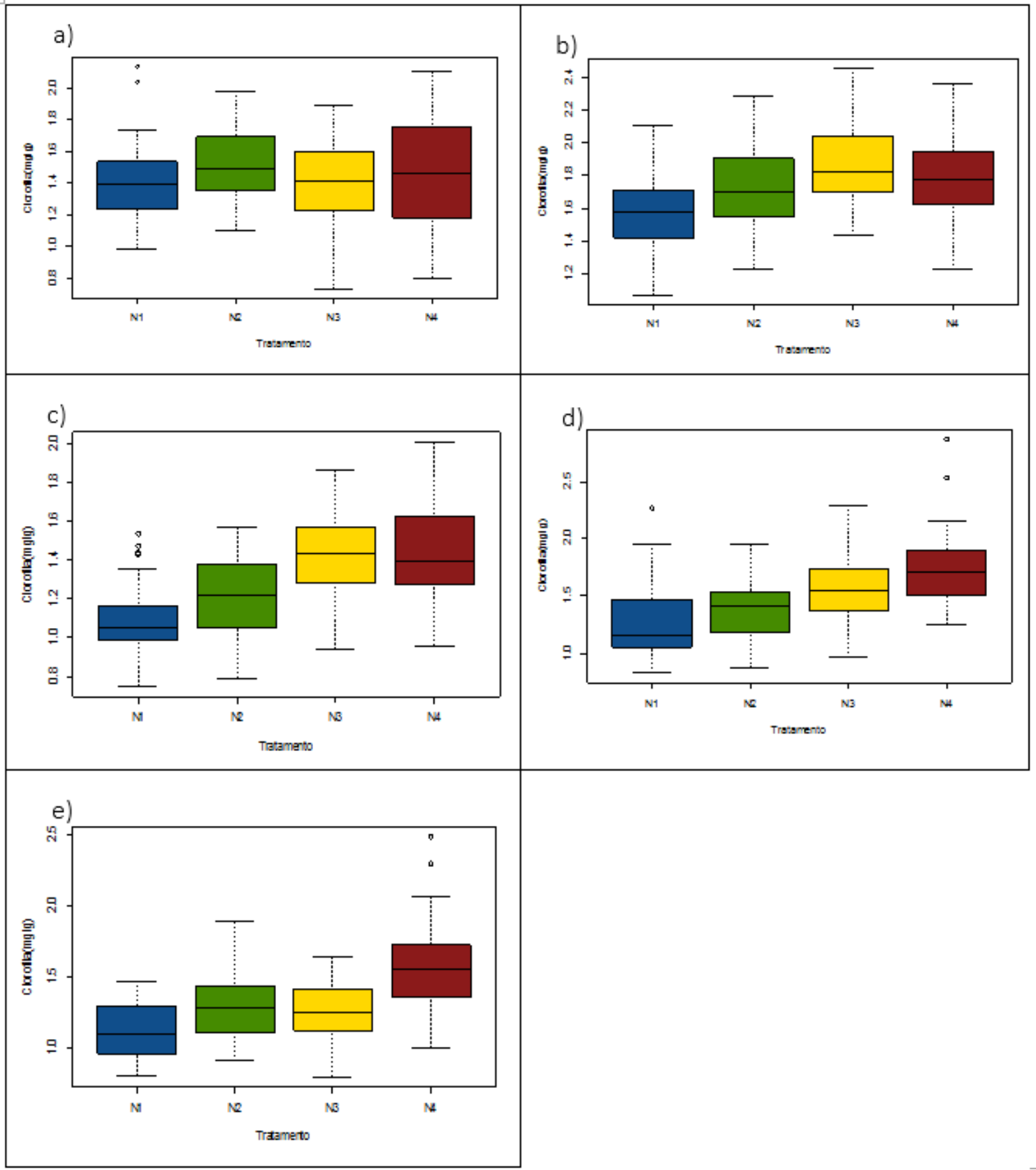

Figura 3. Gráficos de boxplot do conteúdo de clorofila para a) setembro; b) outubro; c) novembro; d) dezembro; e) janeiro.

\subsubsection{Análise descritiva da assinatura espectral dos tratamentos}

A reflectância espectral dos tratamentos analisados mostrou alterações ao longo dos meses avaliados. Assim, para o mês de setembro, um mês após a primeira adubação, a maior diferença nos valores de reflectância espectral foi encontrada na faixa correspondente ao infravermelho próximo, sendo o tratamento N1 o de menor reflectância nestes comprimentos de onda em relação aos demais tratamentos.

Para o mês de outubro, as principais diferenças na reflectância espectral dos tratamentos foi observada no comprimento de onda correspondente ao verde, sendo que o tratamento N1 obteve maior reflectância 
nesta faixa do espectro, enquanto que os outros tratamentos obtiveram uma reflectância média de $2 \%$ a menos em relação à superfície lambertiana de calibração.

Em novembro, a diferença na reflectância espectral para os diferentes tratamentos continuou sendo maior no comprimento de onda correspondente à faixa do verde (525-570 nm), sendo que a mediana da reflectância dos tratamentos N1 e N2 é maior do que das reflectância dos tratamentos que receberam maiores doses de adubo nitrogenado. Este padrão de comportamento da reflectância na faixa do comprimento de onda do verde foi mantido também para o mês de dezembro, apresentando uma clara tendência de maior reflectância para os dois tratamentos que receberam menor doses de nitrogênio no mês imediatamente anterior, e de menor reflectância para os tratamentos com as maiores doses de ureia. Finalmente, para o mês de janeiro, enquanto o tratamento N1 continuou tendo a maior refletância no comprimento de onda do verde, e o tratamento N2 persistiu como o tratamento com a menor reflectância. Os tratamentos N3 e N2 tiveram um comportamento similar na reflectância espectral para essa faixa especifica do visível.

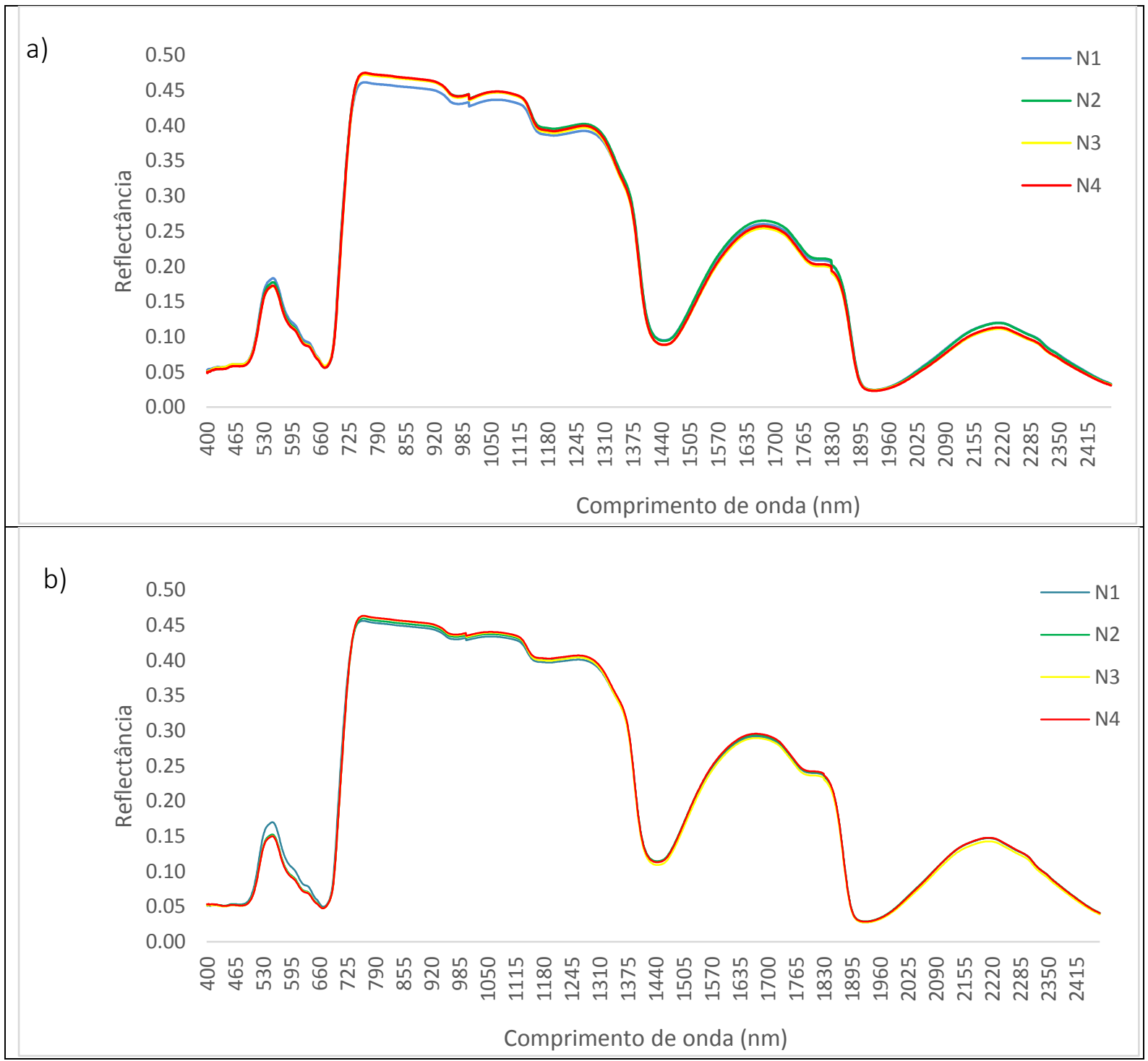




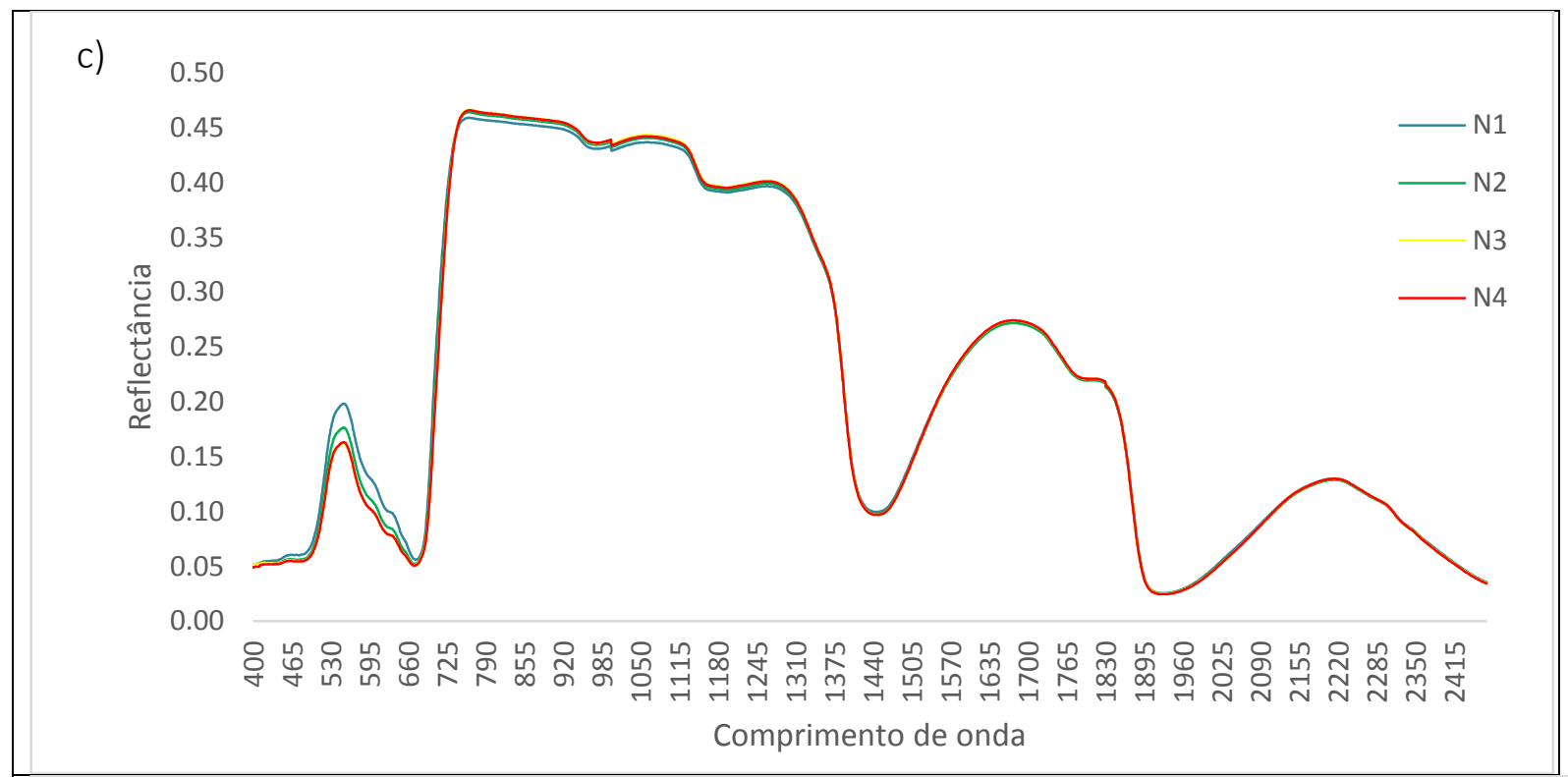

d)

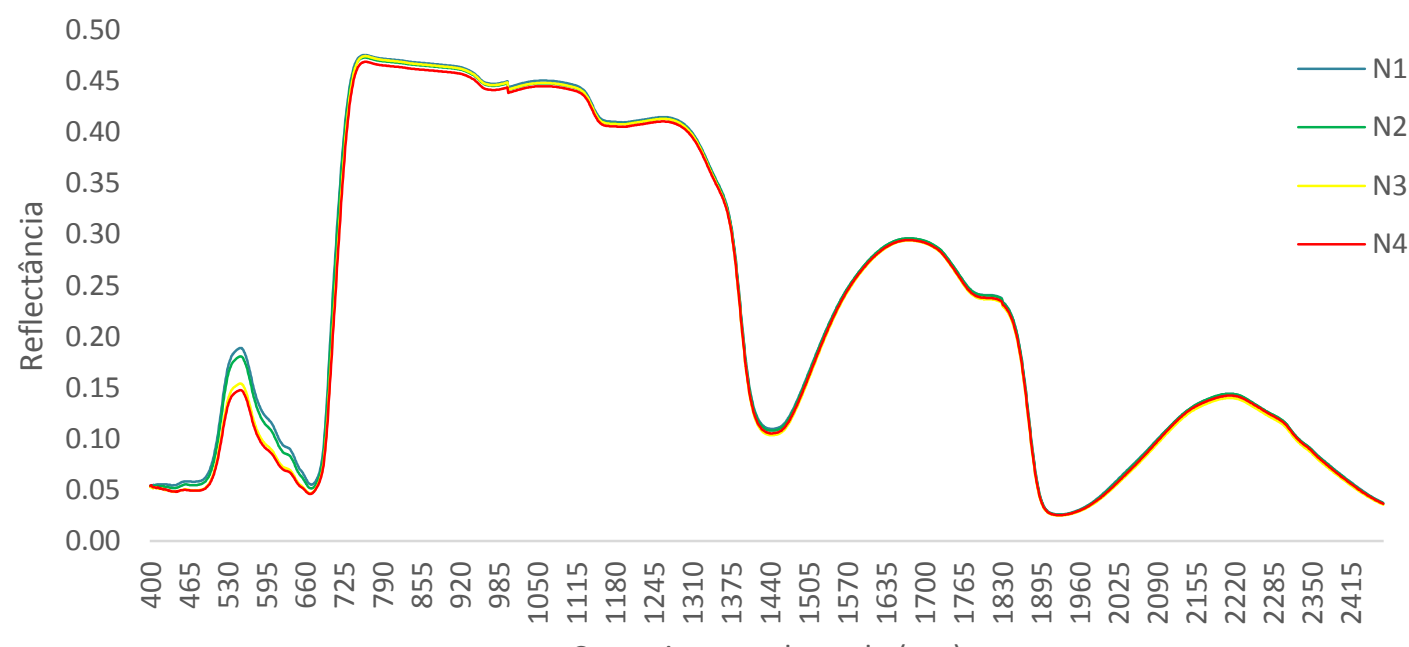

Comprimento de onda $(\mathrm{nm})$

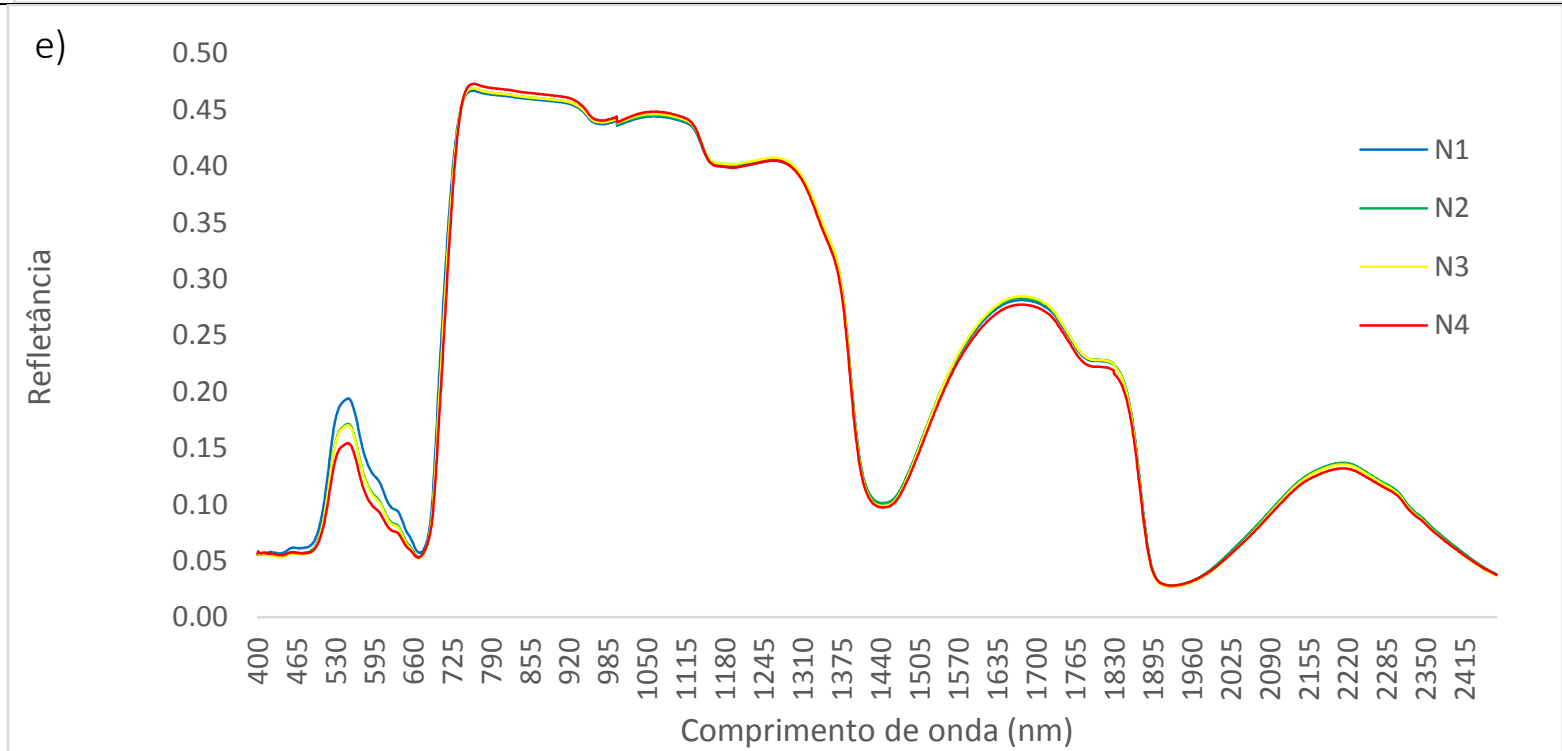

Figura 4. Gráficos das assinaturas espectrais dos tratamentos para a) setembro; b) outubro; c) novembro;

d) dezembro; e) janeiro 


\subsubsection{Análise discriminante das assinaturas espectrais}

Os dados hiperespectrais coletados no mês de setembro foram avaliados através da análise discriminante, onde cada ponto é a representação da assinatura espectral das folhas medidas em laboratório. Desta forma, para esse mês, a primeira função discriminante explica $44,4 \%$ da variabilidade dos dados, enquanto que a segunda função explica $33,5 \%$ desta. Com base no gráfico gerado, é possível identificar que a maioria das assinaturas espectrais correspondentes ao tratamento N1 estão agrupadas no eixo negativo da componente LD2, ao mesmo tempo que o resto das assinaturas dos tratamentos avaliados neste mês estão localizadas no eixo positivo deste componente (Figura 5a). Ao analisar estatisticamente por meio do teste Tukey os centroides das doses de nitrogênio, não foram encontradas diferenças significativas entre o tratamento N4 e o tratamento N2 considerando a componente do LD1, enquanto que para a componente LD2 as diferenças entre os N4 e N1 não foram significativas.

No caso do mês de outubro, a primeira função discriminante consegue explicar 50,5\% da variabilidade dos dados da amostragem deste mês, enquanto que a segunda explica 30,2\%. A avaliação visual da análise discriminante agrupa a maioria dos dados do tratamento N1 no mesmo quadrante, com valores positivos para a componente LD1 e negativos para a LD2. Igualmente, todos os pontos correspondentes ao tratamento N2 estão reunidos no eixo negativo do componente LD1. No caso das doses de maior adubação, estes seguem a mesma tendência, estando a maioria das assinaturas destes tratamentos inseridas no primeiro quadrante. Para esse mês, os centroides dos tratamentos N3 e N4 não apresentaram diferenças significativas levando em consideração as duas funções discriminantes. Além disso, para a componente LD2, o tratamento N1 também não tem diferenças significativas com os tratamentos N3 e N4.

Para o mês de novembro, a componente LD1 conseguiu explicar 59,7\% da variabilidade dos dados, enquanto que a componente LD2 foi a responsável de 26,2\%. Contudo, a agrupação dos dados no gráfico 5c, apresenta o mesmo padrão que foi obtido na amostragem do mês imediatamente anterior, assim, as assinaturas espectrais dos tratamentos com maior dose de adubo nitrogenado continuam se agrupando no quadrante 1, enquanto que o tratamento N1 permanece no quadrante 2. Considerando os centroides dos representados na análise discriminante, o teste de Tukey indicou somente os tratamentos N3 e N4 não tiveram diferenças significativas na componente LD1, enquanto que para o LD2 os dois tratamentos de maior adubação não apresentaram diferenças significativas com o tratamento N1.

Em dezembro, a função da primeira discriminante explica $77,1 \%$ da variabilidade, enquanto que a segunda representa 12,8\%. Também é importante destacar que para este mês os tratamentos N3 e N4 foram desagregados, pois as assinaturas destes estiveram distribuídas, na maioria dos casos, nos quadrantes 1 e 3 , respectivamente. Por sua parte, os tratamentos $\mathrm{N} 1$ e $\mathrm{N} 2$ estiveram concentrados no eixo negativo da componente LD2, sendo que o tratamento de menor dose de nitrogênio, presentou valores menores neste eixo do que o tratamento N2. Ao considerar os centroides na análise discriminante foi encontrado que nenhum dos tratamentos avaliados teve comportamentos similares, existindo diferenças significativas para as duas componentes LD1 e LD2.

Finalmente, para o mês de janeiro, a componente LD1 representou 61,3\% da variabilidade dos dados, enquanto que a LD2 foi responsável por 20,6\%. Além disso, foi encontrado um padrão de agrupamento similar ao mês de dezembro, sendo que os tratamentos N3 e N4 estiveram concentrados nos quadrantes 1 e 4, respectivamente. $\mathrm{Na}$ sua vez, os tratamentos $\mathrm{N} 1$ e N2 foram misturados nos quadrantes 2 e 3, sendo que as assinaturas do tratamento N2 tiveram uma maior aglomeração no eixo positivo da LD1. No entanto, para esse mês, considerando o componente 
LD1, houve diferenças significativas para todos os tratamentos. Contudo, para o componente LD2 os tratamentos N4 e N2 tiveram um comportamento estatisticamente igual, segundo o teste de Tukey.

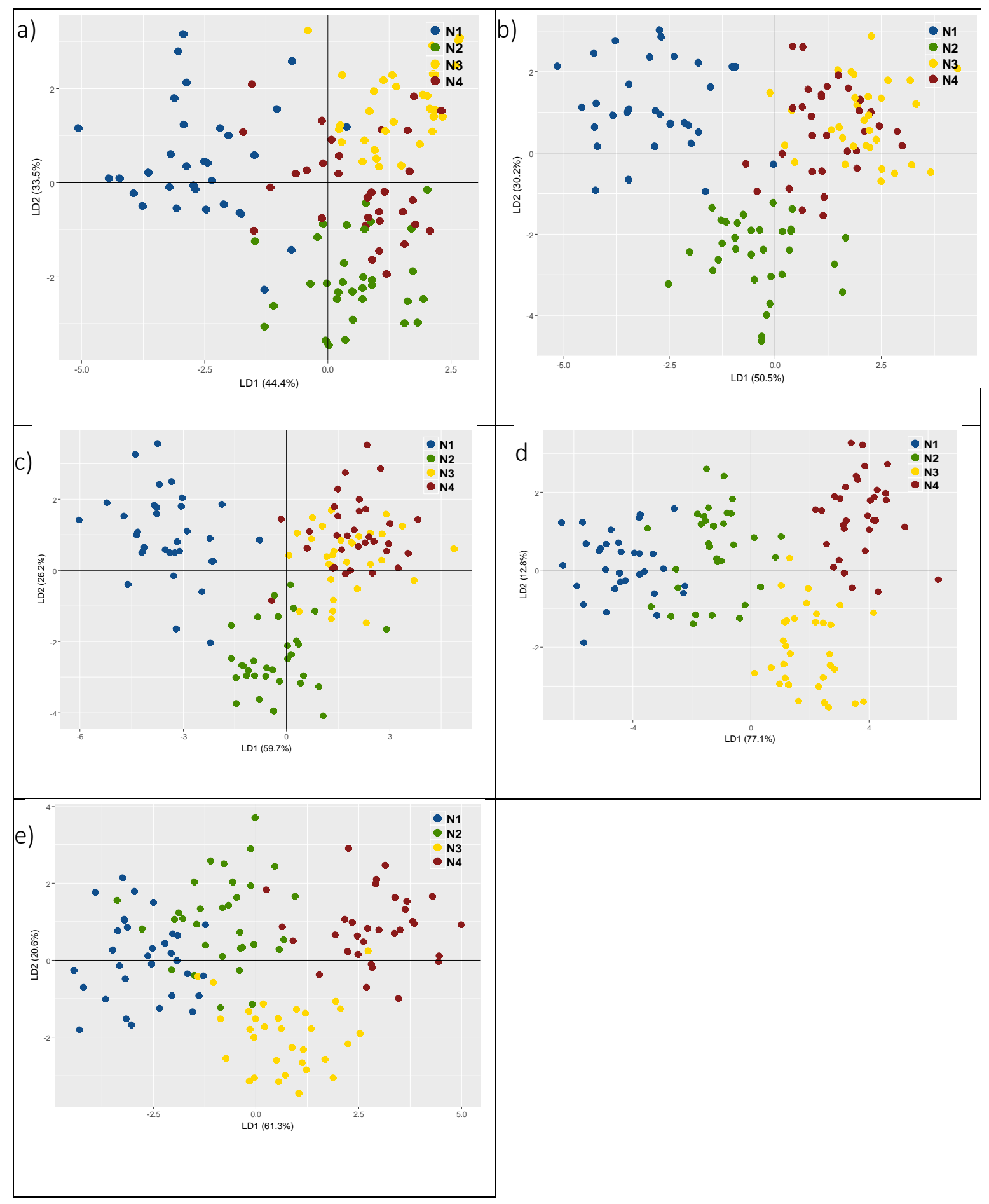

Figura 5. Gráficos das análises discriminantes das assinaturas espectrais dos tratamentos para a) setembro; b) outubro; c) novembro; d) dezembro; e) janeiro 


\subsection{Discussão}

\subsubsection{Teor de clorofila nas folhas}

O teor de clorofila nas folhas de capim 'Mombaça' foi avaliado considerando diferentes estudos que ressaltam a importância deste pigmento em diferentes processos fisiológicos das plantas, o que o leva a ser um parâmetro determinante do rendimento e o desempenho das culturas (Jan G P W Clevers \& Kooistra, 2012; Gitelson et al., 2015; Schlemmer et al., 2013). Um dos fatores que torna a clorofila se torne ainda mais relevante é sua relação com o teor de nitrogênio foliar na planta, permitindo que a concentração deste pigmento seja utilizada como um importante indicador da eficiência da adubação nitrogenada (Lucas R. Amaral et al., 2015; Filella et al., 1995; Kooistra \& Clevers, 2016; X. Li et al., 2015). Assim, diferentes trabalhos têm evidenciado essa relação, estabelecendo que quanto maior a dose de nitrogênio utilizada na fertilização, maior será o teor de clorofila nas culturas (Escarela et al., 2017; Filella et al., 1995; Kooistra \& Clevers, 2016; Thakur et al., 2013). Contudo, neste experimento esse comportamento foi evidente só até o segundo mês de adubação, o qual pode-se atribuir às baixas temperaturas apresentadas durante o mês de setembro, às quais não permitem o correto desempenho do metabolismo de plantas C4, pois este é influenciado por fatores extrínsecos, como a temperatura, que determinam sua produtividade (Alexandrino et al., 2005; Macedo et al., 2010).

A partir do segundo mês de medições, as amostragens comprovaram que o tratamento com a menor dose de adubo nitrogenado foi o que apresentou o menor teor de clorofila ao longo do experimento, corroborando os resultados de diferentes autores (Filella et al., 1995; Hatfield et al., 2008; Kooistra \& Clevers, 2016; A. Neto et al., 2017). No entanto, nem sempre o tratamento com maior dose de ureia foi aquele que obteve maiores concentrações de clorofila foliar, sendo que na maioria dos casos não houve diferenças significativas entre os tratamentos N3 e N4, mesmo tendo uma diferença de $25 \%$ a mais, na aplicação de adubo nitrogenado. Este resultado pode ser uma resposta do metabolismo da planta na qual a dose de ureia N3 foi a mais eficiente e conseguiu atingir o mesmo nível fisiológico da maior dose com menos recursos. Este comportamento foi reportado também por trabalhos prévios nos quais foi proposto que acima de uma quantidade ótima de nitrogênio nas folhas, as plantas C4 não podem usar seu metabolismo totalmente e os maiores rendimentos são encontrados em tratamentos com doses intermediarias de nitrogênio, sob condições limitantes para as plantas (Greef, 1994).

\subsubsection{Análise descritiva da assinatura espectral dos tratamentos}

As assinaturas espectrais dos tratamentos com maiores doses de fertilização nitrogenada tiveram menores reflectâncias no comprimento de onda correspondente ao verde, na região entre os $525 \mathrm{~nm}$ e os $570 \mathrm{~nm}$. Este mesmo resultado foi encontrado em trabalhos anteriores, destacando que mudanças na reflectância espectral no comprimento de onda do verde são geradas, principalmente pelo teor de clorofila nas plantas, sendo que folhas mais verdes, geralmente, absorvem mais do 80\% da luz incidente neste comprimento de onda (Féret et al., 2017; Gitelson et al., 2003). Isto acontece porque a interação da luz com as folhas das plantas depende das características químicas e fisiológicas dos tecidos, ou seja, no caso das folhas com maior teor de nitrogênio o nível de absorbância é maior pela elevada concentração de clorofila nos tecidos das mesmas (Diezma et al., 2013). 
É importante ressaltar que a diferença na reflectância espectral no comprimento de onda do verde nos diferentes tratamentos incrementou-se ao decorrer dos meses. Observou-se queo, as plantas que receberam maiores doses de nitrogênio desde o começo apresentam as melhores condições fisiológicas, tais como raízes maiores e mais profundas, ou maior área foliar, o que permite melhorar a eficiência na absorção de nutrientes, além de aumentar a formação de clorofila através da fotossíntese (Rasmussen et al., 2015; Rosolem et al., 2017).

Ao longo do experimento, o tratamento N1 apresentou maior reflectância na faixa dos 600 e os $680 \mathrm{~nm}$, correspondente ao vermelho. Segundo diferentes autores, este comportamento é característico de plantas que têm deficiências nutricionais, o qual é expressado pela falta de clorofila nas folhas, gerando menos absorbância no comprimento de onda do vermelho (J.G.P.W. Clevers \& Gitelson, 2013; S. Cui \& Zhou, 2017; Gitelson et al., 2003).

Por outra parte, o comportamento da reflectância espectral no comprimento de onda correspondente ao chamado "Red Edge", localizado na transição do vermelho para o infravermelho próximo, manifestou diferenças entre os tratamentos a partir do mês de outubro, sendo que o tratamento N1 apresentou maior reflectância espectral neste comprimento de onda, ao ser comparado com os demais. Este resultado corrobora com diferentes pesquisas que apontam a reflectância no comprimento de onda do "Red-Edge" como um indicador das mudanças de diferentes variáveis biológicas e físicas características da fisiologia das plantas (Verrelst et al., 2015). Além de mudanças nos valores da reflectância espectral nesta faixa específica, dependendo do teor de clorofila, foi possível encontrar mudanças nos comprimentos de onda que representam o Red-Edge, sendo que os tratamentos que com maior quantidade de adubações nitrogenadas apresentaram um deslocamento desta região do espectro eletromagnético para comprimentos de onda maiores. Este comportamento encontrado por diferentes autores em culturas gramíneas está associado ao teor de clorofila nos tecidos das folhas, podendo se aplicar o posicionamento do Red-Edge na assinatura espectral como um parâmetro para caracterizar a composição bioquímica dos pigmentos fotossintéticos (B.-B. Guo et al., 2017; Horler et al., 1983; Kooistra \& Clevers, 2016; D. Li et al., 2017).

Finalmente, ressalta-se que em vários estudos foi identificado o infravermelho próximo, como uma das regiões do espectro que tem sido utilizada para caracterizar o estado nutricional de diferentes culturas (Lucas R. Amaral et al., 2015; Lucas Rios Amaral \& Molin, 2014; Jan G P W Clevers \& Kooistra, 2012; Hatfield et al., 2008). Porém, estas pesquisas utilizam a relação da reflectância emitida pelo dossel das culturas e o teor de clorofila e do nitrogênio, sendo que o infravermelho próximo é altamente influenciado pelo índice de área foliar das culturas, fazendo que seja usado no cálculo de índices de vegetação relacionados com a biomassa (Emanuel et al., 2009; Houborg et al., 2015; Kooistra \& Clevers, 2016; A. J. Neto et al., 2017; Tan et al., 2018). No presente estudo foi utilizada a reflectância espectral a nível de folha, utilizando-se de equipamentos que permitiram fazer constante a área e a biomassa medida, razão pela qual o comprimento de onda do infravermelho próximo não obteve diferenças nas leituras realizadas. Este resultado foi obtido por outros autores, encontrando que os valores de reflectância no comprimento do infravermelho próximo tiveram baixa correlação com o conteúdo de clorofila (Sonobe et al., 2018).

\subsubsection{Análise discriminante das assinaturas espectrais}

As análises discriminantes para as diferentes amostragens apresentaram um comportamento similar desde o mês de outubro até o final do experimento, fazendo com que o tratamento com a menor dose de adubo nitrogenado fosse separado daqueles com as maiores doses de nitrogênio. Isto sugere a possibilidade de utilizar dados de reflectância hiperespectral a nível foliar, associados com técnicas de análise discriminante, para determinar tratamentos de fertilização deficiente em capim 'Mombaça', como foi proposto por outros autores que encontraram que esta técnica permitiu a clara distinção entre tratamentos de adubação nitrogenada em outras culturas como o trigo (Filella et al., 
1995). Além disso, foi encontrado que nos três primeiros meses de avaliações, os tratamentos N3 e N4 não tiveram diferenças significativas e não foram separados pela analise discriminante. Isto sugere que as plantas com maiores doses têm características anatômicas e fisiológicas similares fazendo com que sua reflectância tenha um comportamento semelhante, como foi encontrado por outros trabalhos, nos quais, forragens com doses de adubação nitrogenada, acima de $100 \mathrm{mg} \mathrm{N} / \mathrm{dm}^{3}$ não tiveram diferenças significativas no teor de nitrogênio foliar, nem no peso da biomassa da parte aérea da planta (Basso et al., 2014; Paciullo et al., 2016).

Por outro lado, na conformação das equações canônicas da análise discriminante, o maior peso foi dado para os comprimentos de onda correspondentes ao vermelho e o red-edge. Isto faz que as diferenças na reflectância espectral desta faixa do espectro sejam determinantes no agrupamento das diferentes assinaturas espectrais em cada um dos tratamentos avaliados. Segundo diferentes autores, estas regiões do espectro são indicativos da composição bioquímica das folhas e sua combinação pode ter uma alta correlação com o teor de clorofila nas mesmas (Kooistra \& Clevers, 2016; Sonobe et al., 2018; Tan et al., 2018; Wu et al., 2008).

A reflectância no comprimento de onda do verde teve um comportamento diferente dependendo da quantidade de adubo aplicado, porém na análise discriminante não foi uma das variáveis mais influenciadas. Este resultado é coerente com pesquisas que apontam que a região do red-edge pode chegar a ter melhores resultados para discriminar teores de nitrogênio e clorofila em diferentes culturas, fazendo com que seja utilizado para a construção de diversos índices de vegetação para a obtenção destes parâmetros (J.G.P.W. Clevers \& Gitelson, 2013; C. Li et al., 2018; D. Li et al., 2017).

\subsection{Conclusões}

As doses de nitrogênio utilizadas fizeram com que os tratamentos apresentassem teores de clorofila diferentes, o qual é corroborado pelas mudanças de reflectância espectral, principalmente na região do verde (560 nm) e red-edge $(700 \mathrm{~nm})$.

O uso da análise discriminante em dados de reflectância hiperespectral, permitiu fazer a separação dos tratamentos utilizados, sendo coerente com o teor de clorofila encontrado em cada caso.

Para o capim 'Mombaça', a faixa mais relevante para separar plantas com diferentes teores de clorofila foi a região do red-edge $(700 \mathrm{~nm})$.

\section{Referências}

Abdel-Rahman, E. M., Ahmed, F. B., \& Ismail, R. (2013). Random forest regression and spectral band selection for estimating sugarcane leaf nitrogen concentration using EO-1 Hyperion hyperspectral data. International Journal of Remote Sensing, 34(2), 712-728. doi:10.1080/01431161.2012.713142

Abdel-Rahman, E. M., Mutanga, O., Odindi, J., Adam, E., Odindo, A., \& Ismail, R. (2014). A comparison of partial least squares (PLS) and sparse PLS regressions for predicting yield of Swiss chard grown under different irrigation water sources using hyperspectral data. Computers and Electronics in Agriculture, 106, 11-19. doi:10.1016/j.compag.2014.05.001

Abdel-Rahman, E. M., Mutanga, O., Odindi, J., Adam, E., Odindo, A., \& Ismail, R. (2017). Estimating Swiss chard foliar macro- and micronutrient concentrations under different irrigation water sources using ground-based hyperspectral data and four partial least squares (PLS)-based (PLS1, PLS2, SPLS1 and SPLS2) regression algorithms. Computers and Electronics in Agriculture, 132, 21-33. doi:10.1016/j.compag.2016.11.008

Alexandrino, E., Gomide, J. A., \& De Miranda Gomide, C. A. (2005). Crescimento e desenvolvimento do dossel de 
Panicum maximum cv. Mombaça. Revista Brasileira de Zootecnia, 34(6 SUPPL.), 2164-2173. doi:10.1590/S151635982005000700002

Amaral, L. R., \& Molin, J. P. (2014). The effectiveness of three vegetation indices obtained from a canopy sensor in identifying sugarcane response to nitrogen. Agronomy Journal, 106(1), 273-280. doi:10.2134/agronj2012.0504

Amaral, L. R., Molin, J. P., \& Schepers, J. S. (2015). Algorithm for variable-rate nitrogen application in sugarcane based on active crop canopy sensor. Agronomy Journal, 107(4), 1513-1523. doi:10.2134/agronj14.0494

Araujo, L. C., Santos, P. M., Rodriguez, D., Pezzopane, J. R. M., Oliveira, P. P. A., \& Cruz, P. G. (2013). Simulating guinea grass production: Empirical and mechanistic approaches. Agronomy Journal, 105(1), 61-69. doi:10.2134/agronj2012.0245

Arshad, M., Ullah, S., Khurshid, K., \& Ali, A. (2017). Estimation of leaf water contents from mid- A nd thermal infrared spectra by coupling genetic algorithm and partial least squares regression. Journal of Applied Remote Sensing, 12(2), 10. doi:10.1117/12.2277822

Azadbakht, M., Ashourloo, D., Aghighi, H., \& Radiom, S. (2019). Wheat leaf rust detection at canopy scale under di ff erent LAI levels using machine learning techniques. Computers and Electronics in Agriculture, 156(September 2018), 119-128. doi:10.1016/j.compag.2018.11.016

Bandos, T. V., Bruzzone, L., \& Camps-Valls, G. (2009). Classification of hyperspectral images with regularized linear discriminant analysis. IEEE Transactions on Geoscience and Remote Sensing, 47(3), 862-873. doi:10.1109/TGRS.2008.2005729

Bao, Y., Xu, K., Min, J., \& Xu, J. (2013). Estimating wheat shoot nitrogen content at vegetative stage from in situ hyperspectral measurements. Crop Science, 53(5), 2063-2071. doi:10.2135/cropsci2013.01.0012

Barnes, J. D., Balaguer, L., Manrique, E., Elvira, S., \& Davison, A. W. (1992). A reappraisal of the use of DMSO for the extraction and determination of chlorophylls $\mathrm{a}$ and $\mathrm{b}$ in lichens and higher plants. Environmental and Experimental Botany, 32(2), 85-100. doi:10.1016/0098-8472(92)90034-Y

Basso, K. C., Cecato, U., Barbero, L. M., Lempp, B., Gomes, J. A. N., \& Lugão, S. M. B. (2014). INFLUENCE OF NITROGEN LEVELS ON LEAF ANATOMY AND NUTRITIVE VALUE OF MILLENIUM GRASS. Bioscience Journal, 30(3), 792-801.

Belgiu, M., \& Drăgu, L. (2016). Random forest in remote sensing: A review of applications and future directions. ISPRS Journal of Photogrammetry and Remote Sensing, 114, 24-31. doi:10.1016/j.isprsjprs.2016.01.011

Cavallo, D. Pietro, Cefola, M., Pace, B., Logrieco, A. F., \& Attolico, G. (2017). Contactless and non-destructive chlorophyll content prediction by random forest regression: A case study on fresh-cut rocket leaves. Computers and Electronics in Agriculture, 140, 303-310. doi:10.1016/j.compag.2017.06.012

Chemura, A., Mutanga, O., \& Dube, T. (2017). Remote sensing leaf water stress in coffee (Coffea arabica) using secondary effects of water absorption and random forests. Physics and Chemistry of the Earth, 100, 317-324. doi:10.1016/j.pce.2017.02.011

Chen, B., Li, S., Wang, K., Zhou, G., \& Bai, J. (2012). Evaluating the severity level of cotton Verticillium using spectral signature analysis. International Journal of Remote Sensing, 33(9), 2706-2724. doi:10.1080/01431161.2011.619586

Chlingaryan, A., Sukkarieh, S., \& Whelan, B. (2018). Machine learning approaches for crop yield prediction and nitrogen status estimation in precision agriculture : A review. Computers and Electronics in Agriculture, 151(November 2017), 61-69. doi:10.1016/j.compag.2018.05.012

Chun, H., \& Keleş, S. (2010). Sparse partial least squares regression for simultaneous dimension reduction and variable selection. Journal of the Royal Statistical Society. Series B: Statistical Methodology, 72(1), 3-25. doi:10.1111/j.14679868.2009.00723.x

Clevers, J. G. P. W., \& Gitelson, A. A. (2013). Remote estimation of crop and grass chlorophyll and nitrogen content using red-edge bands on Sentinel-2 and -3. International Journal of Applied Earth Observation and Geoinformation, 23(1), 334-343. doi:10.1016/j.jag.2012.10.008

Clevers, J. G. P. W., \& Kooistra, L. (2012). Using Hyperspectral Remote Sensing Data for Retrieving Canopy Chlorophyll and Nitrogen Content. Journal of Selected Topics in Applied Earth Observation and Remote Sensing, 5(2), 574-583. doi:10.1109/JSTARS.2011.2176468

Colombani, C., Croiseau, P., Fritz, S., Guillaume, F., Legarra, a, Ducrocq, V., \& Robert-Granie, C. (2012). A comparison of partial least squares (PLS) and sparse PLS regressions in genomic selection in French dairy cattle. J Dairy Sci, 95(4), 2120-2131. doi:10.3168/jds.2011-4647

Costa, F., Corrêa, E., Melo, G., Cardoso, E., Pereira, M., \& Miranda, C. (2009). Avaliação dos impactos econômicos de quatro forrageiras lançadas pela Embrapa. (E. C. Lima, Ed.) Embrapa Gado de ... (Primeira.). Campo Grande, MS: Embrapa. Retrieved from https://www.infoteca.cnptia.embrapa.br/infoteca/bitstream/doc/853367/1/DOC174.pdf

Croft, H., Chen, J. M., \& Zhang, Y. (2014). The applicability of empirical vegetation indices for determining leaf chlorophyll content over different leaf and canopy structures. Ecological Complexity, 17(1), 119-130. doi:10.1016/j.ecocom.2013.11.005

Cui, S., \& Zhou, K. (2017). A comparison of the predictive potential of various vegetation indices for leaf chlorophyll content. Earth Science Informatics, 10(2), 169-181. doi:10.1007/s12145-016-0281-3

Cui, Z., \& Kerekes, J. (2018). Potential of Red Edge Spectral Bands in Future Landsat Satellites on Agroecosystem Canopy Green Leaf Area Index Retrieval. Remote Sensing, 10(1), 1-14. doi:10.3390/rs10091458

Curran, P. J., Dungan, J. L., \& Peterson, D. L. (2001). Estimating the foliar biochemical concentration of leaves with 
reflectance spectrometry: Testing the Kokaly and Clark methodologies. Remote Sensing of Environment, 76(3), 349359. doi:10.1016/S0034-4257(01)00182-1

Da Silva, M., Pinto, F., Queiroz, D., Vieira, L., \& Resende, R. (2013). USING AN AERIAL SYSTEM OF REMOTE SENSING TO DETECT DIFFERENT NUTRITIONAL STATUS IN Brachiaria decumbens. Engenharia Agricola Jaboticabal, 34(5), 1049-1062.

Delegido, J., Verrelst, J., Meza, C. M., Rivera, J. P., Alonso, L., \& Moreno, J. (2013). A red-edge spectral index for remote sensing estimation of green LAI over agroecosystems. European Journal of Agronomy, 46, 42-52. doi:10.1016/j.eja.2012.12.001

Diacono, M., Rubino, P., \& Montemurro, F. (2013). Precision nitrogen management of wheat. A review. Agronomy for Sustainable Development, 33(1), 219-241. doi:10.1007/s13593-012-0111-z

Diezma, B., Lléo, L., Roger, J. M., Herrero-Lengreo, A., Lunadei, L., \& Ruiz-Altisent, M. (2013). Examination of the quality of spinach leaves using hyperspectral imaging. Postharvest Biology and Technology, 85, 8-17.

Doktor, D., Lausch, A., Spengler, D., \& Thurner, M. (2014). Extraction of plant physiological status from hyperspectral signatures using machine learning methods. Remote Sensing, 6(12), 12247-12274. doi:10.3390/rs61212247

Emanuel, M., Costa, D. A., Duarte, S. N., Neto, D. D., Cabral, E., \& Silva, D. A. (2009). TEOR DE NITROGÊNIO, ÍNDICES DE ÁREA FOLIAR E DE COLHEITA, NO MILHO, EM FUNÇÃO DA ADUBAÇÃO NITROGENADA, EM SOLO DE VÁRZEA. Revista Brasileira de Milho e Sorgo, 8(1), 13-26.

Erudel, T., Fabre, S., Houet, T., Mazier, F., \& Briottet, X. (2017). Criteria Comparison for Classifying Peatland Vegetation Types Using In Situ Hyperspectral Measurements. Remote Sensing, 9(7), 748. doi:10.3390/rs9070748

Escarela, C. M., Pietroski, M., De Mello Prado, R., Campos, C. N. S., \& Caione, G. (2017). Effect of nitrogen fertilization on productivity and quality of Mombasa forage (Megathyrsus maximum cv. Mombasa). Acta Agronomica, 66(1), 42-48. doi:10.15446/acag.v66n1.53420

Féret, J. B., Gitelson, A. A., Noble, S. D., \& Jacquemoud, S. (2017). PROSPECT-D: Towards modeling leaf optical properties through a complete lifecycle. Remote Sensing of Environment, 193, 204-215. doi:10.1016/j.rse.2017.03.004

Fernandes, J. C., Buzetti, S., Dupas, E., Teixeira, C. M., \& Andreotti, M. (2015). Sources and rates of nitrogen fertilizer used in Mombasa guineagrass in the Brazilian Cerrado region. African Journal of Agricultural Research, 10(19), 20762082. doi:10.5897/AJAR2014.9276

Filella, I., Serrano, L., Serra, J., \& Peñuelas, J. (1995). Evaluating Wheat Nitrogen Status with Canopy Reflectance Indexes and Discriminant-Analysis. Crop Science, 35(5), 1400-1405. doi:10.2135/cropsci1995.0011183X003500050023x

Gbenou, B., Adjolohoun, S., Bignon, D., Houndjo, M., Ahoton, L., Saidou, A., ... Sinsin, B. A. (2018). Practical aspects of grass forage seed production and quality with particular reference to planting row spacing and nitrogen fertilization in tropical regions : A review. International Journal of Biological and Chemical Sciences, 12(February), 508518.

Gitelson, A. A., Arkebauer, T. J., \& Suyker, A. E. (2018). Convergence of daily light use e ffi ciency in irrigated and rainfed C3 and C4 crops. Remote Sensing of Environment, 217(August), 30-37. doi:10.1016/j.rse.2018.08.007

Gitelson, A. A., Gritz, Y., \& Merzlyak, M. N. (2003). Relationships between leaf chlorophyll content and spectral reflectance and algorithms for non-destructive chlorophyll assessment in higher plant leaves reflectance and algorithms for non-destructive chlorophyll assessment. Journal of Plant Physiology, 160(November), 271-282. doi:10.1078/0176-1617-00887

Gitelson, A. A., Merzlyak, M. N., \& Lichtenthaler, H. K. (1996). Detection of Red Edge Position and Chlorophyll Content by Reflectance Measurements Near $700 \mathrm{~nm}$. Journal of Plant Physiology, 148(3-4), 501-508. doi:10.1016/S0176-1617(96)80285-9

Gitelson, A. A., Peng, Y., Arkebauer, T. J., \& Suyker, A. E. (2015). Productivity, absorbed photosynthetically active radiation, and light use efficiency in crops: Implications for remote sensing of crop primary production. Journal of Plant Physiology, 177, 100-109. doi:10.1016/j.jplph.2014.12.015

Greef, J. M. (1994). Productivity of Maize ( Zea mays L .) in Relation to Morphological and Physiological Characteristics under Varying Amounts of Nitrogen Supply. J. Agronomy and crop Science, 172, 317-326.

Guo, B.-B., Qi, S.-L., Heng, Y.-R., Duan, J.-Z., Zhang, H.-Y., Wu, Y.-P., ... Zhu, Y.-J. (2017). Remotely assessing leaf $\mathrm{N}$ uptake in winter wheat based on canopy hyperspectral red-edge absorption. European Journal of Agronomy, 82, 113-124. doi:10.1016/j.eja.2016.10.009

Guo, P. T., Shi, Z., Li, M. F., Luo, W., \& Cha, Z. Z. (2018). A robust method to estimate foliar phosphorus of rubber trees with hyperspectral reflectance. Industrial Crops and Products, 126(September), 1-12. doi:10.1016/j.indcrop.2018.09.055

Haboudane, D., Tremblay, N., Miller, J. R., \& Vigneault, P. (2008). Remote Estimation of Crop Chlorophyll Content Using Spectral Indices Derived From Hyperspectral Data. IEEE Transactions on Geoscience and Remote Sensing, 46(2), 423-437. doi:10.1109/TGRS.2007.904836

Hansen, P. M., \& Schjoerring, J. K. (2003). Reflectance measurement of canopy biomass and nitrogen status in wheat crops using normalized difference vegetation indices and partial least squares regression. Remote Sensing of Environment, 86(4), 542-553. doi:10.1016/S0034-4257(03)00131-7 
Hatfield, J. L., Gitelson, A. A., Schepers, J. S., \& Walthall, C. L. (2008). Application of spectral remote sensing for agronomic decisions. Agronomy Journal, 100(3 SUPPL.), 117-131. doi:10.2134/agronj2006.0370c

Heinrichs, R., Monreal, C. M., Santos, E. T., Soares Filho, C. V., Rebonatti, M. D., Teixeira, N. M., \& Moreira, A. (2016). Phosphorus Sources and Rates Associated with Nitrogen Fertilization in Mombasa Grass Yield. Communications in Soil Science and Plant Analysis, 47(5), 657-669. doi:10.1080/00103624.2016.1141923

Horler, D. N. H., Dockray, M., \& Barber, J. (1983). The red edge of plant leaf reflectance. International Journal of Remote Sensing, 4(2), 37-41.

Houborg, R., McCabe, M. F., Cescatti, A., \& Gitelson, A. A. (2015). Leaf chlorophyll constraint on model simulated gross primary productivity in agricultural systems. International Journal of Applied Earth Observation and Geoinformation, 43, 160-176. doi:10.1016/j.jag.2015.03.016

Inoue, Y., Guérif, M., Baret, F., Skidmore, A., Gitelson, A., Schlerf, M., ... Olioso, A. (2016). Simple and robust methods for remote sensing of canopy chlorophyll content: a comparative analysis of hyperspectral data for different types of vegetation. Plant, Cell \& Environment, 2609-2623. doi:10.1111/pce.12815

Jay, S., Maupas, F., Bendoula, R., \& Gorretta, N. (2017). Retrieving LAI, chlorophyll and nitrogen contents in sugar beet crops from multi-angular optical remote sensing: Comparison of vegetation indices and PROSAIL inversion for field phenotyping. Field Crops Research, 210(March), 33-46. doi:10.1016/j.fcr.2017.05.005

Kira, O., Linker, R., \& Gitelson, A. (2015). Non-destructive estimation of foliar chlorophyll and carotenoid contents: Focus on informative spectral bands. International Journal of Applied Earth Observation and Geoinformation, 38, 251260. doi:10.1016/j.jag.2015.01.003

Kooistra, L., \& Clevers, J. G. P. W. (2016). Estimating potato leaf chlorophyll content using ratio vegetation indices. Remote Sensing Letters, 7(6), 611-620. doi:10.1080/2150704X.2016.1171925

Krishna, G., Sahoo, R. N., Singh, P., Bajpai, V., Patra, H., Kumar, S., ... Sahoo, P. M. (2019). Comparison of various modelling approaches for water deficit stress monitoring in rice crop through hyperspectral remote sensing. Agricultural Water Management, 213(October 2017), 231-244. doi:10.1016/j.agwat.2018.08.029

Li, C., Zhu, X., Wei, Y., Cao, S., Guo, X., Yu, X., \& Chang, C. (2018). Estimating apple tree canopy chlorophyll content based on Sentinel-2A remote sensing imaging. Scientific Reports, 8(1), 1-10. doi:10.1038/s41598-018-21963-0

Li, D., Cheng, T., Zhou, K., Zheng, H., Yao, X., Tian, Y., ... Cao, W. (2017). WREP: A wavelet-based technique for extracting the red edge position from reflectance spectra for estimating leaf and canopy chlorophyll contents of cereal crops. ISPRS Journal of Photogrammetry and Remote Sensing, 129, 103-117. doi:10.1016/j.isprsjprs.2017.04.024

Li, X., Chen, X., Zhou, Y., Nong, M., Liu, X., \& Ai, J. (2015). Spectral characteristics analysis and chlorophyll content of sugarcane leaves under different fertilizer treatments. Transactions of the Chinese Society if Agricultural Engineering, $31(2), 1-6$.

LI, Z. wang, XIN, X. ping, TANG, H., YANG, F., CHEN, B. rui, \& ZHANG, B. hui. (2017). Estimating grassland LAI using the Random Forests approach and Landsat imagery in the meadow steppe of Hulunber, China. Journal of Integrative Agriculture, 16(2), 286-297. doi:10.1016/S2095-3119(15)61303-X

Liang, L., Qin, Z., Zhao, S., Di, L., Zhang, C., Deng, M., ... Liu, Z. (2016). Estimating crop chlorophyll content with hyperspectral vegetation indices and the hybrid inversion method. International Journal of Remote Sensing, 37(13), 2923-2949. doi:10.1080/01431161.2016.1186850

Liao, Q., Wang, J., Yang, G., Zhang, D., Li, H., Fu, Y., \& Li, Z. (2013). Comparison of spectral indices and wavelet transform for estimating chlorophyll content of maize from hyperspectral reflectance. Journal of Applied Remote Sensing, 7(1), 073575. doi:10.1117/1.JRS.7.073575

Liu, B., Yue, Y.-M., Li, R., Shen, W.-J., \& Wang, K.-L. (2014). Plant Leaf Chlorophyll Content Retrieval Based on a Field Imaging Spectroscopy System. Sensors, 14(10), 19910-19925. doi:10.3390/s141019910

Macedo, C. H. O., Alexandrino, E., Jakelaitis, A., Vaz, R. G. M. V., Reis, R. H. P. dos, \& Vendrusculo, J. (2010). Características agronômicas, morfogênicas e estruturais do capim Panicum maximum cv. Mombaça sob desfolhação intermitente. Revista Brasileira de Saúde e Produção Animal, 11(4), 941-952.

Mirzaie, M., Darvishzadeh, R., Shakiba, A., Matkan, A. A., Atzberger, C., \& Skidmore, A. (2014). Comparative analysis of different uni- and multi-variate methods for estimation of vegetation water content using hyper-spectral measurements. International Journal of Applied Earth Observation and Geoinformation, 26(1), 1-11. doi:10.1016/j.jag.2013.04.004

Morellos, A., Pantazi, X., Moshou, D., Alexandridis, T., Whetton, R., Tziotzios, G., ... Mouazen, A. M. (2016). Machine learning based prediction of soil total nitrogen, organic carbon and moisture content by using VIS-NIR spectroscopy. Biosystems Engineering, 152, 104-116. doi:10.1016/j.biosystemseng.2016.04.018

Mountrakis, G., Im, J., \& Ogole, C. (2011). Support vector machines in remote sensing: A review. ISPRS Journal of Photogrammetry and Remote Sensing, 66(3), 247-259. doi:10.1016/j.isprsiprs.2010.11.001

Müller, M. S., Fancelli, A. L., Dourado-Neto, D., García, A. G., \& Ovejero, R. F. L. (2002). Produtividade do Panicum maximum cv . Mombaça, sob pastejo rotacionado. Scientia Agricola, 59(3), 427-433. doi:10.1590/S010390162002000300003

Neto, A. J., Lopes, D. C., Pinto, F. A. C., \& Zolnier, S. (2017). Vis/NIR spectroscopy and chemometrics for nondestructive estimation of water and chlorophyll status in sunflower leaves. Biosystems Engineering, 155, $124-133$. doi:10.1016/j.biosystemseng.2016.12.008

Neto, A. J., Lopes, D. de C., Silva, T. G. F. da, Ferreira, S. O., \& Grossi, J. A. S. (2016). Estimation of leaf water 
content in sunflower under drought conditions by means of spectral reflectance. Engineering in Agriculture, Environment and Food, 1-5. doi:10.1016/j.eaef.2016.11.006

Neto, A., Lopes, D., \& Borges Júnior, J. (2017). Assessment of Photosynthetic Pigment and Water Contents in Intact Sunflower Plants from Spectral Indices. Agriculture, 7(2), 8. doi:10.3390/agriculture7020008

Newman, Y. C., Sinclair, T. R., Blount, A. S., Lugo, M. L., \& Valencia, E. (2007). Forage production of tropical grasses under extended daylength at subtropical and tropical latitudes. Enviromental and Experimental Botany, 61(1), 18-24. doi:10.1016/j.envexpbot.2007.02.005

Paciullo, D. S. C., Gomide, C. A. M., Castro, C. R. T., Maurício, R. M., Fernandes, P. B., \& Morenz, M. J. F. (2016). Morphogenesis, biomass and nutritive value of Panicum maximum under different shade levels and fertilizer nitrogen rates. Grass and Forage Science, (August), 1-11. doi:10.1111/gfs.12264

Peng, Y., \& Gitelson, A. A. (2012). Remote estimation of gross primary productivity in soybean and maize based on total crop chlorophyll content. Remote Sensing of Environment, 117, 440-448. doi:10.1016/j.rse.2011.10.021

Pontes, L. da S., Baldissera, T. C., Giostri, A. F., Stafin, G., dos Santos, B. R. C., \& Carvalho, P. C. d. F. (2017). Effects of nitrogen fertilization and cutting intensity on the agronomic performance of warm-season grasses. Grass and Forage Science, 72(4), 663-675. doi:10.1111/gfs.12267

Putnam, R. A., Mohaidat, Q. I., Daabous, A., \& Rehse, S. J. (2013). A comparison of multivariate analysis techniques and variable selection strategies in a laser-induced breakdown spectroscopy bacterial classification. Spectrochimica Acta - Part B Atomic Spectroscopy, 87, 161-167. doi:10.1016/j.sab.2013.05.014

Rasmussen, I. S., Dresbøll, D. B., \& Thorup-Kristensen, K. (2015). Winter wheat cultivars and nitrogen (N) fertilization-Effects on root growth, $\mathrm{N}$ uptake efficiency and $\mathrm{N}$ use efficiency. European Journal of Agronomy, 68, 38-49. doi:10.1016/j.eja.2015.04.003

Rosolem, C. A., Ritz, K., Cantarella, H., Galdos, M. V., Hawkesford, M. J., Whalley, W. R., \& Mooney, S. J. (2017). Enhanced Plant Rooting and Crop System Management for Improved N Use Efficiency. Advances in Agronomy (1st ed., Vol. 146). Elsevier Inc. doi:10.1016/bs.agron.2017.07.002

Sarmento, P., Rodrigues, L., Lugão, S., Da Cruz, M., Campos, F., \& Ferreira, M. (2005). Respostas agronômicas e morfológicas de Panicum maximum Jacq. Cv IPR - 86 Milênio, sob pastejo, à adubação nitrogenada. Boletim de Induistria Animal, 62(4), 333-346.

Schlemmer, M., Gitelson, A., Schepersa, J., Fergusona, R., Peng, Y., Shanahana, J., \& Rundquist, D. (2013). Remote estimation of nitrogen and chlorophyll contents in maize at leaf and canopy levels. International Journal of Applied Earth Observation and Geoinformation, 25(1), 47-54. doi:10.1016/j.jag.2013.04.003

Silva, R., Gomes, V., Mendes-Faia, A., \& Melo-Pinto, P. (2018). Using support vector regression and hyperspectral imaging for the prediction of oenological parameters on different vintages and varieties ofwine grape berries. Remote Sensing, 10(2), 1-23. doi:10.3390/rs10020312

Sonobe, R., Sano, T., \& Horie, H. (2018). Using spectral reflectance to estimate leaf chlorophyll content of tea with shading treatments. Biosystems Engineering, 175, 168-182. doi:10.1016/j.biosystemseng.2018.09.018

Stewart, S., Ivy, M. A., \& Anslyn, E. V. (2013). The use of principal component analysis and discriminant analysis in differential sensing routines. Chemical Society Reviews, 43(1), 70-84. doi:10.1039/c3cs60183h

Tan, K., Wang, S., Song, Y., Liu, Y., \& Gong, Z. (2018). Estimating nitrogen status of rice canopy using hyperspectral reflectance combined with BPSO-SVR in cold region. Chemometrics and Intelligent Laboratory Systems, 172(November 2017), 68-79. doi:10.1016/j.chemolab.2017.11.014

Thakur, A. K., Rath, S., \& Mandal, K. G. (2013). Differential responses of system of rice intensification ( SRI) and conventional flooded-rice management methods to applications of nitrogen fertilizer. Plant Soil, 370, 59-71. doi:10.1007/s11104-013-1612-5

Verrelst, J., Camps-Valls, G., Muñoz-Marí, J., Rivera, J. P., Veroustraete, F., Clevers, J. G. P. W., \& Moreno, J. (2015). Optical remote sensing and the retrieval of terrestrial vegetation bio-geophysical properties - A review. ISPRS Journal of Photogrammetry and Remote Sensing, 108, 273-290. doi:10.1016/j.isprsjprs.2015.05.005

Vibhute, A., Kale, K., Mehrotra, S., Dhumal, R., \& Nagne, A. (2018). Determination of soil physicochemical attributes in farming sites through visible, near-infrared diffuse reflectance spectroscopy and PLSR modeling. Ecological Processes, 7(26), 12.

Wang, L., Zhou, X., Zhu, X., Dong, Z., \& Guo, W. (2016). Estimation of biomass in wheat using random forest regression algorithm and remote sensing data. Crop Journal, 4(3), 212-219. doi:10.1016/j.cj.2016.01.008

Were, K., Bui, D. T., Dick, Ø. B., \& Singh, B. R. (2015). A comparative assessment of support vector regression, artificial neural networks, and random forests for predicting and mapping soil organic carbon stocks across an Afromontane landscape. Ecological Indicators, 52, 394-403. doi:10.1016/j.ecolind.2014.12.028

Wu, C., Niu, Z., Tang, Q., \& Huang, W. (2008). Estimating chlorophyll content from hyperspectral vegetation indices: Modeling and validation. Agricultural and Forest Meteorology, 148(8-9), 1230-1241. doi:10.1016/j.agrformet.2008.03.005

Xie, Y., Sha, Z., \& Yu, M. (2008). Remote sensing imagery in vegetation mapping: a review. Journal of Plant Ecology, 1(1), 9-23. doi:10.1093/jpe/rtm005

Zago, L. A., Lempp, B., Borges do Valle, C., Jank, L., Rocha, L., Postiglioni, S., ... Soares, C. (2010). Principais espécies forrageiras utilizadas em pastagens para gado de corte. In Bovinoultura de corte (pp. 375-417). Retrieved from 
file:// C:/Users/usuario/Downloads/digitalizar0006.pdf 


\section{COMPARAÇÃO DE TÉCNICAS DE ESTATÍSTICA MULTIVARIADA E MACHINE LEARNING NA ESTIMATIVA DE CLOROFILA A PARTIR DA RESPOSTA ESPECTRAL DE FOLHAS DE CAPIM 'MOMBAÇA'}

RESUMO

Com o constante crescimento da população mundial, aumenta a necessidade de desenvolver ferramentas para incrementar o rendimento das culturas de maneira sustentável, sendo o sensoriamento remoto uma das mais relevantes. Neste sentido, o estudo dos pigmentos contidos nas plantas, principalmente a clorofila, por meio da reflectância espectral é de grande importância. Nos últimos anos, novos algoritmos e metodologias mais sofisticadas, associados à inteligência artificial e ao machine learning, tem-se usado para obter resultados mais robustos e com maior precisão a partir de informação de sensores remotos. O objetivo deste trabalho foi comparar técnicas de estatística multivariada comumente usadas na literatura, com técnicas de machine learning para a obtenção de valores de clorofila presentes em capim 'Mombaça' por meio de dados hiperespectrais. Utilizou-se dados de reflectância espectral de folhas de capim 'Mombaça' com diferentes doses de adubação nitrogenada, e dados de concentração de clorofila extraídos das folhas coletadas. Foi comparado o desempenho de três metodologias na obtenção dos valores de concentração de clorofila: Sparse Partial Least Square Regression (SPLSR), Random Forest Regression (RFR) e Support Vector Regression (SVR). Para medir a capacidade de predição das metodologias, foram usados o coeficiente de determinação $\left(\mathrm{R}^{2}\right)$, o erro quadrático médio (RMSE) e o erro absoluto médio (MAE). Além disso, para medir a consistência dos métodos empregados, foi usada a medição do coeficiente de assimetria de Bowley. O SVR apresentou melhores resultados na predição do teor de clorofila, enquanto que o SPLSR obteve o pior desempenho, considerando os parâmetros usados na comparação. Além disso, a região do visível e do red-edge foram as melhores bandas para o cálculo do teor de clorofila.

Palavras-chave: Megathyrsus maximus; Reflectância espectral; Clorofila; Machine Learning; Sparse Partial Least Square

ABSTRACT

With the constant growth of the world population, the need to develop tools to increase the yield of crops in a sustainable manner increases, with remote sensing being the most relevant. In this sense, the study of the pigments contained in plants, mainly chlorophyll, through spectral reflectance is of great importance. In recent years, new algorithms and more sophisticated methodologies, associated with artificial intelligence and machine learning, have been used to obtain more robust and more accurate results from remote sensing data. The aim of this work was to compare multivariate statistical techniques commonly used in the literature, and machine learning techniques to obtain chlorophyll values present in 'Mombaça' grass through hyperspectral data. Spectral reflectance data from 'Mombaça' grass leaves with different doses of nitrogen fertilization, and leaf chlorophyll concentration data extracted from the collected leaves were used. The performance of three methodologies was compared in order to obtain chlorophyll concentration values: Sparse Partial Least Square Regression (SPLSR), Random Forest Regression (RFR) and Support Vector Regression (SVR). The coefficient of determination (R2), the mean square error (RMSE) and the mean absolute error (MAE) were used to measure the prediction capacity of the methodologies. In addition, to measure the consistency of the methods employed, the Bowley asymmetry coefficient measurement was used. SVR showed better results in predicting chlorophyll content, while SPLSR had the worst performance considering the parameters used in the comparison. In addition, the visible and red-edge regions were the best bands for calculating chlorophyll content.

Keywords: Megathyrsus maximus; Spectral reflectance; Chlorophyll; Machine Learning; Sparse Partial Least Square 


\subsection{Introdução}

Com o constante crescimento da população mundial, aumenta a necessidade de desenvolver ferramentas para melhorar o rendimento das culturas de maneira sustentável (Diacono et al., 2013). Assim, o monitoramento das culturas e o reconhecimento de problemas nutricionais e fitossanitários das lavouras por meio de sensores remotos tem se tornado um tema muito relevante nos últimos anos (Azadbakht et al., 2019; J.G.P.W. Clevers \& Gitelson, 2013; Peng \& Gitelson, 2012).

Neste sentido, o estudo dos pigmentos contidos nas folhas das plantas ocupa um lugar importante nesta problemática, podendo dar informação relacionada à produtividade das culturas e ao estado fisiológico das mesmas (Kira et al., 2015). Dentro destes pigmentos, destaca-se a clorofila como o mais importante, por ser um indicador de estresse nutricional, da capacidade fotossintética e do estado fisiológico (S. Cui \& Zhou, 2017). Em relação ao monitoramento da produtividade, a quantidade de radiação solar absorvida pelas plantas é uma função do teor de clorofila, fazendo com que esteja diretamente relacionada com o potencial fotossintético e com a produção primária (Kira et al., 2015). Desta forma, estabeleceu-se que o teor total de clorofila do dossel é o principal fator que interfere na produtividade primária bruta das culturas, sendo este um parâmetro essencial para estudar o armazenamento de carbono e monitorar o estado fisiológico das plantas (Gitelson et al., 2015; Peng \& Gitelson, 2012). Por outra parte, quando as plantas são atacadas por doenças ou pragas, tanto o teor de clorofila, quanto o conteúdo de água na folha diminuem, fazendo com que aumente a temperatura no interior dos tecidos do dossel e a estrutura celular seja destruída (Chen et al., 2012). No entanto, a extração de clorofila de maneira convencional depende de análises químicas, as quais não são universalmente aplicáveis à dinâmica de monitoramento de plantas em grandes extensões, pois tais medições são altamente demandantes de tempo e requerem a destruição das amostras (S. Cui \& Zhou, 2017).

Como alternativa para estas medições, tem sido estudadas metodologias óticas, não destrutivas, as quais conseguem medir variáveis relacionadas com o estado das plantas por meio da sua reflectância espectral (Kira et al., 2015). A partir disto, têm sido desenvolvidas diferentes pesquisas para conseguir medir o teor de clorofila das plantas por meio de sensores remotos, utilizando desde instrumentos com medições pontuais em campo até medições da reflectância espectral por meio de imagens de satélite (Liu et al., 2014). Estes, por sua vez, possuem limitações na hora de realizar estimativas de parâmetros da vegetação tais como o índice de área foliar ou o teor de clorofila, devido à obtenção de reflectância espectral em faixas largas e pouco específicas, enquanto que equipamentos com alta resolução espectral facilitam a detecção de características de absorção sutis ao longo da assinatura espectral da vegetação (Doktor et al., 2014).

No entanto, o uso de informação de sensores hiperespectrais requerem a aplicação de técnicas especializadas que permitam obter informação relevante e precisa das variáveis desejadas (Chlingaryan et al., 2018; Morellos et al., 2016). Dentro das principais técnicas empregadas no estudo de dados hiperespectrais podem ser destacadas o método dos mínimos quadrados parciais ou partial least square (PLS), com algumas variações; análises de componentes principais (PCA), entre outras (Abdel-Rahman et al., 2014; Colombani et al., 2012; Stewart et al., 2013; Vibhute et al., 2018). Porém, nos últimos anos começou-sea utilizar algoritmos mais sofisticados, associados à inteligência artificial e ao machine learning, com a ideia de obter resultados mais robustos e com maior precisão na hora de modelar variáveis de cultivo a partir de informação de sensores remotos (Abdel-Rahman et al., 2013; Cavallo et al., 2017; LI et al., 2017; Mirzaie et al., 2014). Desta forma, o objetivo deste trabalho é comparar técnicas de estatística multivariada comumente usadas na literatura, com técnicas de machine learning para a obtenção de valores de clorofila presentes em capim 'Mombaça' por meio de dados hiperespectrais. 


\subsection{Material e métodos}

\subsubsection{Caracterização da área experimental}

O estudo foi realizado na área experimental da Escola Superior de Agricultura "Luiz de Queiroz"

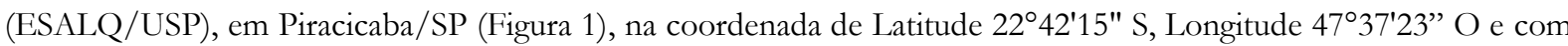
altitude $530 \mathrm{~m}$ ). O solo da área experimental foi classificado como Nitossolo Vermelho Eutroférrico latossólico segundo o Sistema Brasileiro de Classificação de Solos (EMBRAPA, 2006). O clima da região é subtropical úmido (Cwa), segundo a classificação de Köppen-Geiger, com verão quente e úmido e inverno seco, com temperatura média inferior a $18^{\circ} \mathrm{C}$ no mês mais frio e superior a $22^{\circ} \mathrm{C}$ no mês mais quente (ALVARES et al., 2013). As condições meteorológicas consideradas para o desenvolvimento do experimento foram registradas de julho de 2017 a janeiro de 2018. (Tabela 1).

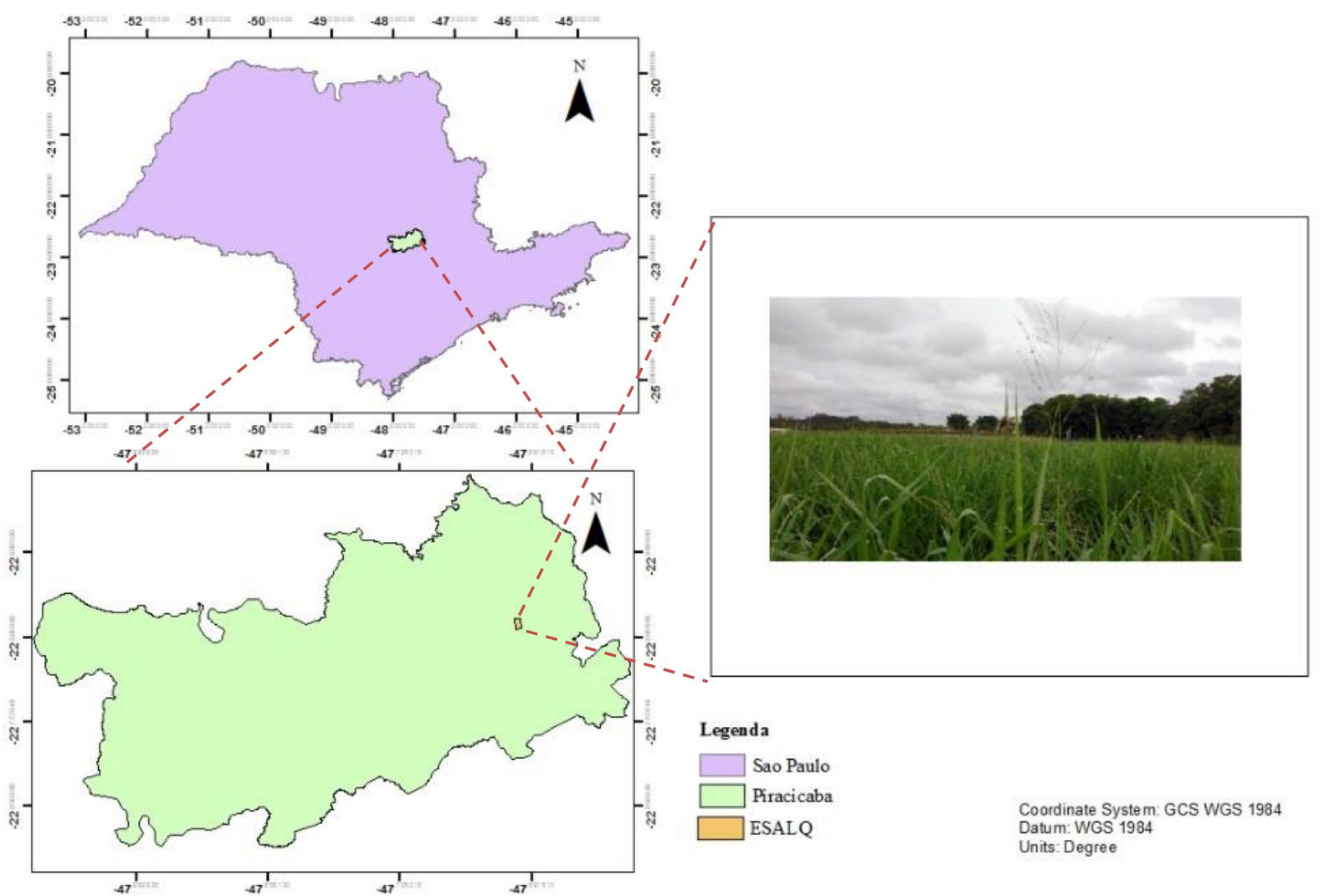

Figura 1 - Localização do experimento destacando a cidade de Piracicaba e a área experimental. 
Tabela 1. Condições meteorológicas médias durante o desenvolvimento do experimento

\begin{tabular}{cccccc}
\hline Mês & $\begin{array}{c}\text { Precipitação } \\
(\mathbf{m m})\end{array}$ & $\begin{array}{c}\text { Temperatura } \\
\text { média }\left({ }^{\circ} \mathbf{C}\right)\end{array}$ & $\begin{array}{c}\text { Temperatura } \\
\text { máxima média } \\
\left({ }^{\circ} \mathbf{C}\right)\end{array}$ & $\begin{array}{c}\text { Temperatura } \\
\text { mínima } \\
\text { média }\left({ }^{\circ} \mathbf{C}\right)\end{array}$ & $\begin{array}{c}\text { Radiação } \\
\text { Global } \\
(\mathbf{M J} / \mathbf{m} \mathbf{2 . d})\end{array}$ \\
\hline Julho & 0 & 17 & 25.2 & 9.5 & 13.69 \\
Agosto & 51.3 & 19.2 & 26.6 & 12.6 & 14.64 \\
Setembro & 46.7 & 23.2 & 32.1 & 14.4 & 21.82 \\
Outubro & 81.5 & 23.3 & 30.4 & 17.5 & 18.72 \\
Novembro & 236 & 22.7 & 29.6 & 17.2 & 22.43 \\
Dezembro & 152.2 & 24.3 & 31 & 19.7 & 21.39 \\
Janeiro & 224.9 & 23.7 & 30.3 & 19.5 & 20.3 \\
\hline
\end{tabular}

A cultura utilizada para esse experimento foi Megathyrsus maximus cv. Mombaça, semeada em fevereiro de 2016, sendo realizados cortes sucessivos e irrigação suplementar até conseguir as condições de fertilidade ideais para o estabelecimento do experimento. Uma vez atingidos os níveis desejados de nutrientes no solo, começou o processo de adubação com doses de nitrogênio e boro, as quais foram distribuídas em quatro blocos ao acaso, cada um de 88 $\mathrm{m}^{2}$, com quatro repetições cada, e usando irrigação suplementar até atingir a capacidade de campo (Figura 2).

Utilizou-se para o delineamento experimental, quatro doses de adubação nitrogenada, sendo estes nomeados como N1 (104,2 $\left.\mathrm{kg} \mathrm{ha}^{-1}\right)$, N2 (208,4 $\left.\mathrm{kg} \mathrm{ha}^{-1}\right)$, N3 $\left(312,5 \mathrm{~kg} \mathrm{ha}^{-1}\right)$ e N4 (416,7 $\left.\mathrm{kg} \mathrm{ha}^{-1}\right)$. Foi utilizada ureia como fonte nitrogenada, dividindo-se a aplicação em 5 doses iguais para cada um dos tratamentos, as quais foram incorporadas igualmente entre os meses de agosto a dezembro de 2017. O ácido bórico foi utilizado como fonte de boro, aplicado em uma única dose $\left(0,92 \mathrm{~kg} \mathrm{ha}^{-1}\right)$ no começo do experimento.
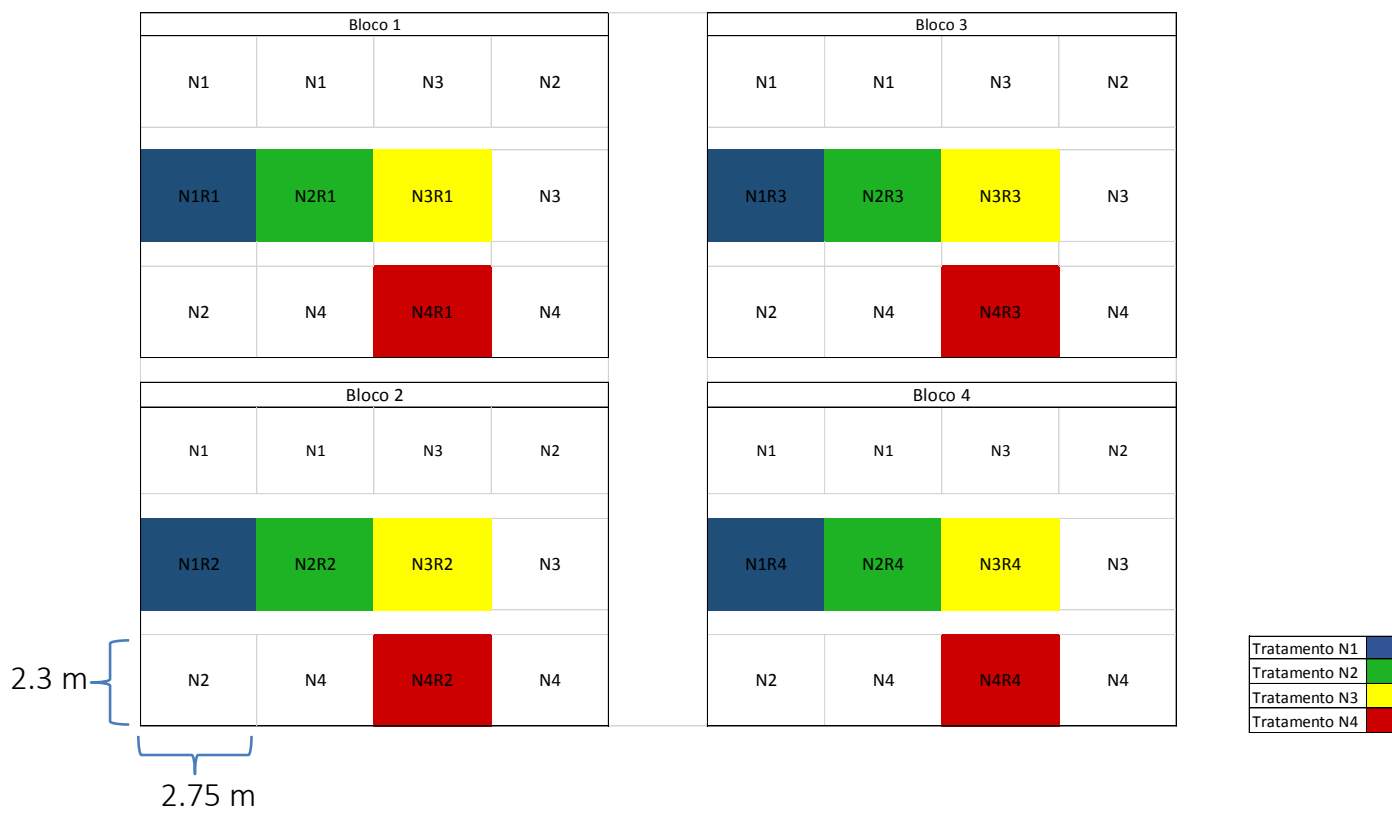

$2.75 \mathrm{~m}$

Figura 2 - Croqui da área experimental com a distribuição dos tratamentos e dos blocos casualizados. 


\subsubsection{Medição da reflectância espectral e do teor de clorofila}

As medições de refletância espectral e clorofila foram realizadas em seis ocasiões, de agosto de 2017, a janeiro de 2018, a cada 28 dias, antes do corte periódico da cultura. Foram colhidas 8 folhas +1 de 'Mombaça', por repetição, totalizando 128 folhas para cada amostragem, exeto na primeira amostragem, a qual foi realizada antes da implementação dos tratamentos, com a coleta de apenas 32 folhas.

A refletância espectral foi medida usando um espectroradiômetro ASD FieldSpec FR Spectroradiometer ${ }^{\circledR}$ (Analytical Spectral Devices, Boulder, CO, EUA) com uma faixa de comprimento de onda de 350 até $2500 \mathrm{~nm}$, utilizando uma resolução espectral de $1,4 \mathrm{~nm}$ no comprimento de onda dos 350 até os $1050 \mathrm{~nm}$ e de $2 \mathrm{~nm}$ no comprimento de onda dos 1050 até os $2500 \mathrm{~nm}$. Para facilitar a tomada de dados de refletância das folhas amostradas, foi acoplado ao espectroradiômetro o equipamento Leaf Clip ${ }^{\circledR}$ (ASD - Analytical Spectral Devices Inc., Boulder, CO, EUA), o qual provê uma fonte de iluminação estável, com um campo de visada fixo e um ângulo constante de 90 graus.

\subsubsection{Determinação do teor de clorofila na folha em laboratório}

Depois da leitura espectral, as folhas recolhidas em campo foram congeladas em nitrogênio líquido e armazenadas a $0^{\circ} \mathrm{C}$ para evitar a degradação da clorofila. Depois, foi utilizado o protocolo para extração de pigmentos foliares baseado no uso de dimetilsulfóxido (DMSO) (Barnes et al., 1992). Utilizou-se 0,025 g de tecido vegetal de cada folha coletada, os quais foram submergidos em tubos de ensaio, cada um com $2 \mathrm{ml}$ de DMSO. Estes tubos foram armazenados durante 48 horas em um espaço escuro à temperatura ambiente. Decorrido 48 horas, foram adicionados $3 \mathrm{ml}$ de DMSO em cada tubo de ensaio e com a solução resultante realizou-se a leitura em um espectrofotômetro usando aproximadamente $2 \mathrm{ml}$ do sobrenadante para cada tubo de ensaio. Os teores de cada pigmento foram calculados utilizando os valores de refletância nos comprimentos de onda dos 645 e 663 nm e aplicando as seguintes equações

$$
\begin{aligned}
& \text { Clorofila A }(\mathrm{mg} / \mathrm{g})=[(12,7 * \mathrm{~A} 663)-(2,69 * \mathrm{~A} 645)]^{*}(\mathrm{~V} / 1000 * \mathrm{~W}) \\
& \text { Clorofila B }(\mathrm{mg} / \mathrm{g})=\left[(22,9 * \mathrm{~A} 645)-\left(4,68^{*} \mathrm{~A} 663\right)\right]^{*}(\mathrm{~V} / 1000 * \mathrm{~W}) \\
& \text { Clorofila Total }=\left(20,08^{*} \mathrm{~A} 645+8,02 * \mathrm{~A} 663\right) *(\mathrm{~V} / 1000 * \mathrm{~W})
\end{aligned}
$$

Sendo A645, o valor da leitura no comprimento de onda dos 645 nm; A663 o valor da leitura no comprimento de onda dos $663 \mathrm{~nm}$; V o volume total da solução de DMSO, e W o peso fresco da amostra.

\subsubsection{Processamento prévio dos dados hiperespectrais}

Antes de analisar as assinaturas espectrais coletadas foi realizado um processo de limpeza das mesmas, eliminando algumas faixas que podem ser consideradas como fontes de ruído nas medições, considerando principalmente aqueles valores nas regiões entre 350 - 399 nm, 1355 - $1420 \mathrm{~nm}, 1810$ - $1940 \mathrm{~nm}$ e 2470 - $2500 \mathrm{~nm}$ 
(Abdel-Rahman et al., 2014). Posteriormente foi aplicado o método de Savitzky-Golay para a suavização das curvas espectrais e eliminação de ruídos. Além disso, foi calculada a primeira derivada dos valores de reflectância originais considerando estudos prévios que mostraram bons resultados na aplicação desta técnica para a obtenção de valores de variáveis químicas relacionadas com os valores de reflectância espectral modificados (Abdel-Rahman et al., 2014; Erudel et al., 2017).

\subsubsection{Análises da reflectância spectral para estimar o teor de clorofila}

Para a obtenção do teor de clorofila foram comparados os seguintes métodos: Sparse Partial Least Square Regresssion (SPLSR), Random Forest Regression (RFR) e Support Vector Regression. Considerando que são os métodos mais utilizados para obter informação de variáveis biofísicas a partir de dados hiperespestrais (Azadbakht et al., 2019).

\subsubsection{Sparse partial least square regression (SPLSR)}

Esta é uma metodologia multivariada, conhecida por ser uma ferramenta eficaz para o modelamento, principalmente quando existe um grande número de variáveis preditoras e a colinearidade é alta (Abdel-Rahman et al., 2017). O SPLSR, embora esteja baseado no PLS, adicional a este, usa uma solução parcial no momento de realizar a diminuição das variáveis explicativas e, além disso, realiza simultaneamente a redução da dimensionalidade com a seleção das variáveis mais importantes na análise (Abdel-Rahman et al., 2014). Assim, baseando-se na dispersão da matriz de dados criada pelos diferentes comprimentos de onda, são selecionadas as variáveis mais relevantes, enquanto que os outros fatores de entrada na matriz são qualificados como irrelevantes para a determinação da resposta (AbdelRahman et al., 2017). Este método extrai informação importante estabelecendo correlações entre múltiplas variáveis independentes, como são os valores de refletância nos diferentes comprimentos de onda, e uma variável resposta, que neste caso é o teor de clorofila da folha (Arshad et al., 2017). Para a aplicação desta metodologia é preciso otimizar dois parâmetros, "eta" e "k", sendo o primeiro parâmetro dos limiares da dispersão, e o segundo, o parâmetro que fixa o número de fatores escondidos. Estes dois valores foram otimizados por meio de validações cruzadas segundo estudos realizados por outros autores (Abdel-Rahman et al., 2014, 2017; Chun \& Keleş, 2010).

\subsubsection{Random forest regression (RFR)}

Este método abrange um conjunto de algoritmos desenvolvidos para resolver problemas de classificação e regressão por meio de árvores de decisão (Chemura et al., 2017). Esta metodologia emprega um processo interativo para construir um número de árvores de maneira independente, usando uma sub-amostra aleatória de um grupo de dados de treinamento (Chlingaryan et al., 2018). Esta técnica pode ser utilizada para reduzir a redundância em bases complexas de dados multiespectrais, além de ser conhecida como uma metodologia precisa para classificação e regressão de diferentes variáveis por sua capacidade para modelar interações complexas (Wang et al., 2016). Os dois principais parâmetros que devem ser otimizados na hora de aplicar esta técnica são o número de árvores a utilizar (ntree) e o número de variáveis a serem levadas em consideração na construção de cada árvore (mtry), neste sentido foram utilizados ntree $=1000$ e mtry $=700$, considerando trabalhos prévios de outros autores (Doktor et al., 2014; Liang et al., 2016). Além disso, considerando outros autores, é possível melhorar a acurácia na predição entre 4 e $8 \%$ 
aplicando técnicas para reduzir a dimensionalidade dos dados, assim foi usado análises de componentes principais antes da RFR (Doktor et al., 2014).

\subsubsection{Support vector regression (SVR)}

Esta é uma técnica de aprendizagem estatística não paramétrica, amplamente utilizada na área do sensoriamento remoto (Mountrakis et al., 2011). Esta técnica usa métodos de kernel para projetar os dados em um hiperplano diferente, fazendo com que padrões complexos não lineares possam ser representados de maneira simples, com o qual é possível construir um modelo para calcular variáveis minimizando o risco de erro (Were et al., 2015). O principal parâmetro usado para otimizar este modelo é o método de kernel a ser empregado em sua construção dentro das quais podem ser definidos dois grupos principais: métodos de kernel locais, baseadas em distância, as quais estabelecem que somente os dados que estão perto tem influência nos valores próximos; e métodos de kernel globais, baseadas no produto escalar, as quais estabelecem que amostras que estão distantes das outras ainda podem influenciar o valor de kernel (R. Silva et al., 2018). Neste trabalho foi empregada o método de kernel radial.

\subsubsection{Avaliação do desempenho dos modelos de predição}

Para os três tipos de modelos, o total da base de dados foi dividida em duas subamostras. A primeira com $75 \%$ dos dados, os quais foram utilizados para a calibração do modelo, e a segunda, com $25 \%$ dos dados iniciais, os quais serviram como como base de dados de teste. A conformação das subamostras foi realizada de maneira aleatória, assim o grupo de dados de calibração e validação não foram repetidos para nenhum dos modelos avaliados. Para medir a capacidade de predição destes modelos foi usado o coeficiente de determinação $\left(\mathrm{R}^{2}\right)$, o erro quadrático médio (RMSE) e o erro absoluto médio (MAE) ao serem estas medições comuns no estudo de modelos de regressão. Para cada um dos modelos avaliados, o processo de calibração e validação foi implementado dez vezes segundo a metodologia reportada por alguns autores (Azadbakht et al., 2019; Doktor et al., 2014; Tan et al., 2018).

Os resultados do coeficiente de determinação, de um total de 30 repetições, foram avaliados utilizando análise de variância, com nível de significância de 5\%, com a hipótese nula de que pelo menos, um dos grupos tem um comportamento estatístico diferente dos demais. Em caso de encontrar diferenças significativas em pelo menos um dos grupos, é aplicado o teste de Tukey HSD, para identificar os grupos que são diferentes.

Para medir a consistência dos métodos empregados, foi usada a medição do coeficiente de assimetria de Bowley (Eq. 4).

$$
\mathrm{SK}_{\text {Bowley }}=\left(\mathrm{Q} 3+\mathrm{Q} 1-2 \mathrm{Q}_{2}\right) /(\mathrm{Q} 3-\mathrm{Q} 1)
$$

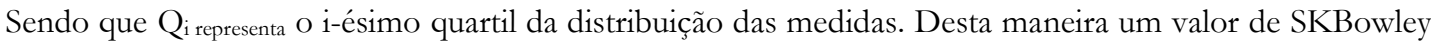
igual a 0 indica a uma distribuição simétrica, enquanto $\mathrm{SK}_{\text {Bowley }}<0$ e $\mathrm{SK}_{\text {Bowley }}>0$ faz referência a distribuições negativas e positivas, respectivamente. 


\subsubsection{Estimativa do peso das bandas utilizadas nos modelos}

A importância das variáveis utilizadas na criação dos modelos foi medida dependendo do método escolhido. No caso do SPLS a relevância das bandas foi analisada considerando os coeficientes corrigidos calculados durante a geração de cada modelo, assim, foram somados os valores absolutos dos coeficientes das dez execuções com o objetivo de analisar quais regiões do espectro tiveram maiores valores.

Enquanto que no caso do RFR, a estimativa da importância das variáveis na construção do modelo foi medida considerando a diminuição do total da soma residual dos quadrados atribuída a cada variável, a qual é calculada durante a calibração do modelo. Neste sentido foram somados os valores deste parâmetro nas diferentes execuções para determinar a participação de cada comprimento de onda na construção dos modelos baseados em RFR.

Para os resultados gerados pelo SVR não foi considerada a importância das variáveis originais, pois o método de kernel utilizado calcula o peso do coeficiente a partir de variáveis transformadas.

\subsection{Resultados}

\subsubsection{Medição de clorofila durante o experimento}

Os valores de clorofila apresentaram uma grande variabilidade para cada um dos meses avaliados, fazendo com que existissem diferenças significativas na maioria dos casos. No entanto, ressalta-se que não houve um incremento na concentração de clorofila ao decorrer do tempo, sendo outubro o mês que apresentou a mediana com o maior teor deste pigmento. Por sua vez, o mês de agosto, por ser um mês mais frio, com menor radiação solar e não ter adubações previas, gero um menor crescimento e da cultura, o qual ajudo a ter menores valores de clorofila (Figura 3).

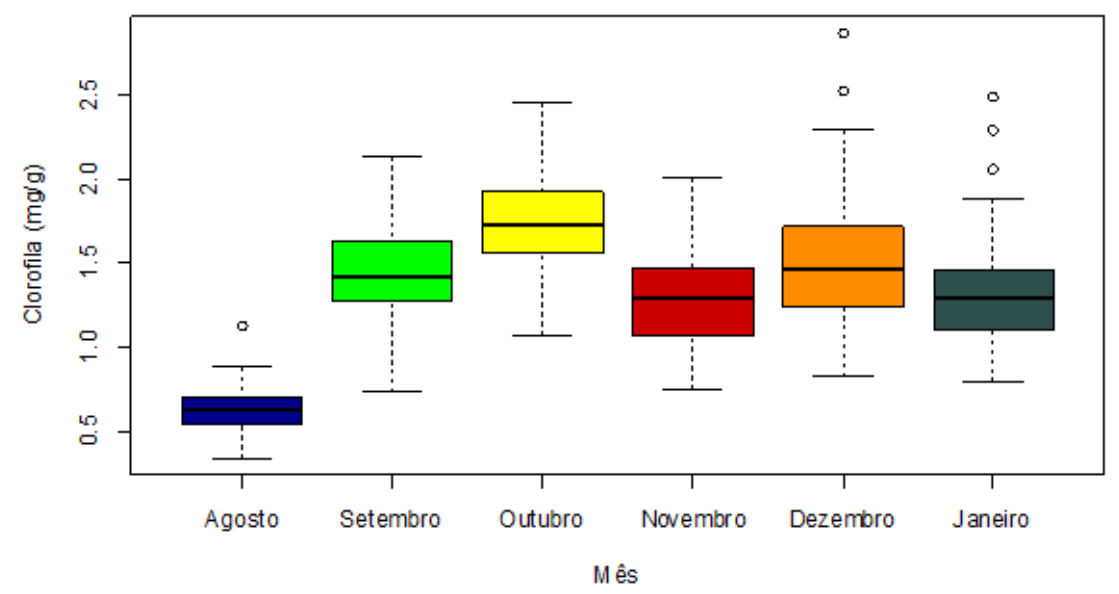

Figura 3. Diagrama de boxplot com os valores médios de clorofila mensais 


\subsubsection{Transformação dos dados hiperespectrais}

Os valores da primeira derivada mostraram que ao longo dos diferentes meses o comportamento espectral das folhas foi constante, destacando-se o verde, o red-edge, e as regiões do infravermelho de onda curta nos 1400 e $1800 \mathrm{~nm}$, como as que maiores diferenças apresentaram em cada tratamento. Porém, ressalta-se que para o mês de agosto, os valores da primeira derivada apresentam que o red-edge tem um deslocamento para o lado esquerdo do gráfico e apresenta maior reflectância espectral, semelhante ao que ocorre com os valores da primeira derivada que são encontrados na região do verde (Figura 4).

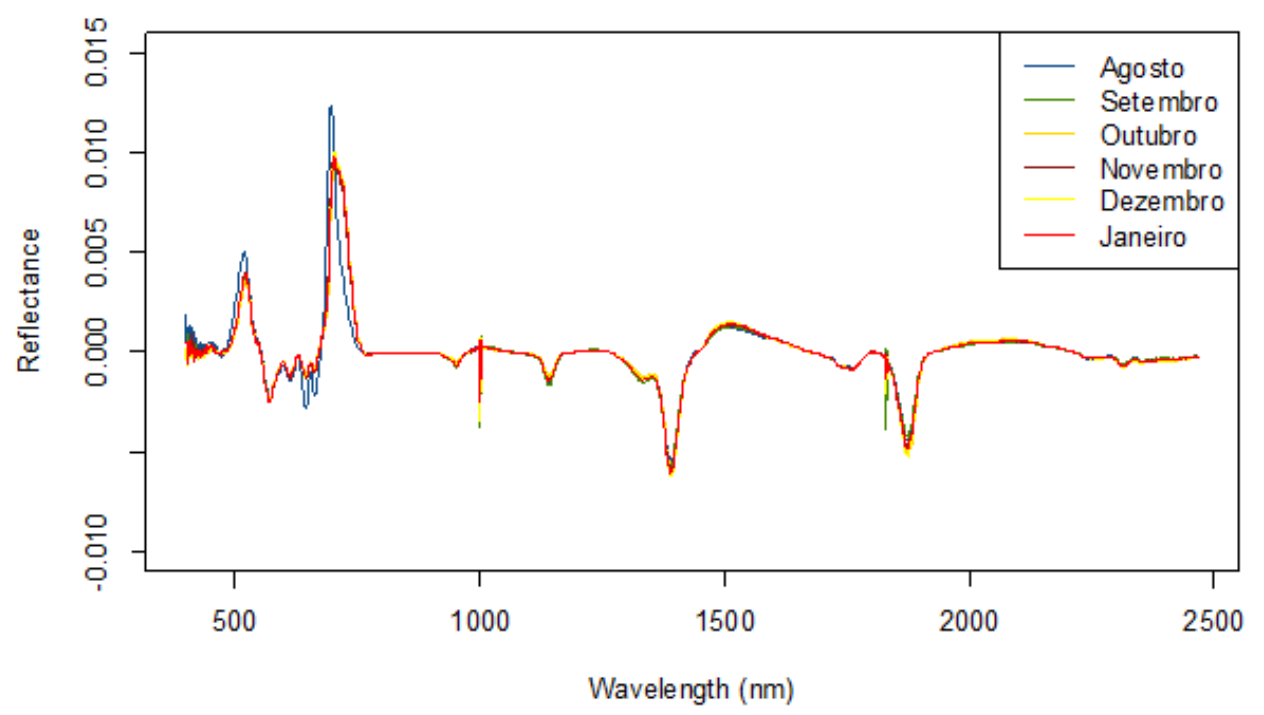

Figura 4. Gráfico da média da primeira derivada calculada a partir dos valores de reflectância original.

\subsubsection{Desempenho dos modelos avaliados}

O desempenho de cada um dos métodos foi avaliado através das medidas de erro mencionadas anteriormente mediante a aplicação do teste de anova (Tabela 1). Assim, depois de 10 repetições com dados de treinamento e teste aleatorizados, o modelo com o maior coeficiente de determinação, $\mathrm{R}^{2}$, foi o SVR apresentando um coeficiente de determinação médio de 0,637, seguido pelo RFR, que teve uma média de 0,628, enquanto que o SPLS teve o coeficiente de determinação com o menor valor médio, sendo este de 0,589 (Figura 5). 
Tabela 1. Valores dos coeficientes de determinação dos modelos avaliados

\begin{tabular}{cccc}
\hline & \multicolumn{2}{c}{ R2 } & \\
\hline Repetição & SPLS & RFR & SVR \\
\hline 1 & 0.585 & 0.573 & 0.614 \\
2 & 0.598 & 0.696 & 0.668 \\
3 & 0.616 & 0.584 & 0.628 \\
4 & 0.561 & 0.620 & 0.644 \\
5 & 0.573 & 0.628 & 0.643 \\
6 & 0.617 & 0.663 & 0.681 \\
7 & 0.542 & 0.675 & 0.623 \\
8 & 0.603 & 0.640 & 0.676 \\
9 & 0.575 & 0.621 & 0.594 \\
10 & 0.621 & 0.586 & 0.607 \\
\hline Média & $0.589 \mathrm{a}$ & $0.629 \mathrm{~b}$ & $0.638 \mathrm{~b}$
\end{tabular}

Médias seguidas por uma mesma letra minuscula não diferem entre si pelo teste de Tukey HSD $(\mathrm{p}<0,05)$

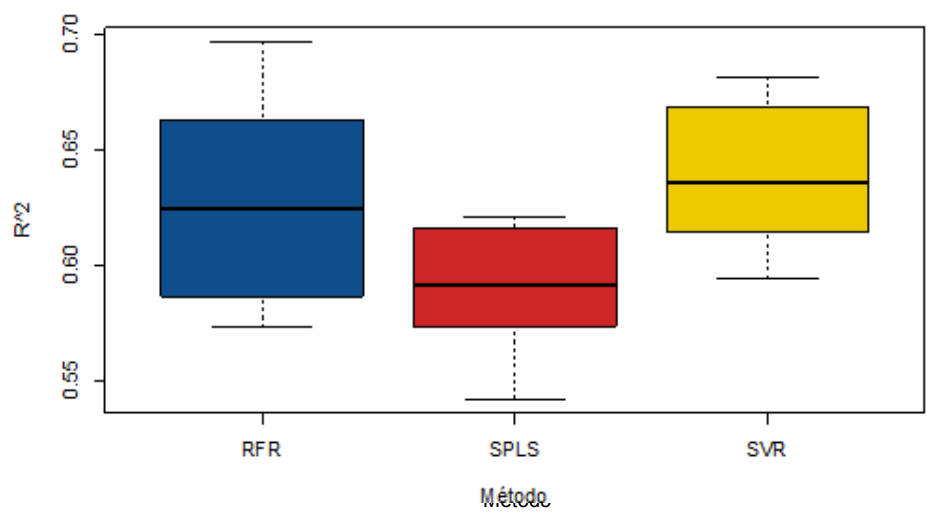

Figura 5. Diagramas de boxplot do coeficiente de determinação para as diferentes metodologias avaliadas.

Por outro lado, na medição do erro quadrático médio (Tabela 2), foi encontrado que o método do SVR teve o valor da mediana menor do que das suas observações, porém, segundo o teste de anova, não houve diferenças significativas neste parâmetro de medição para os modelos avaliados (Figura 6). 
Tabela 2. Valores do erro quadrático médio dos modelos avaliados

\begin{tabular}{cccc}
\hline & \multicolumn{2}{c}{ RMSE } & \\
\hline Repetição & SPLS & RFR & SVR \\
\hline 1 & 0.240 & 0.228 & 0.219 \\
2 & 0.223 & 0.247 & 0.221 \\
3 & 0.232 & 0.252 & 0.230 \\
4 & 0.248 & 0.268 & 0.228 \\
5 & 0.226 & 0.237 & 0.227 \\
6 & 0.228 & 0.234 & 0.231 \\
7 & 0.247 & 0.216 & 0.254 \\
8 & 0.242 & 0.248 & 0.210 \\
9 & 0.243 & 0.235 & 0.221 \\
10 & 0.236 & 0.228 & 0.240 \\
\hline Média & $0.237 \mathrm{a}$ & $0.239 \mathrm{a}$ & $0.228 \mathrm{a}$
\end{tabular}

Médias seguidas por uma mesma letra minuscula não diferem entre si pelo teste de Tukey HSD $(\mathrm{p}<0,05)$

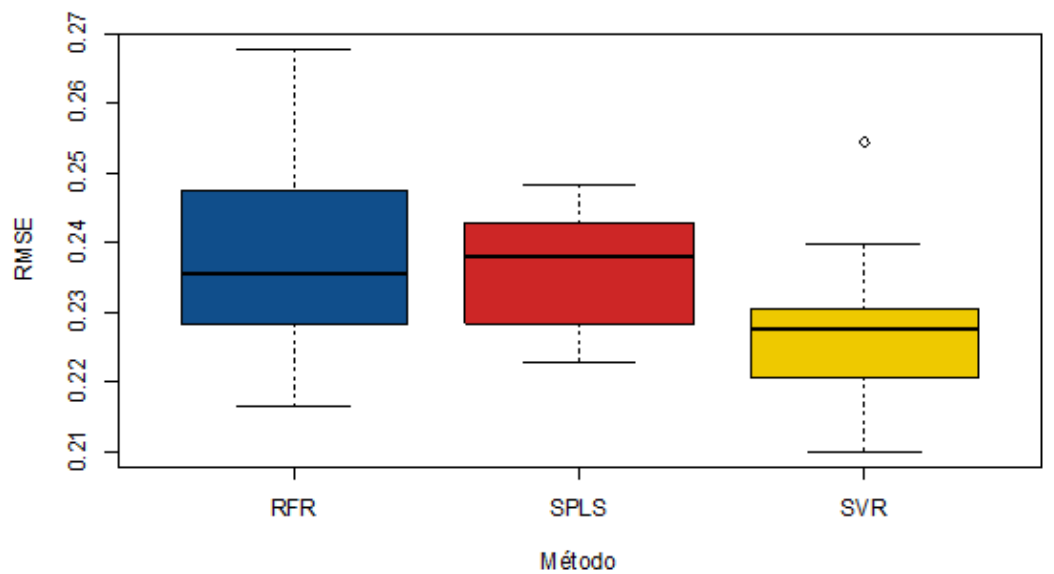

Figura 6. Diagramas de boxplot do erro quadrático médio para as diferentes metodologias avaliadas.

De maneira semelhante, ao comparar os valores do erro absoluto médio (Tabela 3), encontrou-se que os dados do modelo SVR tiveram valores de mediana inferiores aos encontrados nas outras duas metodologias, no entanto a hipótese de que os modelos avaliados tiveram comportamentos diferentes para este parâmetro foi rejeitada pelo teste de anova (Figura 7). 
Tabela 3. Valores do erro absoluto médio dos modelos avaliados

\begin{tabular}{cccc}
\hline \multicolumn{4}{c}{ MAE } \\
\hline Repetição & SPLS & RFR & SVR \\
\hline 1 & 0.191 & 0.175 & 0.172 \\
2 & 0.180 & 0.186 & 0.175 \\
3 & 0.179 & 0.206 & 0.177 \\
4 & 0.186 & 0.215 & 0.184 \\
5 & 0.182 & 0.186 & 0.181 \\
6 & 0.179 & 0.179 & 0.183 \\
7 & 0.197 & 0.174 & 0.200 \\
8 & 0.188 & 0.192 & 0.163 \\
9 & 0.184 & 0.187 & 0.172 \\
10 & 0.184 & 0.182 & 0.185 \\
Média & $0.185 \mathrm{a}$ & $0.188 \mathrm{a}$ & $0.179 \mathrm{a}$
\end{tabular}

Médias seguidas por uma mesma letra minuscula não diferem entre si pelo teste de Tukey $\operatorname{HSD}(\mathrm{p}<0,05)$

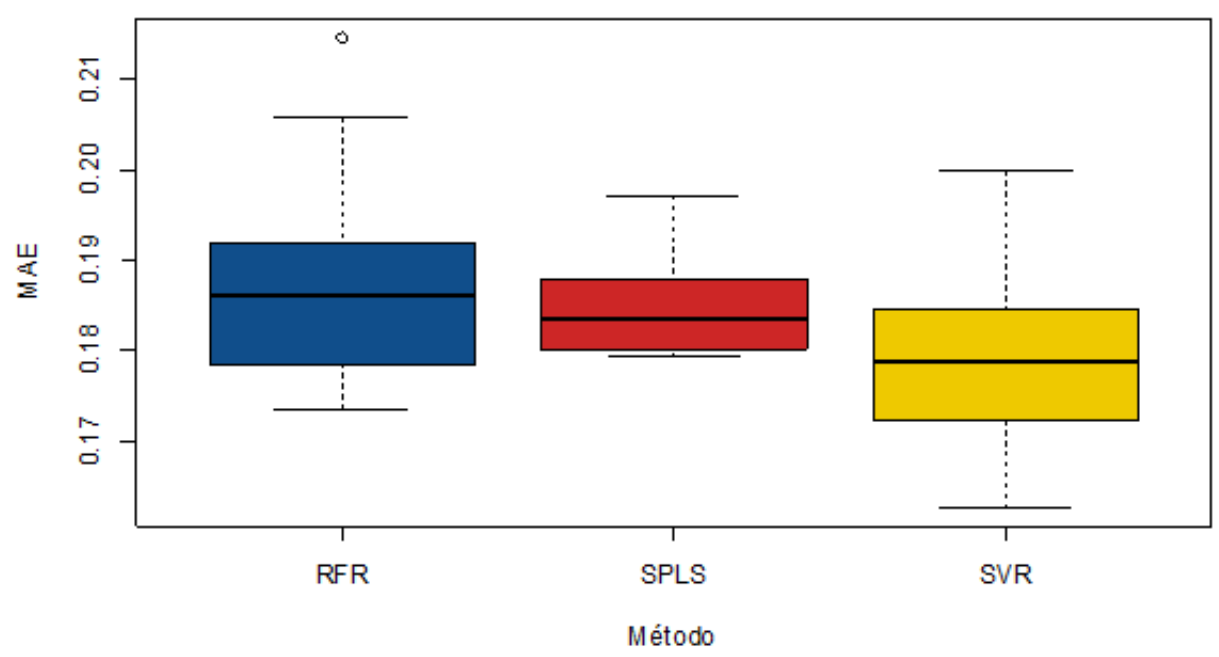

Figura 7. Diagramas de boxplot do erro absoluto médio para as diferentes metodologias avaliadas

Finalmente, segundo o coeficiente de assimetria Bowley, o coeficiente de determinação, todos os modelos avaliados apresentaram valores maiores do que 0 , indicando assimetria positiva. No entanto, para os dados do erro quadrático médio, somente o método de RFR apresentou assimetria positiva. No caso das medições do erro absoluto médio, estas geraram assimetria negativa unicamente para os dados do modelo de SVR. Tabela 4. 
Tabela 4. Coeficiente de assimetria de Bowley para as medidas de erro dos modelos avaliados

\begin{tabular}{llll}
\hline & RMSE & R2 & MAE \\
\hline SPLS & -0.251 & 0.079 & 0.161 \\
RFR & 0.263 & 0.024 & 0.052 \\
SVR & -0.164 & 0.191 & -0.070 \\
\hline
\end{tabular}

\subsubsection{Importancia das bandas utilizadas}

Depois de executar os diferentes modelos para a obtenção de valores clorofila, foi analisada a participação de cada comprimento de onda na construção dos modelos. Assim, no caso do SPLS, 90\% das bandas do espectro foram utilizadas na calibração do modelo em pelo menos uma das execuções. Além disso, as regiões do red-edge, do infravermelho próximo, do azul, e do infravermelho de onda curta tiveram foram as que tiveram a maior participação. Figura 8 .

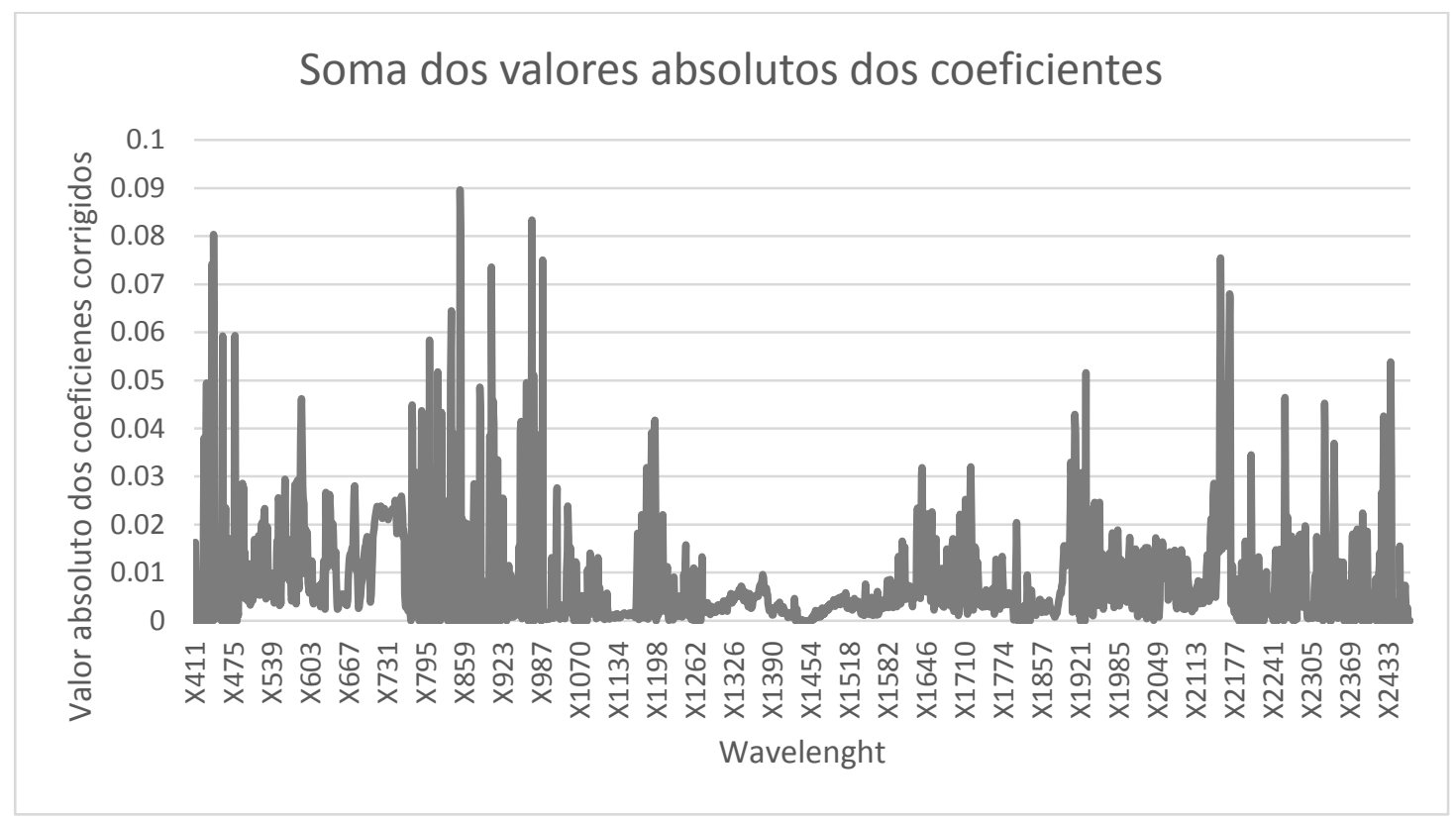

Figura 8. Soma dos valores absolutos dos coeficientes corrigidos para os modelos gerados pelo SPLS.

Para os valores gerados a partir do RFR, 91\% das bandas do espectro participaram pelo menos uma vez na construção do modelo de predição nas diferentes execuções realizadas. Além disso, as regiões de maior destaque nesta somatória foram o azul, o vermelho, o verde e o red-edge. Figura 9. 


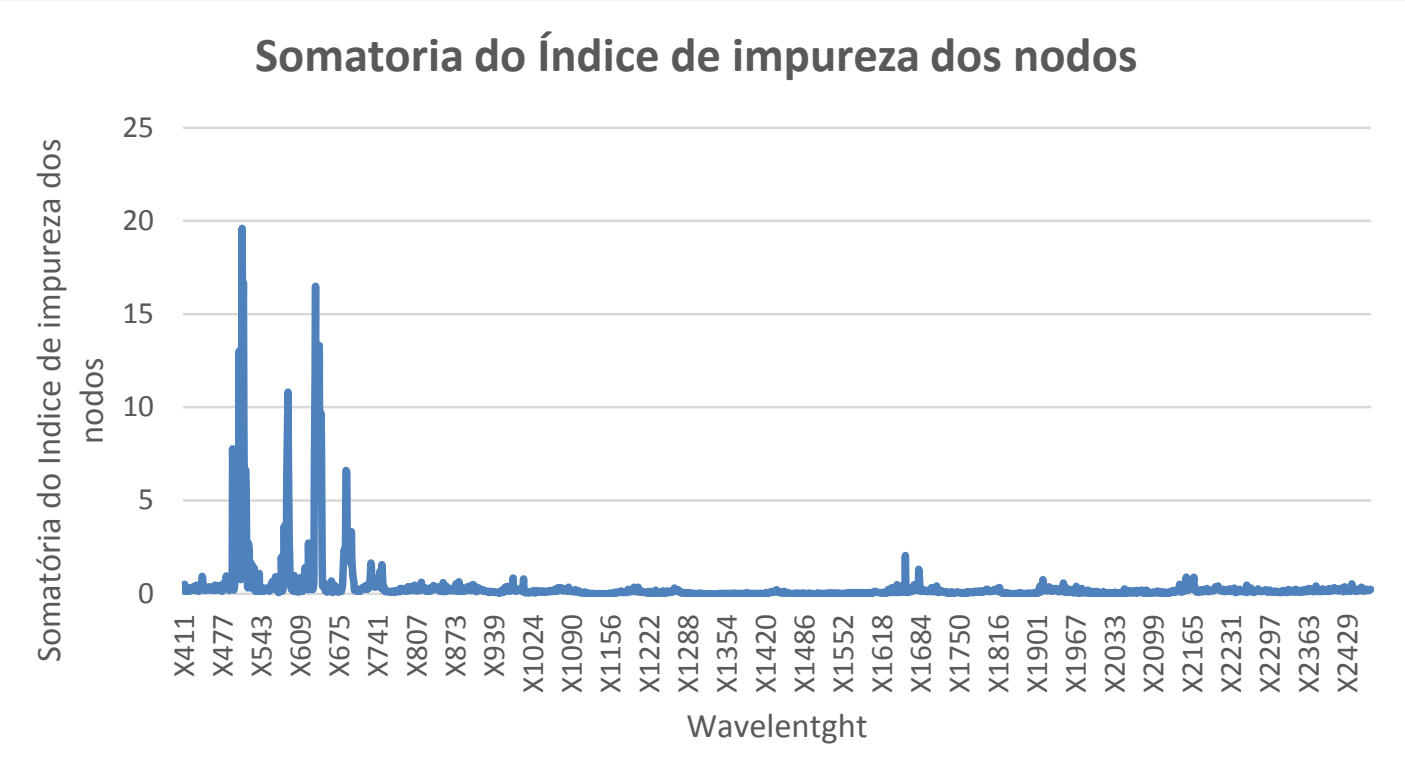

Figura 9. Soma do índice de impureza dos nós para os modelos gerados pelo RFR

\subsection{Discussão}

\subsubsection{Variação dos valores de clorofila}

A partir dos dados de clorofila medidos, foram encontradas variações no comportamento mensal da concentração deste pigmento. Neste sentido, é necessário considerar a influência das variáveis climáticas no desenvolvimento das forragens tropicais, pois temperaturas frias, baixos níveis de radiação solar e poucas precipitações têm sido associadas a quedas na produção, principalmente em períodos de inverno (Newman et al., 2007) . Portanto, as concentrações de clorofila apresentadas durante os meses de novembro e janeiro, as quais foram as menores durante a época de adubação da cultura, podem ter sido uma resposta aos dois meses com os menores níveis de radiação solar desde o início da fertilização. Em contraste, outubro e setembro foram antecedidos pelos dois meses com maior radiação solar desde o início do experimento, o qual influenciou na concentração de clorofila mostrada nestes meses, devido a relação de estímulo que tem a radiação na ativação do metabolismo fotossintético da planta e da produção de diferentes componentes fisiológicos (Gitelson et al., 2018). Por outra parte, é de se ressaltar que não houve aumento no teor de clorofila ao longo do tempo, mesmo considerando que foram feitas fertilizações contínuas durante os meses do experimento, porém, segundo alguns autores, o aumento de nitrogênio disponível para a cultura pode ser representado não só no aumento de clorofila, mas também no aumento de biomassa fazendo com que outras variáveis como o IAF ou a produção de matéria seca também aumentem (Araujo et al., 2013; Gbenou et al., 2018; Müller et al., 2002; Pontes et al., 2017). 


\subsubsection{Transformação dos dados hiperespectrais}

A transformação dos valores de reflectância espectral por meio da aplicação da primeira derivada foi considerada levando em conta os bons resultados reportados por outros autores quando são aplicados este tipo de procedimentos nos dados, previamente à determinação de variáveis relacionadas à bioquímica das plantas (AbdelRahman et al., 2014, 2017; P. T. Guo et al., 2018). Geralmente, a aplicação da primeira derivada ressalta a posição do red-edge, sendo este um dos comprimentos de ondas mais importantes na hora de explicar a variabilidade do teor de clorofila por meio da reflectância espectral (Z. Cui \& Kerekes, 2018; Delegido et al., 2013; Gitelson et al., 1996). No caso dos dados avaliados, esta análise conseguiu ressaltar as diferenças do comportamento espectral das medições feitas em agosto, quando não tinha sido aplicada nenhuma dose de nitrogênio e diminuir ruídos contidos nas assinaturas espectrais que são gerados durante as medições. É importante destacar que um dos procedimentos prévios, mais comuns na hora de trabalhar com dados hiperespectrais, é o uso de técnicas estatísticas para a reduzir a dimensionalidade dos dados, encontrando-se dentro das mais comuns a análise de componentes principais (Krishna et al., 2019; Putnam et al., 2013; Tan et al., 2018; Xie et al., 2008). O uso destas técnicas tem mostrado ser tão útil quanto o cálculo da primeira derivada, porém considerando os métodos de modelagem a serem usados neste trabalho, não foram empregadas técnicas externas para a reduzir a dimensionalidade dos dados.

\subsubsection{Avaliação do desempenho dos modelos}

$\mathrm{Na}$ avaliação dos modelos escolhidos encontraram-se diferenças significativas para o valor do coeficiente de determinação, mostrando que os métodos de RFR e SVR tiveram um melhor desempenho que o SPLS, considerando o valor de $\mathrm{R}^{2}$ (Tabela 1). O rendimento destacado dos métodos relacionados com técnicas de machine learning sobre metodologias convencionais de análises de dados tem sido reportado por outros autores (Abdel-Rahman et al., 2013; Azadbakht et al., 2019; Belgiu \& Drăgu, 2016; Doktor et al., 2014; Mountrakis et al., 2011). Por outra parte, ao considerar o coeficiente assimetria de Bowley, para os valores de $\mathrm{R}^{2}$ dos modelos avaliados, é possível ver que o SVR apresenta assimetria positiva o qual indica que, mesmo tendo o maior valor de $\mathrm{R}^{2}$, segundo as execuções avaliadas este método poderia tender a um desempenho pior do relatado nesta avaliação (Azadbakht et al., 2019).

O número de bandas escolhidas por cada método para fazer o cálculo do teor de clorofila esteve dentro dos valores encontrados na literatura encontrando, porém o SPLS foi o método que apresentou mais flutuações para este parâmetro (Abdel-Rahman et al., 2014; Doktor et al., 2014). Em ambos modelos, mais de 90\% das bandas do espectro participaram em pelo menos uma ocasião na determinação de valores de concentração de clorofila, sendo que no caso do RFR foi mais consistente a escolha da região mais importante.

Na maioria dos trabalhos que usaram técnicas de machine learning para a obtenção de valores de clorofila a partir da reflectância espectral, os coeficientes de determinação foram maiores aos aqui relatados (Curran et al., 2001; Doktor et al., 2014; Inoue et al., 2016; Liao et al., 2013; Schlemmer et al., 2013). No entanto, estes estudos utilizam valores de clorofila associados ao dossel, os quais levam em consideração a concentração de clorofila em uma unidade de área, enquanto que neste estudo a relação de clorofila é feita pelo peso da amostra, pelo qual, as metodologias de estimação não são totalmente comparáveis. 


\subsection{Conclussões}

A variabilidade nos valores de clorofila para cada mês foi influenciada pelas mudanças nas condições, principalmente as flutuações da radiação solar.

As técnicas de machine learning, RFR e SVR, tiveram melhor desempenho que o método SPLS, considerado como convencional na modelagem de variáveis a partir da reflectância espectral.

Os comprimentos de onda mais importantes para realizar a modelagem da concentração de clorofila estão na faixa do visível e do infravermelho próximo.

\section{Referências}

Abdel-Rahman, E. M., Ahmed, F. B., \& Ismail, R. (2013). Random forest regression and spectral band selection for estimating sugarcane leaf nitrogen concentration using EO-1 Hyperion hyperspectral data. International Journal of Remote Sensing, 34(2), 712-728. doi:10.1080/01431161.2012.713142

Abdel-Rahman, E. M., Mutanga, O., Odindi, J., Adam, E., Odindo, A., \& Ismail, R. (2014). A comparison of partial least squares (PLS) and sparse PLS regressions for predicting yield of Swiss chard grown under different irrigation water sources using hyperspectral data. Computers and Electronics in Agriculture, 106, 11-19. doi:10.1016/j.compag.2014.05.001

Abdel-Rahman, E. M., Mutanga, O., Odindi, J., Adam, E., Odindo, A., \& Ismail, R. (2017). Estimating Swiss chard foliar macro- and micronutrient concentrations under different irrigation water sources using ground-based hyperspectral data and four partial least squares (PLS)-based (PLS1, PLS2, SPLS1 and SPLS2) regression algorithms. Computers and Electronics in Agriculture, 132, 21-33. doi:10.1016/j.compag.2016.11.008

Alexandrino, E., Gomide, J. A., \& De Miranda Gomide, C. A. (2005). Crescimento e desenvolvimento do dossel de Panicum maximum cv. Mombaça. Revista Brasileira de Zootecnia, 34(6 SUPPL.), 2164-2173. doi:10.1590/S151635982005000700002

Amaral, L. R., \& Molin, J. P. (2014). The effectiveness of three vegetation indices obtained from a canopy sensor in identifying sugarcane response to nitrogen. Agronomy Journal, 106(1), 273-280. doi:10.2134/agronj2012.0504

Amaral, L. R., Molin, J. P., \& Schepers, J. S. (2015). Algorithm for variable-rate nitrogen application in sugarcane based on active crop canopy sensor. Agronomy Journal, 107(4), 1513-1523. doi:10.2134/agronj14.0494

Araujo, L. C., Santos, P. M., Rodriguez, D., Pezzopane, J. R. M., Oliveira, P. P. A., \& Cruz, P. G. (2013). Simulating guinea grass production: Empirical and mechanistic approaches. Agronomy Journal, 105(1), 61-69. doi:10.2134/agronj2012.0245

Arshad, M., Ullah, S., Khurshid, K., \& Ali, A. (2017). Estimation of leaf water contents from mid- A nd thermal infrared spectra by coupling genetic algorithm and partial least squares regression. Journal of Applied Remote Sensing, 12(2), 10. doi:10.1117/12.2277822

Azadbakht, M., Ashourloo, D., Aghighi, H., \& Radiom, S. (2019). Wheat leaf rust detection at canopy scale under di ff erent LAI levels using machine learning techniques. Computers and Electronics in Agriculture, 156(September 2018), 119-128. doi:10.1016/j.compag.2018.11.016

Bandos, T. V., Bruzzone, L., \& Camps-Valls, G. (2009). Classification of hyperspectral images with regularized linear discriminant analysis. IEEE Transactions on Geoscience and Remote Sensing, 47(3), 862-873. doi:10.1109/TGRS.2008.2005729

Bao, Y., Xu, K., Min, J., \& Xu, J. (2013). Estimating wheat shoot nitrogen content at vegetative stage from in situ hyperspectral measurements. Crop Science, 53(5), 2063-2071. doi:10.2135/cropsci2013.01.0012 
Barnes, J. D., Balaguer, L., Manrique, E., Elvira, S., \& Davison, A. W. (1992). A reappraisal of the use of DMSO for the extraction and determination of chlorophylls $\mathrm{a}$ and $\mathrm{b}$ in lichens and higher plants. Environmental and Experimental Botany, 32(2), 85-100. doi:10.1016/0098-8472(92)90034-Y

Basso, K. C., Cecato, U., Barbero, L. M., Lempp, B., Gomes, J. A. N., \& Lugão, S. M. B. (2014). INFLUENCE OF NITROGEN LEVELS ON LEAF ANATOMY AND NUTRITIVE VALUE OF MILLENIUM GRASS. Bioscience Journal, 30(3), 792-801.

Belgiu, M., \& Drăgu, L. (2016). Random forest in remote sensing: A review of applications and future directions. ISPRS Journal of Photogrammetry and Remote Sensing, 114, 24-31. doi:10.1016/j.isprsjprs.2016.01.011

Cavallo, D. Pietro, Cefola, M., Pace, B., Logrieco, A. F., \& Attolico, G. (2017). Contactless and non-destructive chlorophyll content prediction by random forest regression: A case study on fresh-cut rocket leaves. Computers and Electronics in Agriculture, 140, 303-310. doi:10.1016/j.compag.2017.06.012

Chemura, A., Mutanga, O., \& Dube, T. (2017). Remote sensing leaf water stress in coffee (Coffea arabica) using secondary effects of water absorption and random forests. Physics and Chemistry of the Earth, 100, 317-324. doi:10.1016/j.pce.2017.02.011

Chen, B., Li, S., Wang, K., Zhou, G., \& Bai, J. (2012). Evaluating the severity level of cotton Verticillium using spectral signature analysis. International Journal of Remote Sensing, 33(9), 2706-2724. doi:10.1080/01431161.2011.619586

Chlingaryan, A., Sukkarieh, S., \& Whelan, B. (2018). Machine learning approaches for crop yield prediction and nitrogen status estimation in precision agriculture: A review. Computers and Electronics in Agriculture, 151(November 2017), 61-69. doi:10.1016/j.compag.2018.05.012

Chun, H., \& Keleş, S. (2010). Sparse partial least squares regression for simultaneous dimension reduction and variable selection. Journal of the Royal Statistical Society. Series B: Statistical Methodology, 72(1), 3-25. doi:10.1111/j.14679868.2009.00723.x

Clevers, J. G. P. W., \& Gitelson, A. A. (2013). Remote estimation of crop and grass chlorophyll and nitrogen content using red-edge bands on Sentinel-2 and -3. International Journal of Applied Earth Observation and Geoinformation, 23(1), 334-343. doi:10.1016/j.jag.2012.10.008

Clevers, J. G. P. W., \& Kooistra, L. (2012). Using Hyperspectral Remote Sensing Data for Retrieving Canopy Chlorophyll and Nitrogen Content. Journal of Selected Topics in Applied Earth Observation and Remote Sensing, 5(2), 574-583. doi:10.1109/JSTARS.2011.2176468

Colombani, C., Croiseau, P., Fritz, S., Guillaume, F., Legarra, a, Ducrocq, V., \& Robert-Granie, C. (2012). A comparison of partial least squares (PLS) and sparse PLS regressions in genomic selection in French dairy cattle. J Dairy Sci, 95(4), 2120-2131. doi:10.3168/jds.2011-4647

Costa, F., Corrêa, E., Melo, G., Cardoso, E., Pereira, M., \& Miranda, C. (2009). Avaliação dos impactos econômicos de quatro forrageiras lançadas pela Embrapa. (E. C. Lima, Ed.) Embrapa Gado de ... (Primeira.). Campo Grande, MS: Embrapa. Retrieved from https://www.infoteca.cnptia.embrapa.br/infoteca/bitstream/doc/853367/1/DOC174.pdf

Croft, H., Chen, J. M., \& Zhang, Y. (2014). The applicability of empirical vegetation indices for determining leaf chlorophyll content over different leaf and canopy structures. Ecological Complexity, 17(1), 119-130. doi:10.1016/j.ecocom.2013.11.005

Cui, S., \& Zhou, K. (2017). A comparison of the predictive potential of various vegetation indices for leaf chlorophyll content. Earth Science Informatics, 10(2), 169-181. doi:10.1007/s12145-016-0281-3

Cui, Z., \& Kerekes, J. (2018). Potential of Red Edge Spectral Bands in Future Landsat Satellites on Agroecosystem Canopy Green Leaf Area Index Retrieval. Remote Sensing, 10(1), 1-14. doi:10.3390/rs10091458

Curran, P. J., Dungan, J. L., \& Peterson, D. L. (2001). Estimating the foliar biochemical concentration of leaves with reflectance spectrometry: Testing the Kokaly and Clark methodologies. Remote Sensing of Environment, 76(3), 349_ 359. doi:10.1016/S0034-4257(01)00182-1

Da Silva, M., Pinto, F., Queiroz, D., Vieira, L., \& Resende, R. (2013). USING AN AERIAL SYSTEM OF REMOTE SENSING TO DETECT DIFFERENT NUTRITIONAL STATUS IN Brachiaria decumbens. Engenharia Agricola Jaboticabal, 34(5), 1049-1062.

Delegido, J., Verrelst, J., Meza, C. M., Rivera, J. P., Alonso, L., \& Moreno, J. (2013). A red-edge spectral index for remote sensing estimation of green LAI over agroecosystems. European Journal of Agronomy, 46, 42-52. 
doi:10.1016/j.eja.2012.12.001

Diacono, M., Rubino, P., \& Montemurro, F. (2013). Precision nitrogen management of wheat. A review. Agronomy for Sustainable Development, 33(1), 219-241. doi:10.1007/s13593-012-0111-z

Diezma, B., Lléo, L., Roger, J. M., Herrero-Lengreo, A., Lunadei, L., \& Ruiz-Altisent, M. (2013). Examination of the quality of spinach leaves using hyperspectral imaging. Postharvest Biology and Technology, 85, 8-17.

Doktor, D., Lausch, A., Spengler, D., \& Thurner, M. (2014). Extraction of plant physiological status from hyperspectral signatures using machine learning methods. Remote Sensing, 6(12), 12247-12274. doi:10.3390/rs61212247

Emanuel, M., Costa, D. A., Duarte, S. N., Neto, D. D., Cabral, E., \& Silva, D. A. (2009). TEOR DE NITROGÊENIO, ÍNDICES DE ÁREA FOLIAR E DE COLHEITA, NO MILHO, EM FUNÇÃO DA ADUBAÇÃO NITROGENADA, EM SOLO DE VÁRZEA. Revista Brasileira de Milho e Sorgo, 8(1), 13-26.

Erudel, T., Fabre, S., Houet, T., Mazier, F., \& Briottet, X. (2017). Criteria Comparison for Classifying Peatland Vegetation Types Using In Situ Hyperspectral Measurements. Remote Sensing, 9(7), 748. doi:10.3390/rs9070748

Escarela, C. M., Pietroski, M., De Mello Prado, R., Campos, C. N. S., \& Caione, G. (2017). Effect of nitrogen fertilization on productivity and quality of Mombasa forage (Megathyrsus maximum cv. Mombasa). Acta Agronomica, 66(1), 42-48. doi:10.15446/acag.v66n1.53420

Féret, J. B., Gitelson, A. A., Noble, S. D., \& Jacquemoud, S. (2017). PROSPECT-D: Towards modeling leaf optical properties through a complete lifecycle. Remote Sensing of Environment, 193, 204-215. doi:10.1016/j.rse.2017.03.004

Fernandes, J. C., Buzetti, S., Dupas, E., Teixeira, C. M., \& Andreotti, M. (2015). Sources and rates of nitrogen fertilizer used in Mombasa guineagrass in the Brazilian Cerrado region. African Journal of Agricultural Research, 10(19), 20762082. doi:10.5897/AJAR2014.9276

Filella, I., Serrano, L., Serra, J., \& Peñuelas, J. (1995). Evaluating Wheat Nitrogen Status with Canopy Reflectance Indexes and Discriminant-Analysis. Crop Science, doi:10.2135/cropsci1995.0011183X003500050023x

Gbenou, B., Adjolohoun, S., Bignon, D., Houndjo, M., Ahoton, L., Saidou, A., ... Sinsin, B. A. (2018). Practical aspects of grass forage seed production and quality with particular reference to planting row spacing and nitrogen fertilization in tropical regions : A review. International Journal of Biological and Chemical Sciences, 12(February), 508518.

Gitelson, A. A., Arkebauer, T. J., \& Suyker, A. E. (2018). Convergence of daily light use e ffi ciency in irrigated and rainfed C3 and C4 crops. Remote Sensing of Environment, 217(August), 30-37. doi:10.1016/j.rse.2018.08.007

Gitelson, A. A., Gritz, Y., \& Merzlyak, M. N. (2003). Relationships between leaf chlorophyll content and spectral reflectance and algorithms for non-destructive chlorophyll assessment in higher plant leaves reflectance and algorithms for non-destructive chlorophyll assessment. Journal of Plant Physiology, 160(November), 271-282. doi:10.1078/0176-1617-00887

Gitelson, A. A., Merzlyak, M. N., \& Lichtenthaler, H. K. (1996). Detection of Red Edge Position and Chlorophyll Content by Reflectance Measurements Near $700 \mathrm{~nm}$. Journal of Plant Physiology, 148(3-4), 501-508. doi:10.1016/S0176-1617(96)80285-9

Gitelson, A. A., Peng, Y., Arkebauer, T. J., \& Suyker, A. E. (2015). Productivity, absorbed photosynthetically active radiation, and light use efficiency in crops: Implications for remote sensing of crop primary production. Journal of Plant Physiology, 177, 100-109. doi:10.1016/j.jplph.2014.12.015

Greef, J. M. (1994). Productivity of Maize ( Zea mays L .) in Relation to Morphological and Physiological Characteristics under Varying Amounts of Nitrogen Supply. J. Agronomy and crop Science, 172, 317-326.

Guo, B.-B., Qi, S.-L., Heng, Y.-R., Duan, J.-Z., Zhang, H.-Y., Wu, Y.-P., ... Zhu, Y.-J. (2017). Remotely assessing leaf $\mathrm{N}$ uptake in winter wheat based on canopy hyperspectral red-edge absorption. European Journal of Agronomy, 82, 113-124. doi:10.1016/j.eja.2016.10.009

Guo, P. T., Shi, Z., Li, M. F., Luo, W., \& Cha, Z. Z. (2018). A robust method to estimate foliar phosphorus of rubber trees with hyperspectral reflectance. Industrial Crops and Products, 126(September), 1-12. doi:10.1016/j.indcrop.2018.09.055

Haboudane, D., Tremblay, N., Miller, J. R., \& Vigneault, P. (2008). Remote Estimation of Crop Chlorophyll Content 
Using Spectral Indices Derived From Hyperspectral Data. IEEE Transactions on Geoscience and Remote Sensing, 46(2), 423-437. doi:10.1109/TGRS.2007.904836

Hansen, P. M., \& Schjoerring, J. K. (2003). Reflectance measurement of canopy biomass and nitrogen status in wheat crops using normalized difference vegetation indices and partial least squares regression. Remote Sensing of Environment, 86(4), 542-553. doi:10.1016/S0034-4257(03)00131-7

Hatfield, J. L., Gitelson, A. A., Schepers, J. S., \& Walthall, C. L. (2008). Application of spectral remote sensing for agronomic decisions. Agronomy Journal, 100(3 SUPPL.), 117-131. doi:10.2134/agronj2006.0370c

Heinrichs, R., Monreal, C. M., Santos, E. T., Soares Filho, C. V., Rebonatti, M. D., Teixeira, N. M., \& Moreira, A. (2016). Phosphorus Sources and Rates Associated with Nitrogen Fertilization in Mombasa Grass Yield. Communications in Soil Science and Plant Analysis, 47(5), 657-669. doi:10.1080/00103624.2016.1141923

Horler, D. N. H., Dockray, M., \& Barber, J. (1983). The red edge of plant leaf reflectance. International Journal of Remote Sensing, 4(2), 37-41.

Houborg, R., McCabe, M. F., Cescatti, A., \& Gitelson, A. A. (2015). Leaf chlorophyll constraint on model simulated gross primary productivity in agricultural systems. International Journal of Applied Earth Observation and Geoinformation, 43, 160-176. doi:10.1016/j.jag.2015.03.016

Inoue, Y., Guérif, M., Baret, F., Skidmore, A., Gitelson, A., Schlerf, M., ... Olioso, A. (2016). Simple and robust methods for remote sensing of canopy chlorophyll content: a comparative analysis of hyperspectral data for different types of vegetation. Plant, Cell \& Environment, 2609-2623. doi:10.1111/pce.12815

Jay, S., Maupas, F., Bendoula, R., \& Gorretta, N. (2017). Retrieving LAI, chlorophyll and nitrogen contents in sugar beet crops from multi-angular optical remote sensing: Comparison of vegetation indices and PROSAIL inversion for field phenotyping. Field Crops Research, 210(March), 33-46. doi:10.1016/j.fcr.2017.05.005

Kira, O., Linker, R., \& Gitelson, A. (2015). Non-destructive estimation of foliar chlorophyll and carotenoid contents: Focus on informative spectral bands. International Journal of Applied Earth Observation and Geoinformation, 38, 251260. doi:10.1016/j.jag.2015.01.003

Kooistra, L., \& Clevers, J. G. P. W. (2016). Estimating potato leaf chlorophyll content using ratio vegetation indices. Remote Sensing Letters, 7(6), 611-620. doi:10.1080/2150704X.2016.1171925

Krishna, G., Sahoo, R. N., Singh, P., Bajpai, V., Patra, H., Kumar, S., .. Sahoo, P. M. (2019). Comparison of various modelling approaches for water deficit stress monitoring in rice crop through hyperspectral remote sensing. Agricultural Water Management, 213(October 2017), 231-244. doi:10.1016/j.agwat.2018.08.029

Li, C., Zhu, X., Wei, Y., Cao, S., Guo, X., Yu, X., \& Chang, C. (2018). Estimating apple tree canopy chlorophyll content based on Sentinel-2A remote sensing imaging. Scientific Reports, 8(1), 1-10. doi:10.1038/s41598-018-21963-0

Li, D., Cheng, T., Zhou, K., Zheng, H., Yao, X., Tian, Y., ... Cao, W. (2017). WREP: A wavelet-based technique for extracting the red edge position from reflectance spectra for estimating leaf and canopy chlorophyll contents of cereal crops. ISPRS Journal of Photogrammetry and Remote Sensing, 129, 103-117. doi:10.1016/j.isprsjprs.2017.04.024

Li, X., Chen, X., Zhou, Y., Nong, M., Liu, X., \& Ai, J. (2015). Spectral characteristics analysis and chlorophyll content of sugarcane leaves under different fertilizer treatments. Transactions of the Chinese Society if Agricultural Engineering, 31(2), 1-6.

LI, Z. wang, XIN, X. ping, TANG, H., YANG, F., CHEN, B. rui, \& ZHANG, B. hui. (2017). Estimating grassland LAI using the Random Forests approach and Landsat imagery in the meadow steppe of Hulunber, China. Journal of Integrative Agriculture, 16(2), 286-297. doi:10.1016/S2095-3119(15)61303-X

Liang, L., Qin, Z., Zhao, S., Di, L., Zhang, C., Deng, M., ... Liu, Z. (2016). Estimating crop chlorophyll content with hyperspectral vegetation indices and the hybrid inversion method. International Journal of Remote Sensing, 37(13), 2923-2949. doi:10.1080/01431161.2016.1186850

Liao, Q., Wang, J., Yang, G., Zhang, D., Li, H., Fu, Y., \& Li, Z. (2013). Comparison of spectral indices and wavelet transform for estimating chlorophyll content of maize from hyperspectral reflectance. Journal of Applied Remote Sensing, 7(1), 073575. doi:10.1117/1.JRS.7.073575

Liu, B., Yue, Y.-M., Li, R., Shen, W.-J., \& Wang, K.-L. (2014). Plant Leaf Chlorophyll Content Retrieval Based on a Field Imaging Spectroscopy System. Sensors, 14(10), 19910-19925. doi:10.3390/s141019910 
Macedo, C. H. O., Alexandrino, E., Jakelaitis, A., Vaz, R. G. M. V., Reis, R. H. P. dos, \& Vendrusculo, J. (2010). Características agronômicas, morfogênicas e estruturais do capim Panicum maximum cv. Mombaça sob desfolhação intermitente. Revista Brasileira de Saúde e Producão Animal, 11(4), 941-952.

Mirzaie, M., Darvishzadeh, R., Shakiba, A., Matkan, A. A., Atzberger, C., \& Skidmore, A. (2014). Comparative analysis of different uni- and multi-variate methods for estimation of vegetation water content using hyper-spectral measurements. International Journal of Applied Earth Observation and Geoinformation, 26(1), 1-11. doi:10.1016/j.jag.2013.04.004

Morellos, A., Pantazi, X., Moshou, D., Alexandridis, T., Whetton, R., Tziotzios, G., ... Mouazen, A. M. (2016). Machine learning based prediction of soil total nitrogen, organic carbon and moisture content by using VIS-NIR spectroscopy. Biosystems Engineering, 152, 104-116. doi:10.1016/j.biosystemseng.2016.04.018

Mountrakis, G., Im, J., \& Ogole, C. (2011). Support vector machines in remote sensing: A review. ISPRS Journal of Photogrammetry and Remote Sensing, 66(3), 247-259. doi:10.1016/j.isprsjprs.2010.11.001

Müller, M. S., Fancelli, A. L., Dourado-Neto, D., García, A. G., \& Ovejero, R. F. L. (2002). Produtividade do Panicum maximum cv . Mombaça, sob pastejo rotacionado. Scientia Agricola, 59(3), 427-433. doi:10.1590/S010390162002000300003

Neto, A. J., Lopes, D. C., Pinto, F. A. C., \& Zolnier, S. (2017). Vis/NIR spectroscopy and chemometrics for nondestructive estimation of water and chlorophyll status in sunflower leaves. Biosystems Engineering, 155, $124-133$. doi:10.1016/j.biosystemseng.2016.12.008

Neto, A. J., Lopes, D. de C., Silva, T. G. F. da, Ferreira, S. O., \& Grossi, J. A. S. (2016). Estimation of leaf water content in sunflower under drought conditions by means of spectral reflectance. Engineering in Agriculture, Environment and Food, 1-5. doi:10.1016/j.eaef.2016.11.006

Neto, A., Lopes, D., \& Borges Júnior, J. (2017). Assessment of Photosynthetic Pigment and Water Contents in Intact Sunflower Plants from Spectral Indices. Agriculture, 7(2), 8. doi:10.3390/agriculture7020008

Newman, Y. C., Sinclair, T. R., Blount, A. S., Lugo, M. L., \& Valencia, E. (2007). Forage production of tropical grasses under extended daylength at subtropical and tropical latitudes. Enviromental and Experimental Botany, 61(1), 18-24. doi:10.1016/j.envexpbot.2007.02.005

Paciullo, D. S. C., Gomide, C. A. M., Castro, C. R. T., Maurício, R. M., Fernandes, P. B., \& Morenz, M. J. F. (2016). Morphogenesis, biomass and nutritive value of Panicum maximum under different shade levels and fertilizer nitrogen rates. Grass and Forage Science, (August), 1-11. doi:10.1111/gfs.12264

Peng, Y., \& Gitelson, A. A. (2012). Remote estimation of gross primary productivity in soybean and maize based on total crop chlorophyll content. Remote Sensing of Environment, 117, 440-448. doi:10.1016/j.rse.2011.10.021

Pontes, L. da S., Baldissera, T. C., Giostri, A. F., Stafin, G., dos Santos, B. R. C., \& Carvalho, P. C. d. F. (2017). Effects of nitrogen fertilization and cutting intensity on the agronomic performance of warm-season grasses. Grass and Forage Science, 72(4), 663-675. doi:10.1111/gfs.12267

Putnam, R. A., Mohaidat, Q. I., Daabous, A., \& Rehse, S. J. (2013). A comparison of multivariate analysis techniques and variable selection strategies in a laser-induced breakdown spectroscopy bacterial classification. Spectrochimica Acta - Part B Atomic Spectroscopy, 87, 161-167. doi:10.1016/j.sab.2013.05.014

Rasmussen, I. S., Dresbøll, D. B., \& Thorup-Kristensen, K. (2015). Winter wheat cultivars and nitrogen (N) fertilization-Effects on root growth, $\mathrm{N}$ uptake efficiency and $\mathrm{N}$ use efficiency. European Journal of Agronomy, 68, 38-49. doi:10.1016/j.eja.2015.04.003

Rosolem, C. A., Ritz, K., Cantarella, H., Galdos, M. V., Hawkesford, M. J., Whalley, W. R., \& Mooney, S. J. (2017). Enhanced Plant Rooting and Crop System Management for Improved N Use Efficiency. Advances in Agronomy (1st ed., Vol. 146). Elsevier Inc. doi:10.1016/bs.agron.2017.07.002

Sarmento, P., Rodrigues, L., Lugão, S., Da Cruz, M., Campos, F., \& Ferreira, M. (2005). Respostas agronômicas e morfológicas de Panicum maximum Jacq. Cv IPR - 86 Milênio, sob pastejo, à adubação nitrogenada. Boletim de Induistria Animal, 62(4), 333-346.

Schlemmer, M., Gitelson, A., Schepersa, J., Fergusona, R., Peng, Y., Shanahana, J., \& Rundquist, D. (2013). Remote estimation of nitrogen and chlorophyll contents in maize at leaf and canopy levels. International Journal of Applied Earth Observation and Geoinformation, 25(1), 47-54. doi:10.1016/j.jag.2013.04.003

Silva, R., Gomes, V., Mendes-Faia, A., \& Melo-Pinto, P. (2018). Using support vector regression and hyperspectral 
imaging for the prediction of oenological parameters on different vintages and varieties ofwine grape berries. Remote Sensing, 10(2), 1-23. doi:10.3390/rs10020312

Sonobe, R., Sano, T., \& Horie, H. (2018). Using spectral reflectance to estimate leaf chlorophyll content of tea with shading treatments. Biosystems Engineering, 175, 168-182. doi:10.1016/j.biosystemseng.2018.09.018

Stewart, S., Ivy, M. A., \& Anslyn, E. V. (2013). The use of principal component analysis and discriminant analysis in differential sensing routines. Chemical Society Reviews, 43(1), 70-84. doi:10.1039/c3cs60183h

Tan, K., Wang, S., Song, Y., Liu, Y., \& Gong, Z. (2018). Estimating nitrogen status of rice canopy using hyperspectral reflectance combined with BPSO-SVR in cold region. Chemometrics and Intelligent Laboratory Systems, 172(November 2017), 68-79. doi:10.1016/j.chemolab.2017.11.014

Thakur, A. K., Rath, S., \& Mandal, K. G. (2013). Differential responses of system of rice intensification ( SRI ) and conventional flooded-rice management methods to applications of nitrogen fertilizer. Plant Soil, 370, 59-71. doi:10.1007/s11104-013-1612-5

Verrelst, J., Camps-Valls, G., Muñoz-Marí, J., Rivera, J. P., Veroustraete, F., Clevers, J. G. P. W., \& Moreno, J. (2015). Optical remote sensing and the retrieval of terrestrial vegetation bio-geophysical properties - A review. ISPRS Journal of Photogrammetry and Remote Sensing, 108, 273-290. doi:10.1016/j.isprsjprs.2015.05.005

Vibhute, A., Kale, K., Mehrotra, S., Dhumal, R., \& Nagne, A. (2018). Determination of soil physicochemical attributes in farming sites through visible, near-infrared diffuse reflectance spectroscopy and PLSR modeling. Ecological Processes, 7(26), 12.

Wang, L., Zhou, X., Zhu, X., Dong, Z., \& Guo, W. (2016). Estimation of biomass in wheat using random forest regression algorithm and remote sensing data. Crop Journal, 4(3), 212-219. doi:10.1016/j.cj.2016.01.008

Were, K., Bui, D. T., Dick, Ø. B., \& Singh, B. R. (2015). A comparative assessment of support vector regression, artificial neural networks, and random forests for predicting and mapping soil organic carbon stocks across an Afromontane landscape. Ecological Indicators, 52, 394-403. doi:10.1016/j.ecolind.2014.12.028

Wu, C., Niu, Z., Tang, Q., \& Huang, W. (2008). Estimating chlorophyll content from hyperspectral vegetation indices: Modeling and validation. Agricultural and Forest Meteorology, 148(8-9), $1230-1241$. doi:10.1016/j.agrformet.2008.03.005

Xie, Y., Sha, Z., \& Yu, M. (2008). Remote sensing imagery in vegetation mapping: a review. Journal of Plant Ecology, 1(1), 9-23. doi:10.1093/jpe/rtm005

Zago, L. A., Lempp, B., Borges do Valle, C., Jank, L., Rocha, L., Postiglioni, S., ... Soares, C. (2010). Principais espécies forrageiras utilizadas em pastagens para gado de corte. In Bovinoultura de corte (pp. 375-417). Retrieved from file://C:/Users/usuario/Downloads/digitalizar0006.pdf 